\title{
Resetting Southern Tibet: The serious challenge of obtaining primary records of Paleoaltimetry
}

\section{Authors: J. Quade, R. Leary, M.P. Dettinger, D. Orme, A. Krupa, P.G. DeCelles, A. Kano, H. Kato, R. Waldrip, W. Huang, P. Kapp}

(C) 2020. This manuscript version is made available under the CC-BY-NC-ND 4.0 license https:// creativecommons.org/licenses/by-nc-nd/4.0/

Quade, J., R. Leary, M.P. Dettinger, D. Orme, A. Krupa, P.G. DeCelles, A. Kano, et al. "Resetting Southern Tibet: The Serious Challenge of Obtaining Primary Records of Paleoaltimetry." Global and Planetary Change 191 (August 2020): 103194. doi:10.1016/ j.gloplacha.2020.103194. 


\section{Resetting Southern Tibet: The Serious Challenge of Obtaining Primary Records of Paleoaltimetry}

Quade, J. ${ }^{\mathrm{a},}{ }^{*}$, Leary, R. ${ }^{\mathrm{b}}$, Dettinger, M.P. ${ }^{\mathrm{c}}$, Orme, D. ${ }^{\mathrm{d}}$, Krupa, A. ${ }^{\mathrm{a}}$, DeCelles, P.G., ${ }^{\mathrm{a}}$ Kano, A. ${ }^{\mathrm{e}}$,

Kato, H., Waldrip, R. ${ }^{\mathrm{a}}$, Huang, W. ${ }^{\mathrm{a}}$, and Kapp, P. ${ }^{\mathrm{a}}$,

${ }^{a}$ Department of Geosciences, University of Arizona, Tucson, Arizona, 85721

${ }^{b}$ Department of Earth and Environmental Science, 801 Leroy Place, New Mexico Tech, Socorro, New Mexico 87801

${ }^{c}$ Research Square, Durham, NC 27701 USA

${ }^{d}$ Department of Earth Sciences, Montana State University, Bozeman, Montana, 59717

${ }^{\mathrm{e}}$ Department of Earth and Planetary Science, Graduate School of Science, The University of

Tokyo, 7-3-1 Hongo, Tokyo 113-0033, Japan

*corresponding author: quadej@email.arizona.edu

phone: (520)-818-8006

FAX: (520)-621-2672

Keywords: Tibet; oxygen isotopes; carbon isotopes; clumped isotopes; diagenesis; paleoaltimetry

\section{ABSTRACT}

Over the last several decades a number of studies have attempted to reconstruct the rise of the Himalaya and Tibet since India-Asia collision began in the early Cenozoic, with rather contradictory results. Here, we evaluate the efforts at reconstructing the history of this major mountain-building event as archived in oxygen, carbon, and clumped isotope records from carbonates exposed on the southern Tibetan Plateau. We find that a number of potential isotopic records of paleoaltimetry from Tibet - using both conventional oxygen and clumped isotope systems-may have been reset during burial and heating. Without exception, the marine $\delta^{18} \mathrm{O}$ values 
of Cretaceous and Paleogene marine carbonates across the orogen have been reset from their primary values of $0 \pm 4 \% 0$ (VPDB) to lower values between -5 to $-20 \%$, most conspicuously in the Indo-Asian suture zone. For this and other reasons, we view isotopic records of paleoaltimetry from the suture zone and adjacent Gangdese arc with great caution, especially early Cenozoic basin sediments that have experienced similar burial and heating as the underlying marine limestones. Outside the suture zone/arc, marine carbonates retain the isotopic imprint of low-elevation, meteoric diagenesis, a result that supports paleoaltimetric reconstruction from these areas using younger non-marine carbonates. We are even more cautious about temperature reconstructions using clumped isotope analyses, which previous studies suggest are sensitive to resetting at moest burial temperatures. With a few possible exceptions, primary clumped isotope values have probably not withstood the elevated temperatures of the suture zone and magmatic arc, nor burial depths of $>3 \mathrm{~km}$ in basins outside the suture. In light of susceptibility to alteration of oxygen isotopes in carbonates in orogenic belts, future paleoaltimetric reconstruction prior to the Miocene on the Tibetan Plateau should couple $\delta^{18} \mathrm{O}, \Delta 47$, and $\Delta{ }^{, 17} \mathrm{O}$ analysis of carbonates with analysis of noncarbonate archives — such as silicates and organic matter- that are less susceptible to resetting.

Carbon, unlike oxygen, isotopic values from paleosol carbonate are well preserved from all periods, due to the very low $\mathrm{C} / \mathrm{O}$ ratio of most altering fluids. Samples from within the suture zone yield a record of paleo-vegetation change covering much of the Cenozoic. Carbon isotopic values from paleosols have no analog among modern Tibetan soils and most resemble in appearance and chemical composition the vegetated soils in the lowlands of northern India today. Carbon isotopes from paleosols depict a major reduction in vegetation cover in the suture zone since $20 \mathrm{Ma}$, probably due to a combination of uplift of the suture zone and global cooling. Northward on the Lhasa and Qiantang terranes, the landscape was less vegetated in the Oligocene compared to the 
contemporaneous suture zone, but more vegetated and less arid than it is today.

\section{Introduction}

The Himalaya and Tibet together constitute the largest active orogenic system in the world today, so naturally there is significant interest in the history of their development (see Kapp and DeCelles, 2019 for one recent summary). How the absolute elevation of this system evolved through time is a key and still evolving part of the history. Some of the earliest attempts at paleoaltimetric reconstruction using stable isotopes were conducted in the Himalaya (e.g., Garzione et al., 2000), and there have been dozens of studies since then. Our purpose here, however, is not to summarize the tectonic/geodynamic implications of those studies, which has been undertaken elsewhere (e.g., Rowley and Currie, 2006; Deng and Ding, 2015; Ding et al., 2017). Instead, our focus here is more methodological, on the question of the reliability of these reconstructions, many of them our own, using the stable isotopic $\left(\delta^{18} \mathrm{O}, \delta^{13} \mathrm{C}, \Delta_{47}\right)$ composition of secondary carbonates deposited in lakes, in soils, and by ground water. Our study region lies in southern Tibet (Fig. 1) and focuses on the isotope records from where India sutured to Asia (the Indus-Yarlung suture zone, or IYSZ), and its immediate flanks in the Gandese magmatic arc along the southern edge of the Asian plate. Structural and thermochronologic studies show that deformation and exhumation are much more active inside the IYSZ than outside it (Rohrmann et al., 2012; Carrapa et al., 2014; Laskowski et al., 2018), a difference that may impact patterns of 
isotopic alteration of marine and non-marine carbonate rocks in these areas.

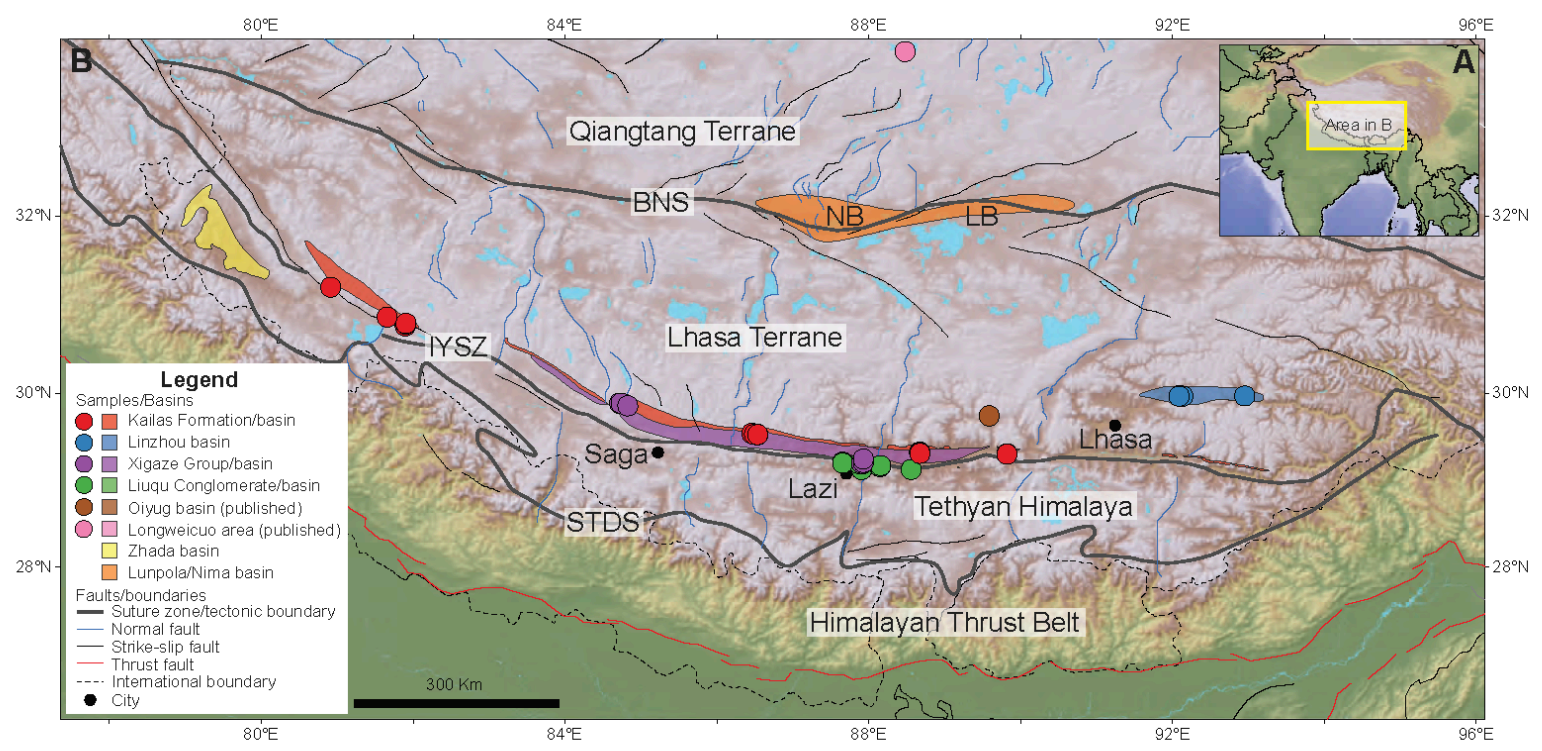

Figure 1 Major tectonic boundaries and features in southern Tibet along with location of the study sections (filled dots).

\subsection{The serious challenge}

The stable oxygen isotopic composition (expressed in \%o using the familiar $\delta^{18} \mathrm{O}$ notation) of carbonates is a mainstay of many aspects of our understanding of Earth history. However, the serious challenge of obtaining unaltered, primary $\delta^{18} \mathrm{O}$ values from carbonates after exposure on land was recognized by even the earliest isotope geochemists (Revelle and Fairbridge, 1957; Clayton and Degens, 1959; Keith and Weber, 1964). It has long been recognized that carbonates undergo oxygen exchange, but much less commonly carbon, when in prolonged contact with meteoric water and terrestrial vegetation. The reason for this is that the atomic $\mathrm{C} / \mathrm{O}$ ratio of 
typical groundwater is $\sim 10^{5}$, meaning that there is far more $\mathrm{O}$ than $\mathrm{C}$ in ground water to exchange with carbonates. As a result, marine carbonates with unaltered $\delta^{13} \mathrm{C}$ values are commonplace back into the Proterozoic, whereas over the same time span unaltered marine $\delta^{18} \mathrm{O}$ values are only preserved in special circumstances (Veizer et al., 1999; Ghosh et al., 2018), if at all (Degens and Epstein, 1962; Killingley, 1983)

To illustrate these issues for our study region, we compiled the published $\delta^{18} \mathrm{O}(\mathrm{VPDB})$ and $\delta^{13} \mathrm{C}$ (VPDB) values (see Fig. 2, caption; Table S1) of mid-Cretaceous to Paleogene (K-Pg) marine limestones from southern Tibet and northern India. These are the youngest marine rocks in the region, and the closest stratigraphically to the non-marine carbonates used for reconstruction of paleoaltitude. We make several observations about this large data set of $\sim 1300$ analyses, the first being that all $\delta^{18} \mathrm{O}$ (VPDB) values from Tibetan/Himalayan limestones, which range from -4.2 to $-22 \%$, are lower than primary marine values $(>-4 \%$ ) for this time period (Veizer et al., 1999; Kobashi et al., 2001), showing that the $\delta^{18} \mathrm{O}$ values of virtually all sampled limestones have been reset. The range of "primary" marine values was established by these studies through analysis of thousands of well-preserved, low-Mg calcites precipitated by brachiopods, belemnites and other organisms living in a wide range of marine habitats. Our second observation is that published $\delta^{18} \mathrm{O}$ values $(-13.6 \pm 2.7 \%$ o $\mathrm{n}=36)$ obtained from limestones in the IYSZ and Gangdese arc are generally much lower than those from surrounding regions to the north and south $(-7.1 \pm 2.2 \%$, $n=620)$. Lastly, the majority $(\sim 1200)$ of $\delta^{13} \mathrm{C}$ values fall within the range of normal marine values $(>-1.9$ to $+5 \%$ ) for the period, whereas $\sim 20$ 
samples yielded low, nonmarine values of $<-2 \%$ (discussed later).

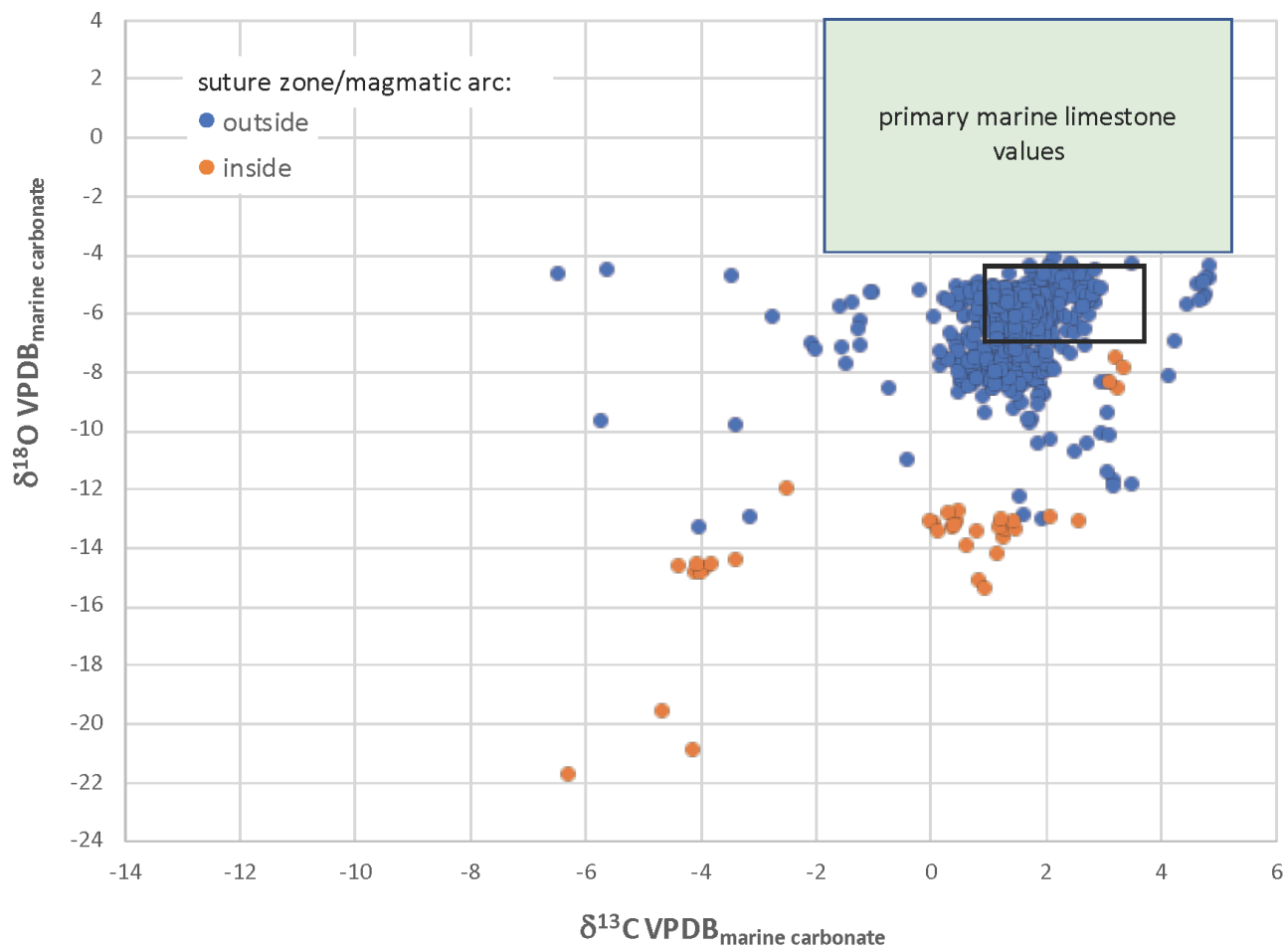




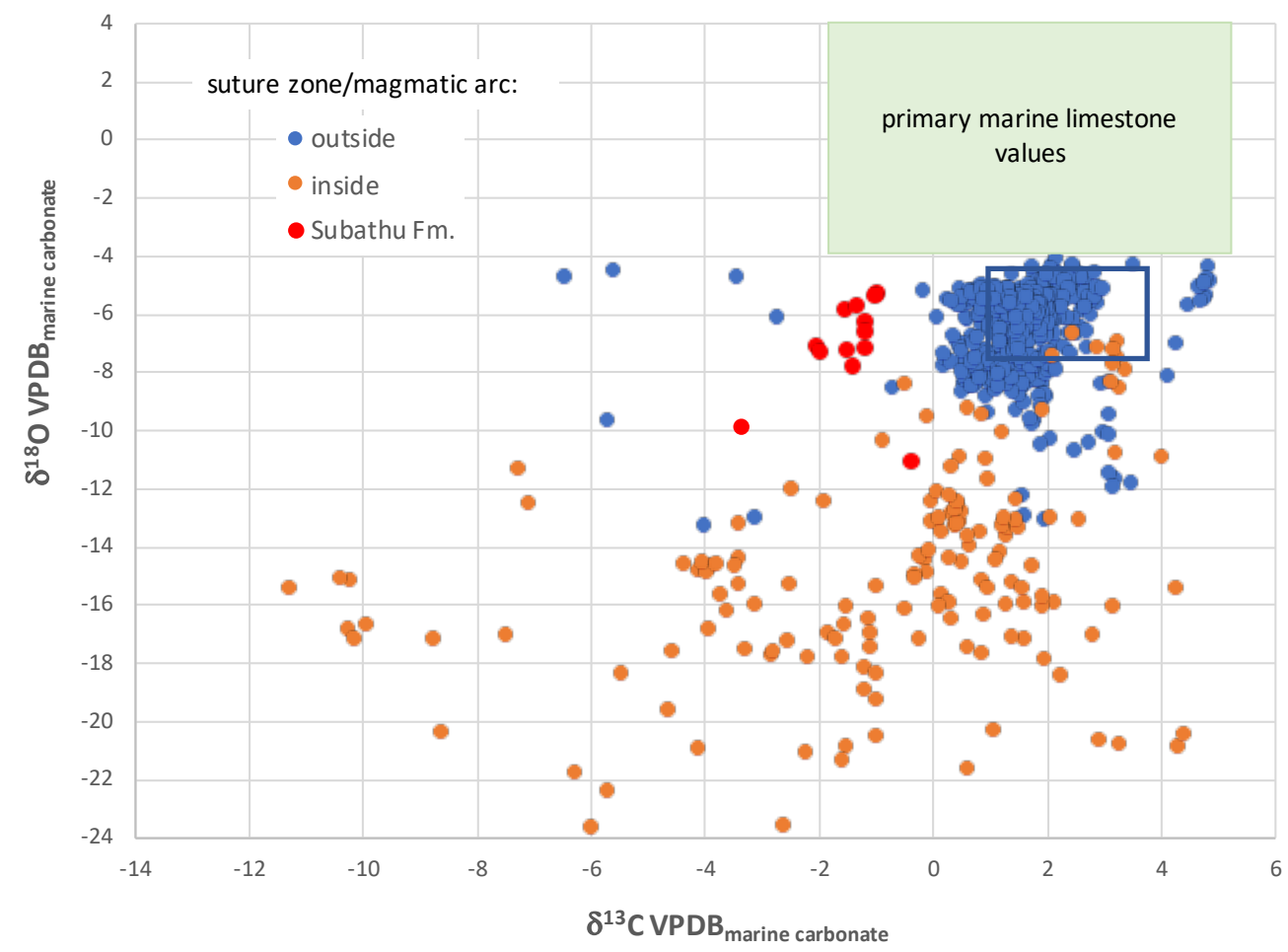

Figure 2. a) The published isotopic compositions of late Cretaceous and Paleogene marine carbonates Tibet and northern India, compiled from Li et al. (2006), Leier et al. (2009), Wendler et al. $(2009,2011)$. Analyses are also divided into those from high elevations inside (solid blue dots) and outside (solid orange dots) the IYSZ and Gangdese magmatic arc in southern Tibet. The blue box outlines the range of isotopic values $(n=616)$ reported by Li et al. (2006) from late Cretaceous limestones outside the IYSZ in the Tingri area (N2843' $860^{\prime \prime}$, E86 ${ }^{\circ} 44^{\prime} 915^{\prime \prime}, 4765 \mathrm{~m}$ ) in southern Tibet. These are compared to isotopic values ( $>95 \%$ confidence, green box) of unaltered late Cretaceous and Paleogene marine carbonates compiled from Vizer et al. (1999) and Kobashi et al. (2001); b) same graph as a) with IYSZ data added from this study and Ingalls 
et al. (2019), and those (solid red dots) from the Eocene Subathu Formation (Leier et al., 2009) from the low elevation $(500 \mathrm{~m})$ foreland in NW India.

A chief takeaway from these observations is that all $\delta^{18} \mathrm{O}$ values of the marine carbonates, as with most older limestones globally (Keith and Weber, 1964; Veizer et al., 1999), have been diagenetically altered due to exchange between marine limestones and meteoric waters, at variable and often elevated diagenetic temperatures (e.g., Hudson, 1977). Paleoelevation reconstruction by isotopic methods is underpinned by the assumption of preservation of primary $\delta^{18} \mathrm{O}$ and $\Delta_{47}$ values in carbonates deposited in lakes and the vadose zone. And so the regional resetting of carbonate $\delta^{18} \mathrm{O}$ values calls into question reconstruction paleoelevations using the $\delta^{18} \mathrm{O}$ values of many equivalent-age (late Eocene and older) nonmarine carbonates in the same region. The same has to be true for $\Delta_{47}$, since it must change if the bulk isotopic composition changes. However, patterns of alteration of $\delta^{18} \mathrm{O}$ values in marine rocks strongly differ inside and outside the IYSZ (Fig. 2a), a distinction that has major implications for the state of isotopic preservation of non-marine carbonates that overlie these marine rocks in the same basins. To strengthen this test, for our study we more than doubled the sample size of marine limestones from the IYSZ.

The effects of diagenesis should diminish in carbonate samples younger than the late Eocene, $(<50 \mathrm{Ma})$, depending on the local circumstances of burial. We will argue that it is vital to evaluate these circumstances from as many perspectives as possible, a practice that much of the published literature on paleoelevation is only now embracing. Other lines of evidence that assist in understanding in burial durations and temperatures include the thickness of overburden, thermochronology $(\mathrm{U}-\mathrm{Th} / \mathrm{He})$ and fission tracks in apatite and zircon, ${ }^{40} \mathrm{Ar}-{ }^{39} \mathrm{Ar}$, petrography, 
and alteration mapping and mineralogy. In this paper, we offer examples of many of these lines of evidence for our study areas.

Finally, our regional survey of published isotopic composition of marine limestones shows that $\sim 98 \%$ of the samples (Fig. $2 \mathrm{a}$ ) preserve plausibly primary $\delta^{13} \mathrm{C}$ values of between -2 to +4\%o; as defined (95\% confidence interval by Veizer et al. (1999) and Kobashi et al. (2001) for $\mathrm{K}-\mathrm{Pg}$ marine limestones globally. As noted above, this is consistent with the low inorganic carbon content of most natural waters and justifies the use of $\delta^{13} \mathrm{C}$ values to interpret paleoenvironmental conditions on land in deep time (e.g., Ekart et al., 1999; Breecker et al., 2010). The $\delta^{13} \mathrm{C}$ value of paleosol carbonate is a valuable and underutilized tool for understanding the evolution of paleoaridity on the Tibetan Plateau.

\subsection{Geologic setting and sampling}

The record of pre-collision and ongoing collision of Indo-Asia is preserved in four lithotectonic zones stretching from south to north across northern India and southern Tibet: the Himalayan thrust belt, the India-Asia suture zone, the Xigaze forearc, and the Gangdese magmatic arc (Fig. 1; for reviews see Hodges, 2000; Yin and Harrison, 2000; Kapp and DeCelles, 2019). Prior to initial Indo-Asia collision ca. 60-55 Ma, Neotethyan oceanic lithosphere was subducted northward beneath the southern margin of Asia. A Neo-Tethyan seaway separated northern India and Asia, bounded to the south by Tethyan marine rocks deposited on the northern passive margin of Greater India (the pre-collisional Indian landmass), and to the north by an accretionary prism/ophiolites and the Xigaze forearc basin along the tectonically active southern margin of Asia. Subduction-generated melts fed the Gangdese 
magmatic arc north of the Xigaze forearc basin. During subduction, this southern part of Asia, underlain by the Lhasa terrane, underwent considerable shortening, and the region may have been raised to high elevations, informally termed the "Lhasaplano" (Kapp et al., 2007; Kapp and DeCelles, 2019).

The collision began in the early to mid-Paleogene (60-55 Ma), suturing the two continents along the IYSZ in southern Tibet (Ding et al., 2005; Najman et al., 2010; Orme et al., 2015; Hu et al., 2016; DeCelles et al., 2018a). Many of the suture zones in central Asia are marked by valleys, and the IYSZ follows the east-west course of the Yarlung-Tsangpo (Brahmaputra) River along much of its $>1000 \mathrm{~km}$ reach (Fig. 1). In addition to the Xigaze forearc basin, thick and widespread Cenozoic nonmarine strata are exposed within and on both sides of the IYSZ in southern Tibet (DeCelles et al., 2018a) and contain a wealth of information about the collision history and paleoelevation changes.

Our study involves over 300 new isotopic analysis of carbonates from all four major lithotectonic zones in the region, merged with considerable data collected by previous studies. Our study sites are grouped into (Fig. 1): (1) marine carbonates and paleosols from the midCretaceous-Eocene Xigaze forearc sequence, (2) lacustrine carbonates from the lower Eocene Nianbo Formation of the Linzizong Group in the Gangdese retroarc, (3) paleosol carbonates from the lower Miocene (?) Liuqu Conglomerate, and (4) paleosol carbonates and other secondary cements from the lower to mid-Miocene Kailas Formation. We augmented our isotopic analysis with petrographic examination of a subset of samples from most areas.

The mid-Cretaceous-Eocene Xigaze forearc sequence is $5-8 \mathrm{~km}$ thick and is exposed for $\sim 550 \mathrm{~km}$ along strike of the central IYSZ zone in southern Tibet (Ding et al., 2005; Wang et al., 2012; An et al., 2014). It consists of turbiditic sediments and channelized conglomerates in the 
lower portion (Xigaze Group, 110 to 84 Ma; Einsele et al., 1994) and in the upper part of mixed marine limestone, sandstone, and shale grading up to shallow marine deposits mixed with paleosols (Tso-Jiangding Group, 83-51 Ma; Ding et al. 2005; Orme et al. 2015). The sequence is thought to record the Indo-Asian collision sequence, starting with deep-water sedimentation in the Xigaze forearc, shoaling upward to shallow marine and continental deposits at the top as the former forearc was uplifted above sea-level, and continental Indian lithosphere entered the trench (Orme et al., 2015). Our sampling of marine and paleosol carbonates covers most of this sequence and was obtained from two areas: marine carbonates from the Xigaze Group exposed northeast of Lazi (Fig. 1; Orme and Laskowski, 2016), and the younger Tso-Jianding Group exposed northwest of Saga in the Lopu Kangri area (Fig. 1 and Orme et al., 2015). The detailed sedimentology and thermochronology of these sections along with sample locations are described in Orme et al. (2015), Orme and Laskowski (2016) and tabulated in Table S2. These samples have also been the focus of one study of the isotopic composition of the carbonates (Ingalls et al., 2019), results that we expand upon here with a larger sample set and consideration of the $\delta^{13} \mathrm{C}$ results.

The Linzhou Basin is located $\sim 30 \mathrm{~km}$ north of Lhasa, within the Gangdese magmatic arc. It contains $\sim 3-4 \mathrm{~km}$ of intercalated volcanic and volcanoclastic rocks referred to as the Linzisong sequence. The Linzizong sequence consists, from bottom to top, of the Dianzhong, Nianbo, and Pana Formations and is capped by an additional $\sim 3 \mathrm{~km}$ of sedimentary rocks due to thrusting. It spans the period $\sim 69$ to $44 \mathrm{Ma}$.

Our sampling focused on the lower Nianbo Formation, dated to 52 Ma, near the village of Linzizong and in the section pictured by Huang et al. (in review). The Nianbo Formation consists of lacustrine marl and siltstone, volcanic tuffs and ash flows, and volcanoclastic sandstone. We 
analyzed seventeen samples from at least five lacustrine carbonate and marl horizons in the lower $40 \mathrm{~m}$ of the section (Table S3). Igneous dikes cut the Nianbo Formation in the area of sampling, and strong hydrothermal alteration is visible along the dikes and in the underlying Dianzhong Formation. Carbonates from the Nianbo and Pana Formations have been previously studied from the perspective of paleoaltimetry by Ding et al. (2014) and Ingalls et al. (2018). More recently, Huang et al. (in review) have undertaken a detailed study of the thermochronologic and paleomagnetic record of the Linzizong Formation at Linzhou.

The Liuqu Conglomerate is exposed in a narrow $(<5 \mathrm{~km})$ belt along a roughly $\sim 150 \mathrm{~km}$ length of the IYSZ. It is sandwiched between two major thrust faults in the IYSZ separating ophiolitic mélanges to the south and uplifted Cretaceous forearc deposits to the north, both of Asian plate affinity. The Luiqu Conglomerate is folded into a syncline that exposes up to several kilometers of redbeds, consisting of fluvial conglomerate, sandstone, and floodplain siltstone and paleosols. The tectono-sedimentary context and age of the Liuqu Conglomerate is the subject of ongoing debate. One view is that the Liuqu Conglomerate was deposited in the Paleogene during a suturing event prior to (Davis et al., 2002, 2004) or early in Indo-Asian collision (Ding et al., 2017). A second view is that the Liuqu Conglomerate was deposited during the Early Miocene (Leary et al., 2017). We favor the latter view but recognize that the age of the Liuqu Conglomerate needs more study. Both studies (Ding et al., 2017; Leary et al., 2017) agree that, whatever the age, the Liuqu Conglomerate was deposited at modest elevations well below $(\leq 2$ kmasl) the current elevation of $\geq 4$ kmasl.

Our samples for this study of the Liuqu Conglomerate come from paleosols exposed in three separate measured sections (Table S4; 1LQ, 4LQ. And 6LQ) which have been described in detail 
in Leary et al. (2016). Our work builds upon two isotopic studies already performed the Liuqu Conglomerate by Leary et al. (2017) and Ning et al. (2019).

The Kailas Formation (Gansser, 1964; DeCelles et al., 2018b) is a narrow (<10 km), 1300 $\mathrm{km}$ long belt of mainly clastic continental rocks $\leq 4 \mathrm{~km}$ thick found on the northern side of the IYSZ. Where not faulted, Kailas Formation rests in depositional contact nonconformably upon granitic and/or volcanic rocks of the Gangdese arc. The age of the base of the formation appears to decrease eastwards, ranging from $\sim 25-26 \mathrm{Ma}$ in the west near Mt. Kailas $\left(\mathrm{E} 81.3^{\circ}\right)$ to $\sim 23 \mathrm{Ma}$ at Dazhuka $\left(\mathrm{E} 89.8^{\circ}\right)$, suggesting that the Kailas basin propagated from west to east at $\sim 0.3 \mathrm{~m} / \mathrm{yr}$ (Leary et al., 2016). The Kailas Formation grades from alluvial fan conglomerates along the paleobasin margins to fine-grained fluvial and lacustrine deposits along the axis of the paleovalley. Deep lacustrine sandy to conglomeratic turbidite facies are also present in the basin center (DeCelles et al., 2018b). Unlike most other Cenozoic basins in the IYSZ, the Kailas basin also contains abundant organic-rich shale and coal. We analyzed carbonates, mostly in paleosols, from the Kailas Formation at seven locations along strike from $81.6-89.8^{\circ} \mathrm{E}$ (Table S5) and combine these results with those of our previous work in the Mt. Kailas region (E80.9; DeCelles et al., 2011).

\section{Methods}

\subsection{Stable isotope analysis of carbonates}

Samples were slabbed and microdrilled for $\sim 0.5$ to $1 \mathrm{mg}$ of powder. Carbonate analyzed for $\delta^{18} \mathrm{O}$ and $\delta^{13} \mathrm{C}$ values was first heated at $250^{\circ} \mathrm{C}$ for 3 hours in vacuo to remove volatile contaminants. Laboratory tests show that the carbon and oxygen isotope ratios of inorganic 
carbonates remain unchanged after roasting at $250^{\circ} \mathrm{C}$ (Wierzbowski, 2007). In organic-rich samples, variance in isotopic measurement is reduced when volatiles associated with organic matter are removed by roasting. Stable isotopic analysis used an automated sample preparation device (Kiel III) attached directly to a Finnigan MAT 252 mass spectrometer at the University of Arizona. Measured $\delta^{18} \mathrm{O}$ and $\delta^{13} \mathrm{C}$ values were corrected using internal laboratory standards calibrated to NBS-19. Precision of repeated standards is $\pm 0.11 \%$ for $\delta^{18} \mathrm{O}(1 \sigma)$. Carbonate isotopic results are reported using standard $\delta$-per mil notation relative to VPDB. $\delta^{18}$ Ovalues of the water $\left(\delta^{18} \mathrm{O}_{w}\right)$ in equilibrium with the carbonates were calculated using the calcite-water thermometry equation of Kim and O'Neil (1997).

\subsection{Clumped isotope analysis of carbonates}

The clumped isotope methods follow those described recently in Kato et al. (2019) and summarized only briefly here. The $\Delta_{47}$ values of carbonate samples were measured at Kyushu University, Japan. Powdered specimens of 5-6 mg were digested by $105 \%$ phosphoric acid at $70^{\circ} \mathrm{C}$ within 20 minutes (until May 2017) and at $90^{\circ} \mathrm{C}$ within 10 minutes (since June 2017). The generated $\mathrm{CO}_{2}$ was trapped immediately and dehydrated by liquid nitrogen and ethanol slush in a stainless-steel vacuum line. Then, the dehydrated $\mathrm{CO}_{2}$ was introduced with helium gas to a 30-mlong capillary column (Supel-Q PLOT) cooled at $-10^{\circ} \mathrm{C}$ in order to remove organic contaminants. All clumped isotope analyses returned low $\Delta_{48}$ values, confirming the effectiveness in purifying samples by the GC capillary column.

Purified $\mathrm{CO}_{2}$ was analyzed by a dual inlet mass spectrometer (Finnigan MAT-253) configured for measurements of masses 44-49 with pressure adjustment that produced a mass 44 signal of 16 
V. We applied the Pressure Baseline (PBL) correction of He et al. (2012) with the off-peak measurement of the background intensities of masses 45-49. Each analysis includes 8 sets of measurement sequences that consists of 4.5 off-peak cycles, 8 on-peak cycles, followed by 4 offpeak cycles. Total analysis time was typically 4 hours. Measured intensities of masses 45-49 were processed to calculate $\delta^{\mathrm{a}} \mathrm{C}$ and $\delta^{\circledR} \mathrm{O}$ values with Isodat, in which the abundance of " $\mathrm{O}$ was calculated with the mass dependent fractionation formulated by Brand et al. (2010). Finally, substitution of the acid correction, $0.064 \%$ at $70^{\circ} \mathrm{C}$ and $0.082 \%$ at $90^{\circ} \mathrm{C}$ (Defliese et al., 2015) yielded the $\Delta_{\text {trARF }}$ values of the analyzed samples expressed in the absolute reference frame (ARF) of Dennis et al. (2011). The stability and reliability of $\Delta_{47}$ measurements were confirmed by the analyses of an in-house standard (Hiroshima standard - Solhofen limestone), $\delta^{\mathrm{s}} \mathrm{C}=-0.47 \% \circ$ and $\delta^{\mathrm{s}} \mathrm{O}=-5.04 \%$; Hori et al., 2009), NBS-19, and Carrara marble. The $\Delta_{\Downarrow}$ values of the in-house standard were stable during the period of sample measurements from August 2016 to August 2017, with an intermeasurement deviation of $0.0085 \%$ o $(1 \sigma, v=23)$, which corresponds to $\pm 1.3^{\circ} \mathrm{C}$ in temperature. The temperature- $\Delta_{\text {traAR }}$ calibration used in this study is described in Kato et al. (2019). Temperatures obtained from $\Delta_{4 \rightarrow \text { AR }}$ values are expressed as $\mathrm{T}(47)$ throughout the text.

\subsection{Water Isotope sampling and analysis}

Clean water was collected in $15 \mathrm{ml}$ vials sealed with Teflon tape. Water samples were analyzed for $\mathrm{D} / \mathrm{H}$ ratio using a dual inlet mass spectrometer (Delta-S, Thermo Finnegan, Bremen, Germany) equipped with an automated chromium reduction device (H-Device, Thermo Finnegan) for the generation of hydrogen gas using metallic chromium at $750^{\circ} \mathrm{C}$. Water $\delta^{18} \mathrm{O}$ values were measured on the same mass spectrometer using an automated $\mathrm{CO}_{2}-\mathrm{H}_{2} \mathrm{O}$ equilibration unit. Standardization is based on internal standards referenced to VSMOW and VSLAP and the 
precision is better than $\pm 0.08 \%$ for $\delta^{18} \mathrm{O}$ and $\pm 1 \%$ for $\delta \mathrm{D}$.

\section{Results}

We analyzed twenty-two water samples for $\delta^{18} \mathrm{O}$ and $\delta \mathrm{D}$ values (Table S7) and $~ 300$ carbonate samples, including marine limestones, lacustrine carbonate, paleosol carbonate, and other forms of secondary carbonate, for $\delta^{18} \mathrm{O}$ and $\delta^{13} \mathrm{C}$ values (Tables $\mathrm{S} 2$ to S5). We also performed twenty-two new $\Delta_{47}$ analyses of lacustrine and soil carbonate (Table S6). In some but not all cases, we also described thin sections of the sampled material to assess the state of preservation of the material.

\subsection{Marine limestone}

For marine limestones $\left(\delta^{3} C_{1 \mathrm{~s}}\right)$ in outcrop and as reworked alluvial clasts, the $\delta^{13} \mathrm{C}(\mathrm{VPDB})$ values range from -11.3 to $+4 \%$ o $\left(\mathrm{n}=40\right.$; $\mathrm{avg}=+1.6 \%$ ), and the $\delta^{18} \mathrm{O}(\mathrm{VPDB})$ values $\left(\right.$ or $\left.\delta^{18} \mathrm{O}_{\mathrm{ls}}\right)$ range from $-23.6 \%$ to $-6.7 \%$ o $(\mathrm{avg}=-15.7 \%$ ). These samples come from the Xigaze forearc sequence, the Kailas Formation, and the Liuqu Conglomerate, all of which are in the IYSZ (Table S1; Fig. 2b). In Figure 2b, we have merged these results with previously published values and see that they strongly overlap with the range of relatively low values compiled from marine limestones in the IYSZ.

In hand specimen, nearly all the samples appear to be limestone, not marble, and only in a few cases dolostone. Five samples from this large dataset, all from the Liuqu Conglomerate, were examined petrographically. Marine limestone clasts from sections 6LQ and 7LQ, sections 
contain mostly sparite and microspar matrix, extensive sparite-filled veins, recrystallized (sparite and quartz) shell fragments, and prominent stylolites.

\subsection{Paleosol carbonate}

For pedogenic carbonate $\left(\delta^{13} C_{p c}\right)$ of all ages (Cretaceous to Miocene), the $\delta^{13} \mathrm{C}(\mathrm{VPDB})$ values range from -15.4 to $-4.5 \%$ ( $\left(n=123\right.$; avg. $-6.7 \%$ ) $($ Tables $S 2-S 5)$, and the $\delta^{18} \mathrm{O}(\mathrm{VPDB})$ values (or $\delta^{18} \mathrm{O}_{\kappa}$ ) range from $-22.8 \%$ to $-10.8 \%$ (avg. $-18.4 \%$ ). The highest and lowest $\delta^{13} \mathrm{C}$ (VPDB) values all come from the Kailas Formation, and those from the Liuqu Conglomerate (from Leary et al., 2017) and Xigaze forearc (Figs. 3-6) lie in the middle of this range. The $\delta^{18} \mathrm{O}_{\mathrm{pc}}$ values are very similar in range to the $\delta^{18} \mathrm{O}_{\mathrm{ss}}$ values, whereas the $\delta^{13} \mathrm{C}_{\mathrm{pc}}$ values are generally $\sim 5 \%$ lower than the $\delta^{3} \mathrm{C}_{\mathrm{s}}$ values. 


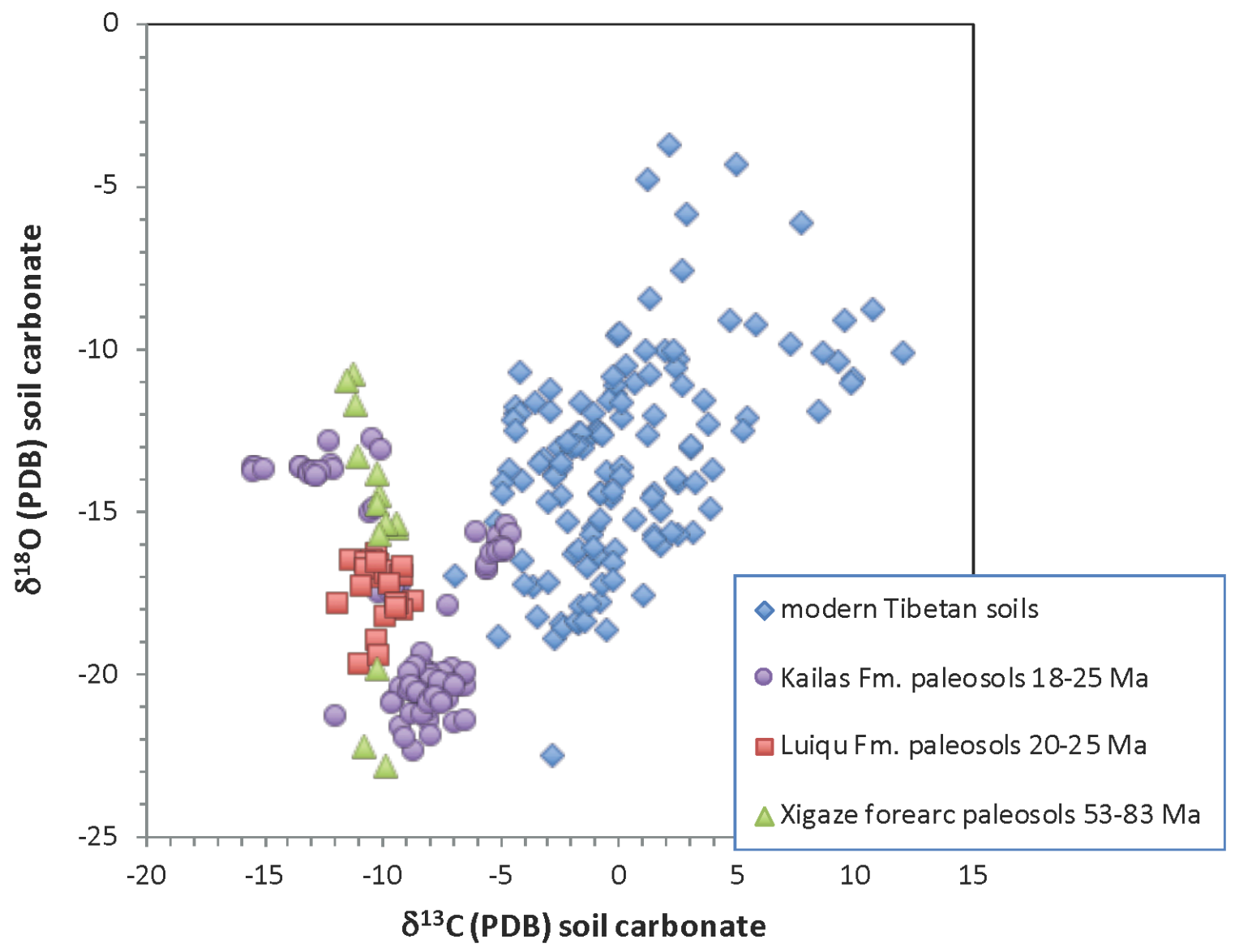

Figure 3. $\delta^{13} \mathrm{C}(\mathrm{VPDB})$ versus $\delta^{18} \mathrm{O}$ (VPDB) values of paleosol carbonates from the Xigaze forearc, Liuqu Formation, and Kailas Formation compared to values from modern soils from across southern Tibet (from Quade et al., 2013). 


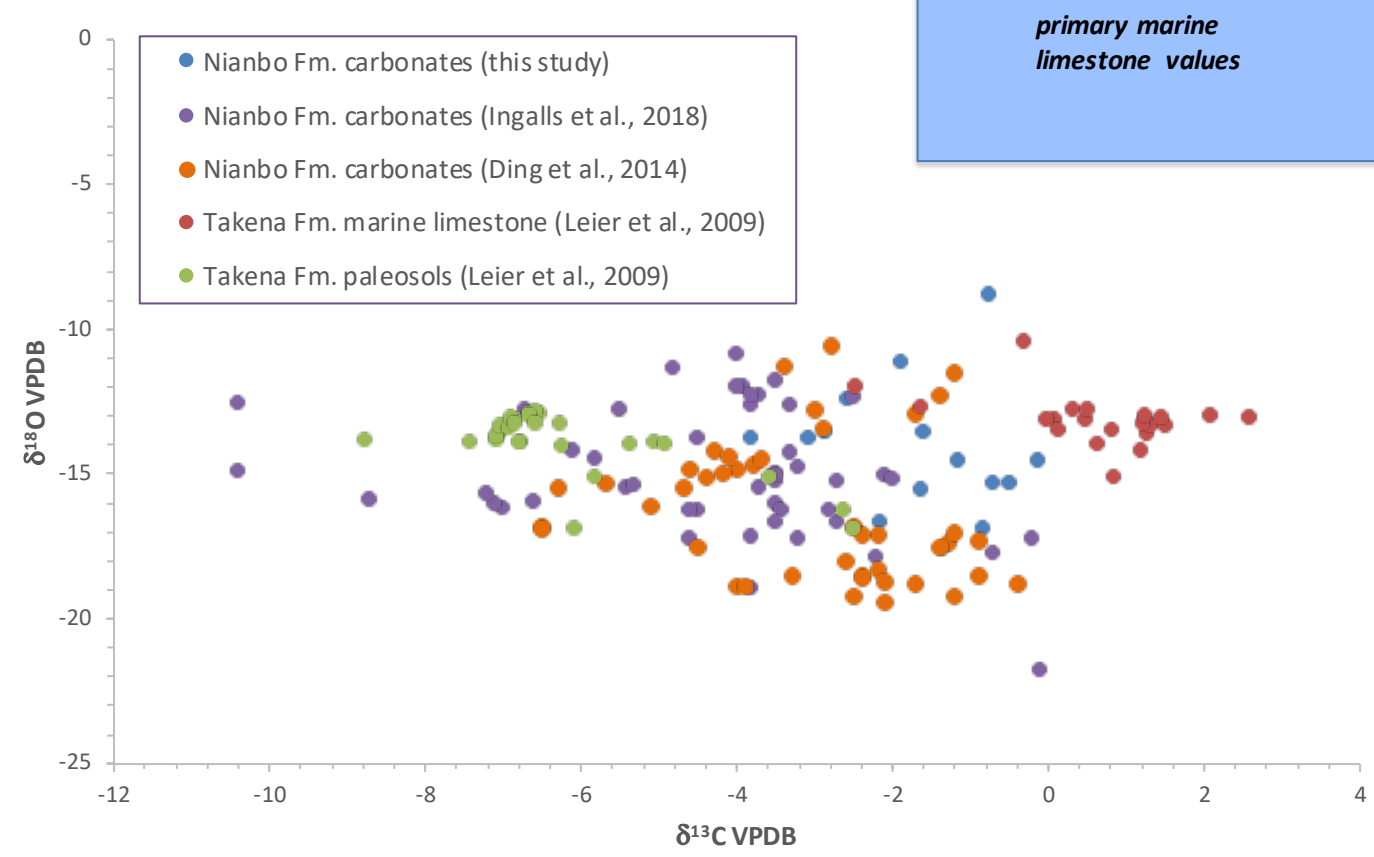

Figure 4. $\delta^{13} \mathrm{C}(\mathrm{VPDB})$ versus $\delta^{18} \mathrm{O}(\mathrm{VPDB})$ values carbonates from the Takena and Nianbo Formations in the Linzhou/Penbo area. Primary marine limestone values from Vizer et al. (1999) and Kobashi et al. (2001). 


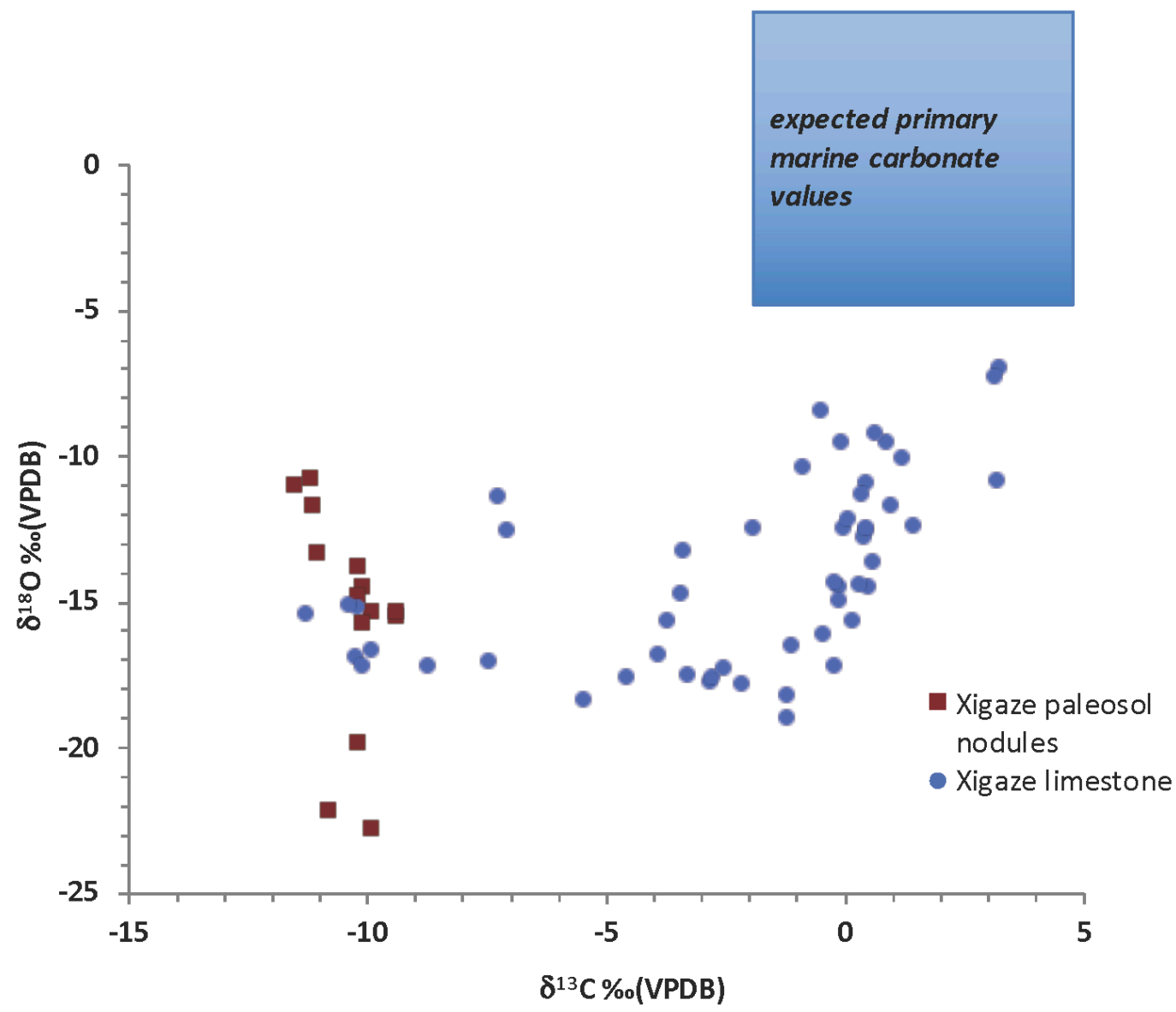

Figure 5. $\delta^{13} \mathrm{C}(\mathrm{VPDB})$ versus $\delta^{18} \mathrm{O}$ (VPDB) values carbonates from the Xigaze Group (Fig. 1) compared to expected values for unaltered and contemporaneous marine carbonates from Veizer et al. (1999). 


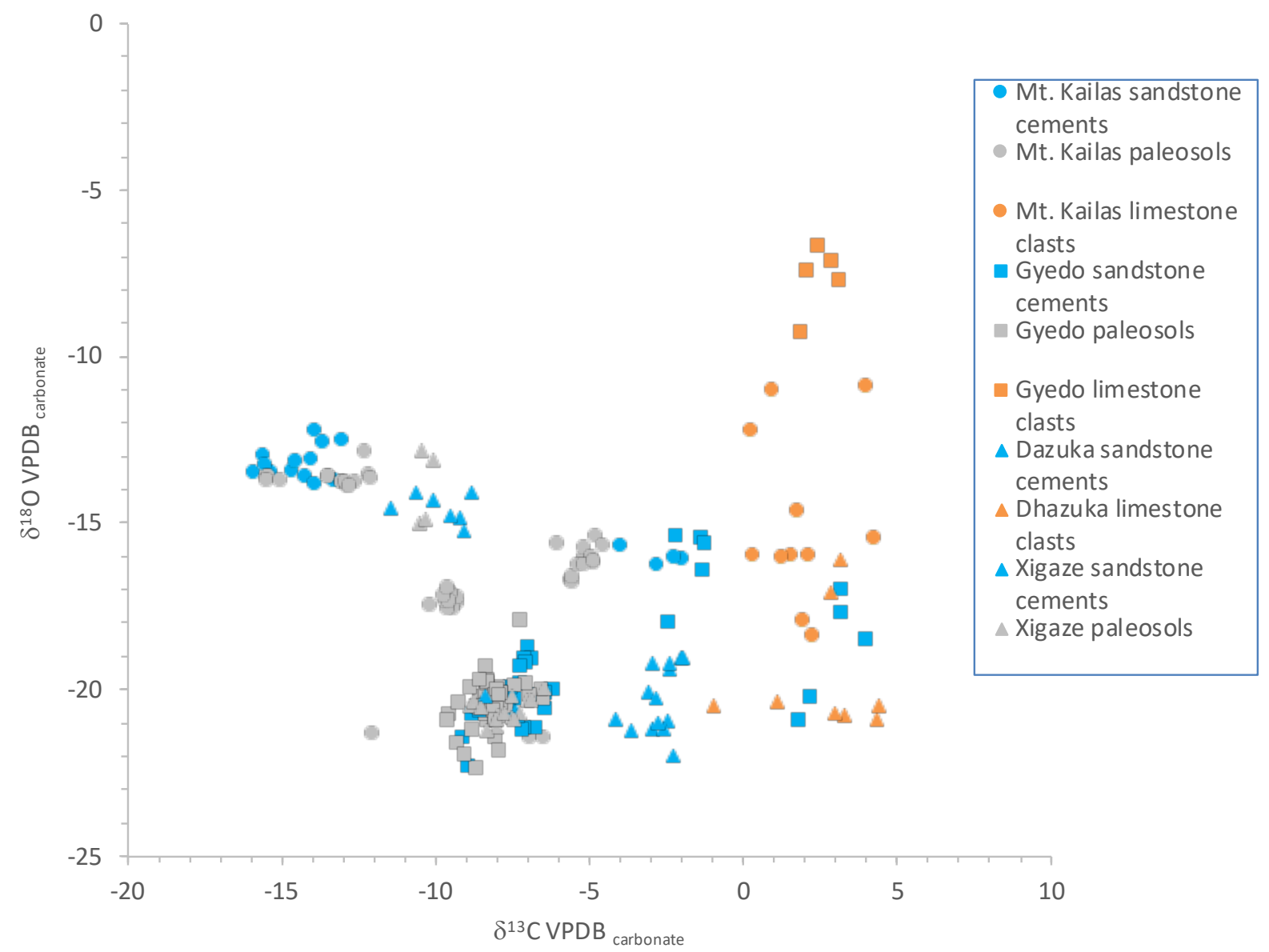

Figure 6. $\delta^{13} \mathrm{C}(\mathrm{VPDB})$ versus $\delta^{18} \mathrm{O}$ (VPDB) values carbonates from four general areas of the Kailas Fm. (Fig. 1).

From the Liuqu Conglomerate, we made ten $\Delta_{47}$ measurements on paleosol nodules from three different measured sections (Table S6) and obtained a very wide range of $\mathrm{T}(47)$ estimates from 20 to $33^{\circ} \mathrm{C}$ from section $1 \mathrm{LQ}, 67$ to 104 from $6 \mathrm{LQ}$, and 221 to $257^{\circ} \mathrm{C}$ from $4 \mathrm{LQ}$. The $\delta^{18} \mathrm{O}_{\mathrm{pc}}$ (VPDB) values from these same samples fall between -12.1 and $-18.5 \%$. Paleosol carbonates sampled from widely spaced sections (Fig. 1) of the Liuqu Conglomerate are composed of a mixture of silty micrite, silty microspar (5-20 $\mu \mathrm{m})$, and sparite-filled vugs and veins (Leary et al., 2017). Carbonate nodules from section 1LQ record surface or near-surface T 
(47) of $20-33^{\circ} \mathrm{C}$ (Table S6) and are mostly microspar and micrite, with sparite filling root channels, vugs, and primary porosity (Fig. 7a, b). Nodules collected from sections 6LQ and 7LQ returned $\Delta_{47}$ values indicating burial temperatures of $67-104^{\circ} \mathrm{C}$ (Table S6) and are composed of silty hematite-rich micrite, microspar, and sparite, although some of the spar and microspar is confined to veins and large vugs and spar, and microspar replace much of the primary micritic groundmass (Fig. 7c, d). Nodules collected from section 4LQ, for which 47 values indicate temperatures of $221-257^{\circ} \mathrm{C}$ (Table S6), are dominantly hematite/manganese oxide-rich microspar cut extensively by sparite and microspar veins. These samples also contain abundant large ( $>200$ $\mu \mathrm{m})$ authigenic albite crystals (Fig. 7e, f). A clast interpreted as a reworked pedogenic nodule from section 4LQ contains micritic matrix surrounding quartz grains and filled rhizoliths; sparite, microspar, and cryptocrystalline quartz cement fill vugs and veins. 

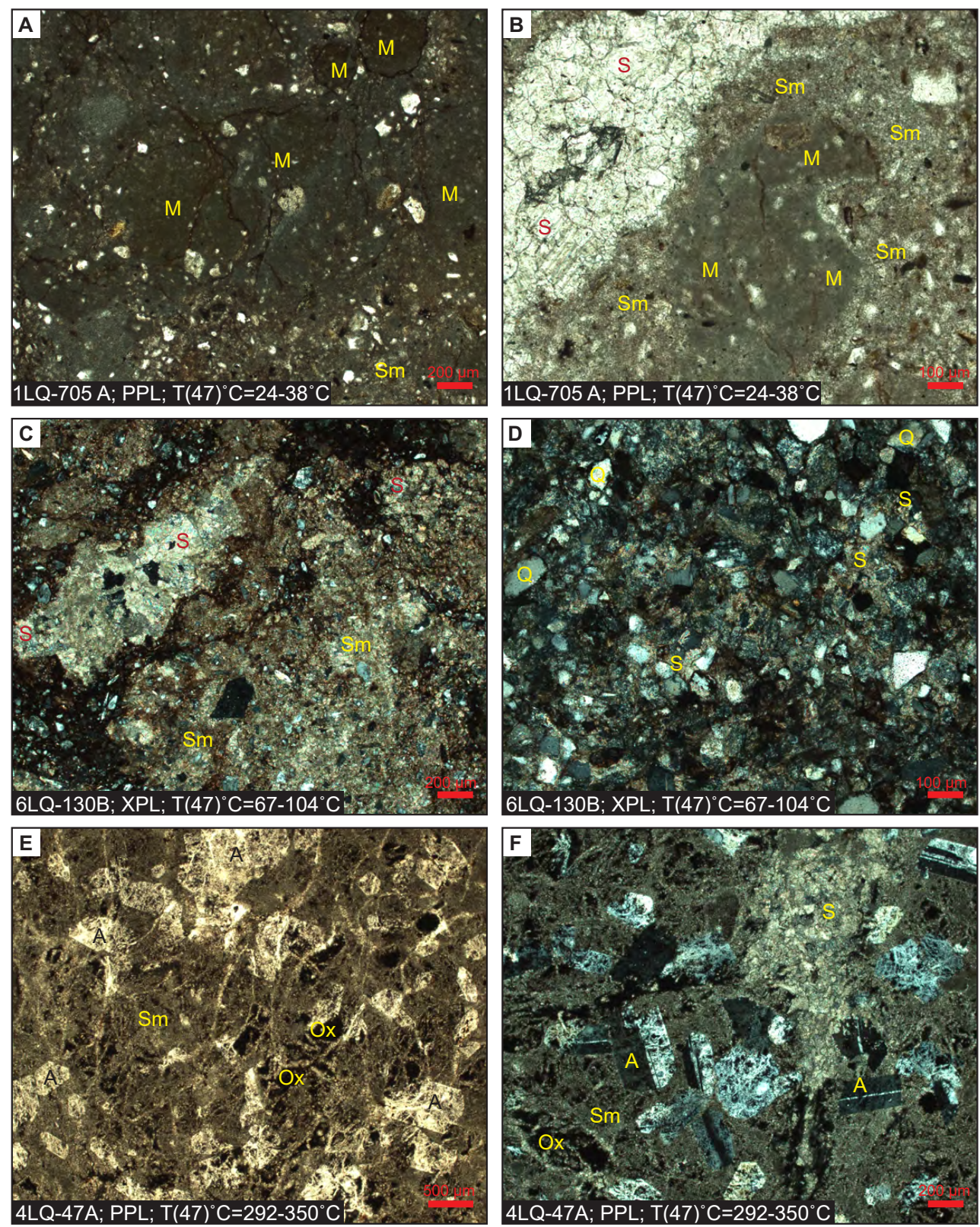

Figure 7. Photomicrographs of pedogenic nodules from sections 1LQ (A,B), 6LQ (C,D), and 4LQ (E,F) showing increasing recrystallization corresponding to higher $\mathrm{T}(47)^{\circ} \mathrm{C}$ temperatures. M-micrite, Sm-microspar, S-sparite, Q-quartz, A-authigenic albite, Ox-opaque metallic oxide. (A) zone of micritic matrix with silt-sized detrital quartz grains. Some microspar is present in the lower portion of the image. (B) zone of micrite in the center of the image, surrounded by microspar, spar-filled vein in the upper right of the image. (C) spar and microspar with silt-sized 
quartz. (D) Microspar matrix cut by numerous small veins with opaque metallic oxides and euhedral authigenic albite. (E) Micropsar, metal oxides, and albite euhedral albite. (F) Close-up of (E) Euhedral albite in microspar matrix with large area of spar in upper right.

\subsection{Lacustrine carbonates}

Lacustrine carbonates were only obtained from the lowermost $\sim 40 \mathrm{~m}$ of the Nianbo Formation in the Linzhou Basin (52 Ma). The $\delta^{\mathrm{g}} \mathrm{C}$ (VPDB) values of these lacustrine carbonates range from -15.4 to $-4.5 \%$ ( $n=17$; avg. $-7.7 \%$ ), and the $\delta^{18} \mathrm{O}(\mathrm{VPDB})$ values range from $15.0 \%$ to $-10.8 \%$ (avg. $-18.4 \%$ ) (Fig. 4; Table S3).

All the carbonates analyzed for $\Delta_{47}$ were first screened petrographically. Compositionally, the lacustrine carbonates from the Nianbo Fm. range from ostracode-rich and peloidal micrites to subspars. All but sample Shar $2 \mathrm{~m}$ (Table S6) retain what appear to be at least some primary micritic mud matrices. However, secondary cementation by spar and microspar of voids and fractures and recrystallization of fossils are common in these samples and occurs at such a fine scale that it could not be avoided during sampling. The twelve $\Delta_{47}$ measurements from these samples yielded estimates of $\mathrm{T}(47)$ from $59-105^{\circ} \mathrm{C}$ (Table S6).

\subsection{Other carbonates}

Most of our remaining results come from calcite in sandstone from the Kailas Formation (Table S5; Fig. 6). Since detritus in most formations was derived from noncalcareous volcanic and deep marine siliceous rocks, we assume most of this carbonate is cement, not detrital, which 
is supported petrographically (DeCelles et al., 2011; Orme et al., 2015; our observations). The $\delta^{\mathrm{B}} \mathrm{C}(\mathrm{VPDB})$ values of this cement (here, $\left.\delta^{\mathrm{g}} \mathrm{C}_{\mathrm{comm}}\right)$ range from -15.9 to $+4 \%$ ( $\mathrm{n}=96$; avg $=-$ $6.7 \%$ ), and the $\delta^{\curvearrowleft} \mathrm{O}(\mathrm{PDB})$ values (here, $\left.\delta^{\mathrm{s}} \mathrm{O}_{\text {cumann }}\right)$ range from -22 to $-12.6 \%$ (avg. $\left.=-18.0\right)$. These averages and ranges are virtually identical to those of pedogenic carbonate in the Kailas Fm.

\subsection{Water}

We focused our water sampling in the IYSZ on small catchment seeps, springs, and creeks, so that the waters reflect as closely as possible the sampling elevation, which ranged from $\sim 3800$ to $5500 \mathrm{~m}$ and spanned $80-89^{\circ}$ west to east (Table S7). When combined with sixty-one unpublished and previously published analyses, we obtained a strong $\left(\mathrm{r}^{2}=0.5\right)$ trend of increasing $\delta^{\mathrm{s}} \mathrm{O}\left(\right.$ VSMOW) values for meteoric water (hereafter, $\left.\delta^{\mathrm{s}} \mathrm{O}_{\mathrm{m}}\right)$ averaging $\sim-20 \%$ in the east to $\sim-15 \%$ in the west (Fig. 8). There is no correlation between $\delta " \mathrm{O}$ (VSMOW) values and elevation, probably because sample site elevations across this transect fall in a narrow range averaging $4700 \pm 380 \mathrm{~m}$ (Table S7). The best fit line to these water analyses follows $\delta \mathrm{D}=8.2 \delta^{18} \mathrm{O}$ +11.5 , close to the global meteoric line (Craig, 1961; Rozanski et al., 1993). 


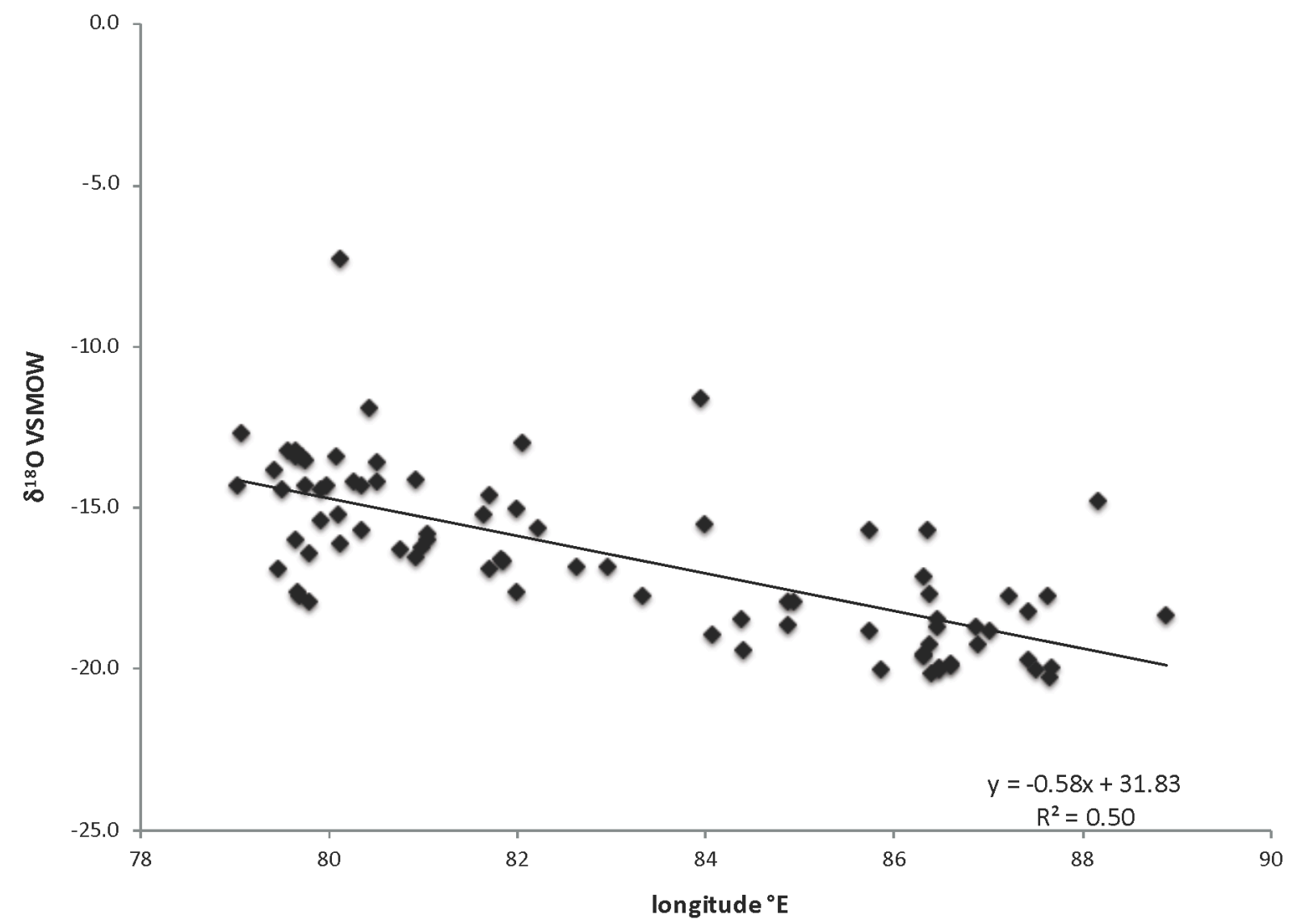

Figure 8. The $\delta^{18} \mathrm{O}$ (VSMOW) value of natural waters (largely small streams and springs) along the IYSZ.

\section{Discussion}

\subsection{Alteration of marine carbonates and its implications}

As shown in Figure 2b, our study more than doubles the number of published isotopic values of K-Pg limestones from various locations in the IYSZ. These data strengthen the view that isotopic alteration in the IYSZ limestones is much more prevalent than outside it; and that alteration of oxygen isotopes is more pervasive than for carbon. Ninety-six percent of the limestones analyzed retain primary $\delta^{13} \mathrm{C}_{\mathrm{ls}}$ values, whereas none of them preserve primary $\delta^{18} \mathrm{O}_{\mathrm{ls}}$ 
values. In short, in the case of oxygen, no analysis among the $\sim 1300$ marine limestone samples reproduced the correct paleoelevation (i.e., sea level), and many $\delta^{18} \mathrm{O}_{\mathrm{ls}}$ values from the IYSZ would result in overestimates of the paleoelevation of $\sim 4-5 \mathrm{~km}$ in the early Cenozoic. In the case of carbon, most analyses, especially outside the IYSZ, should reflect primary conditions of formation. In the next section, we will take advantage of that positive outcome for carbon isotopes to reconstruct past paleoenvironments, followed in the succeeding section by an examination of the probable circumstances of alteration of $\delta^{18} \mathrm{O}_{\mathrm{ls}}$ values. Using these insights, we will close the Discussion with a review some individual studies that use carbonate isotopic records to reconstruct paleoelevation across the southern Tibetan plateau.

\subsection{Carbon isotope record}

Nearly all of the $\delta^{3} C_{1 s}$ values we obtained in this study and from previous studies from inside and outside the IYSZ overlap the expected range of values $(-1.9$ to $+5 \%$ ) for Jurassic through Cenozoic limestones (Fig. 2). This implies that the majority $\delta^{13} \mathrm{C}$ values from carbonates younger and generally overlying the marine limestones can be viewed as primary, not secondary. Approximately 50 (or $\sim 4 \%$ ) of the limestone samples returned $\delta^{13} \mathrm{C}_{\mathrm{ls}}$ values $<-1.9 \%$, most of them from two Cenomanian-age limestones in the Xigaze forearc sequence in the IYSZ (Table S2). There are several explanations for the low $\delta^{13} C_{1 s}$ values, including decarbonation, exchange with methane, or the one we favor, near-surface diagenesis. Decarbonation is unlikely because the estimated burial temperatures of $\leq 160^{\circ}$ (Orme, 2017) are too low. The most common cause of the low $\delta^{13} C_{\mathrm{s}}$ values in near shore environments is near-surface weathering or alteration in the phreatic zone, a process often accompanied by replacement of metastable high-Mg and aragonite cements by low-Mg calcite (Allan and Mathews, 1982). The lowest $\delta^{13} C_{1 s}$ values of -12\%o overlap 
$\delta^{13} C_{p c}$ values from the same sections, suggesting formation in equilibrium with local plant-derived $\mathrm{CO}_{2}$.

The $\delta^{13} \mathrm{C}_{\mathrm{sc}}$ value of soil carbonate is determined by soil respiration rates, atmospheric $\mathrm{pCO}_{2}$ of the atmosphere, soil depth (which influences mixing with atmospheric $\mathrm{CO}_{2}$ ), and the relative contributions of $\mathrm{C}_{3}, \mathrm{C}_{4}$, and CAM plants growing on the site. All our sampling of soils and paleosols is from below $50 \mathrm{~cm}$ soil depth, where the contribution of atmospheric $\mathrm{CO}_{2}$ under modern conditions $\left(\mathrm{pCO}_{2}=10^{3.5} \mathrm{~atm}\right)$ is small in all but the driest settings. CAM plants do not make up a large proportion of most dryland ecosystems, and prior to the late Miocene, which includes all of our sampled material, $\mathrm{C}_{4}$ plants were probably minor to absent. The history of $\mathrm{pCO}_{2}$ can be corrected for and is coarsely known for the Cenozoic from a variety of records (Ekart et al., 1999; Pagani et al., 2005), including paleosols. That leaves the soil respiration rate as the chief control on $\delta^{13} C_{s c}$ values.

Turning to our results, paleosols from nearly all sedimentary sequences (Xigaze, Kailas, and Liuqu) returned $\delta{ }^{13} C_{\mathrm{s}}$ values in the -15 to $-8 \%$ range. These low values are surprising in that they show almost no overlap with the higher $\delta^{13} C_{x}$ values from modern Tibetan soils (Fig. 3). This range of low values is found in wetter settings, such as the Gangetic Plains of India where rainfall ranges from 0.7 to $1.2 \mathrm{~m} / \mathrm{yr}$ (Kothari and Singh, 1996; Kumar et al., 2010). For comparison, our large database $(n=226$; Quade et al., 2011) on modern Tibetan soils from >50 cm soil depth returned $\delta^{13} C_{\mathrm{sc}}$ values ranging from -5 to $+12 \%$. These high values are typical of very dry ( $<300 \mathrm{~mm} / \mathrm{yr}$ ) deserts, such as Tibet today (Quade et al., 2011), where the influence of atmospheric $\mathrm{CO}_{2}$ is higher relative to plant $\mathrm{CO}_{2}$ deep in soil profiles. 
We can use the soil diffusion model developed by Cerling et al. (1984) and refined by Quade et al. (2007) to further contextualize our results (Fig. 9). The $\delta^{13} \mathrm{C}_{\mathrm{s}}$ values in the -9 to $-12 \%$ range, such as those from most of our paleosols, are typical of soils with high respiration rates, namely, in the range of 1 to $10 \mathrm{mmoles} / \mathrm{m}^{2} / \mathrm{yr}$ (Fig. 9). Modern analogs include modern soils in the midwestern USA, the circum-Mediterranean, or northern India (Cerling and Quade, 1993). The $\delta^{13} \mathrm{C}_{\mathrm{sc}}$ values ranging from -5 to $+12 \%$ from modern Tibetan soils require very low soil respiration rates in the range of 0.5 to $0.01 \mathrm{mmoles} / \mathrm{m}^{2} / \mathrm{yr}$, reflecting the suppression of soil productivity due to both very cold temperatures and aridity. Soils from the Mohave and Atacama Deserts, for example, also record respiration rates in this range (Quade et al., 1989; Quade et al., 2007).

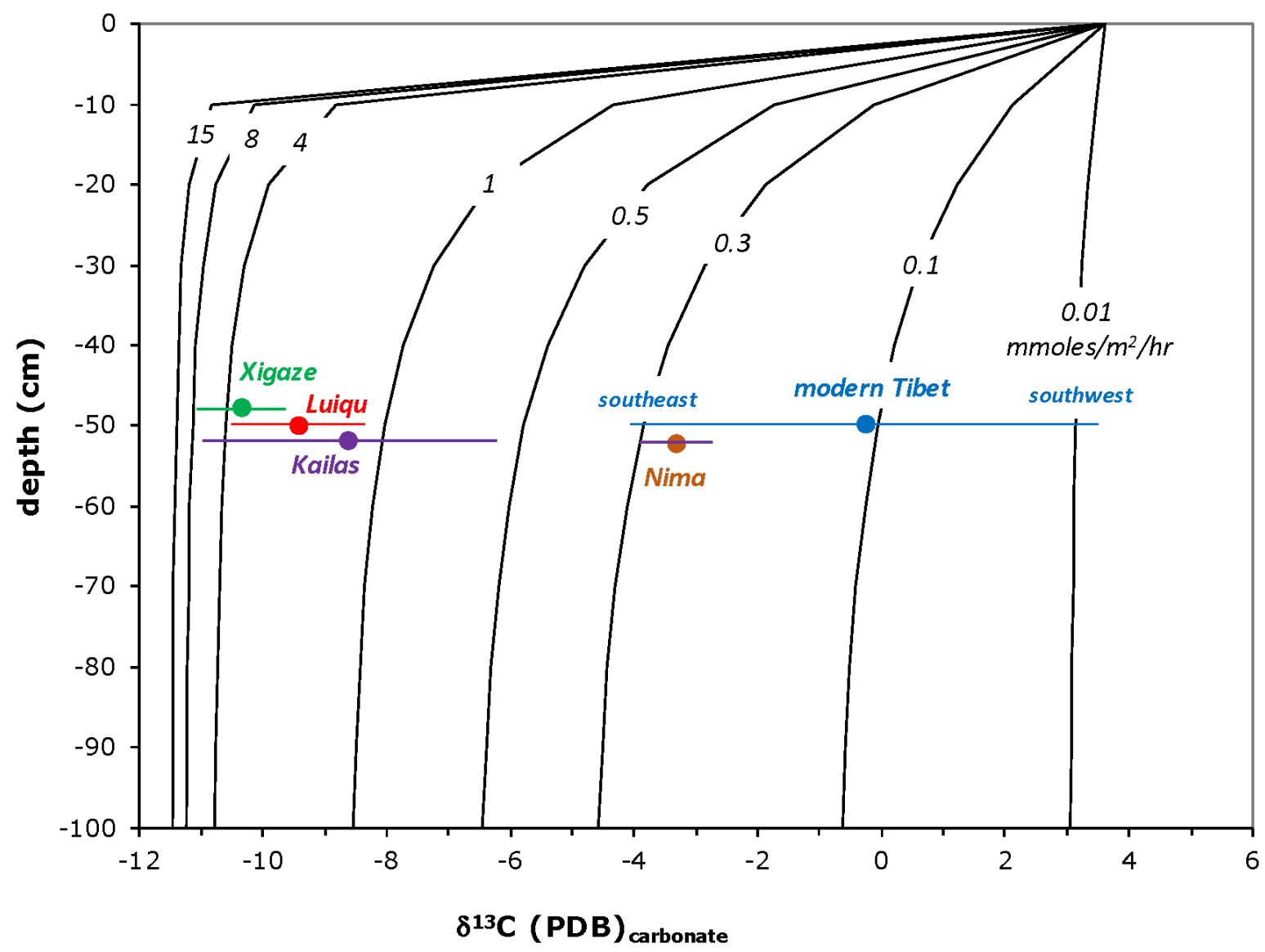

Figure $9 . \delta^{13} \mathrm{C}(\mathrm{VPDB})$ values of soils and paleosols versus profile sampling depth obtained by 
this study. For comparison, lines define modeled soil respiration rates using the one-dimensional soil diffusion model of Cerling et al. (1984) and Quade et al. (2007), assuming $\delta^{13} C_{\text {atmosphere }}=$ $6.5 \%$ o, $\delta^{13} \mathrm{C}_{\text {respiratory } \mathrm{CO} 2}=-26 \%$, $\mathrm{pCO}_{2}=400 \mathrm{ppmV}, \mathrm{T}^{\circ} \mathrm{C}=15$, elevation $=4000 \mathrm{~m}, \rho_{\text {soil }}=0.5$, soil $\mathrm{CO}_{2}$ production depth $=100 \mathrm{~cm}$.

In short, the carbon isotope results from paleosols indicate that conditions in the IYSZ were profoundly different $\geq 20$ Ma than today. Well-vegetated paleosols are no surprise for the Cretaceous and early Cenozoic Xigaze forearc sequence, which would have faced southward toward a subtropical Neo-Tethyan Ocean prior to India-Asia collision. Ingalls et al. (2019) also obtained low $\delta^{\mathrm{s}} \mathrm{C}_{\mathrm{sc}}$ values of $-8.2 \pm 1.1(\mathrm{n}=6)$ from the Xigaze forearc sequence, suggesting wellvegetated conditions in the Paleogene suture. The surprise is the well-vegetated conditions in the IYSZ 40 million years after the collision, in conjunction with orographic shielding by an apparently elevated ancestral Himalaya (Gébelin et al., 2013). A range of other evidence further supports a more vegetated and probably wetter and lower elevation IYSZ during the OligoMiocene. Sedimentologically, the Kailas Formation contains evidence for a system of large, suture-parallel paleo-lakes bounded by coal swamps (DeCelles et al., 2011). DeCelles et al. (2018b), using the $\mathrm{TEX}_{86}$ and MBT/CBT organic paleothermometers from these lake deposits, reconstruct warm $\left(25^{\circ} \mathrm{C}\right)$ lake temperatures from the Kailas Formation. Soil weathering indices in paleosols of the Liuqu Formation are markedly higher than in modern Tibetan soils and are analogous to paleosol weathering indices from low-elevation Miocene-age paleosols of the Siwalik Group in the northwestern Indian subcontinent (Leary et al., 2017). Ding et al. (2017) report paleofloras and fossil leaf forms from the Liuqu and Kailas Formations that indicate low to moderate elevations in the ITCZ up through the mid-Miocene. 
The only instances of higher $\delta^{1} \mathrm{C}_{\mathrm{p}}$ values from our suture paleosol record come from the uppermost Kailas Formation near Mt. Kailas (Table S5) (DeCelles et al., 2011). They range from -4 to $-6 \%$, roughly 3 to $10 \%$ o higher than the values from the rest of the Kailas Formation and are the only paleosol values that overlap with values from modern soils in eastern Tibet. We explain these results as reflecting the late stages of basin infilling by entirely alluvial material derived from the Tethyan Himalaya to the south. It is plausible that by the latest stage of Kailas Formation deposition near Mt. Kailas (at $23 \mathrm{Ma}$ ), the western part of the suture was experiencing drying and uplift akin to the wettest conditions on the plateau today in southeastern Tibet. Putting aside these results from the upper redbeds of the Mt. Kailas section, there is a pattern of increasing $\delta^{3} C_{p c}$ values eastward in the Kailas Formation, indicating drier overall conditions eastward (Fig. 10). It is tempting to relate this pattern to the west-to-east opening of the extensional basin system described in Leary et al. (2016), with the system being older and 
lower in elevation in the west and younger and higher in elevation in the east.

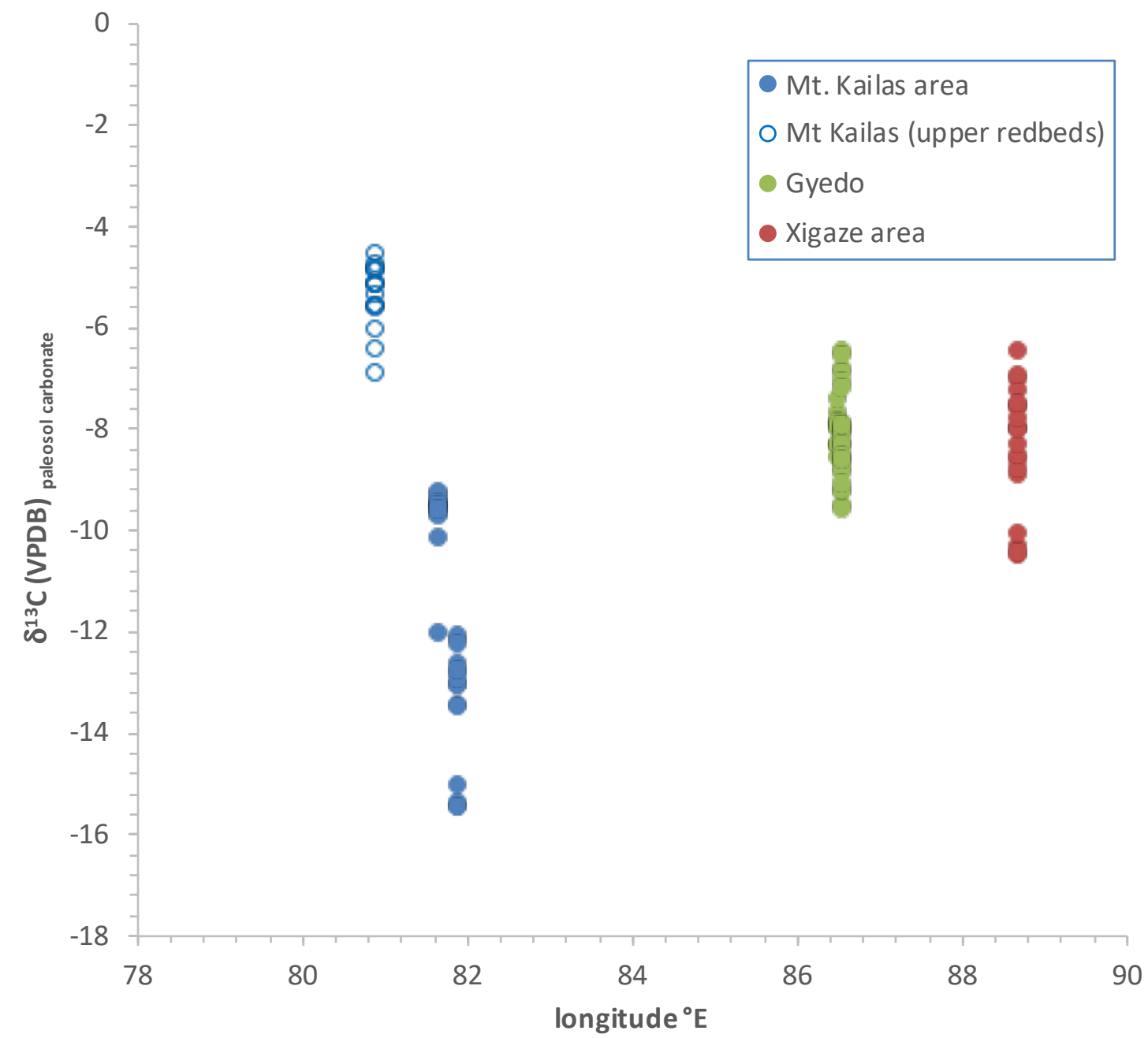

Figure 10. $\delta^{13} \mathrm{C}(\mathrm{VPDB})$ values of paleosol carbonates from the Kailas Formation with longitude along the IYSZ.

$\delta^{3} C_{p}$ values from paleosols in other areas (Fig. 1) of southern Tibet can be merged with ours to produce a more regional view of paleovegetation cover before the Miocene. Published data sets include Currie et al. (2016) from the Namling/Oiyug area and Ingalls et al. (2018) and Ding (2014) from Linzhou, both within the Gangdese magmatic arc; DeCelles et al. (2007) from the Nima area in the Bangong-Nujiang suture at the northern edge of the Lhasa terrane; and Xu et al. (2013) from Longweicuo in the Qiangtang terrane. These areas all yield $\delta^{13} C_{p c}$ values 
(Namling/Oiyug: $\delta^{1} C_{p c}=-6.9 \pm 0.8 \% o(n=13)$; Linzhou: $\delta^{13} C_{p c}=-5.6 \pm 2.1 \% o(n=28):$ Nima: $\delta^{13} C_{p c}=$ $-3.5 \pm 0.6 \%$ o $(n=19)$; Longweicuo $-5.6 \pm 0.8 \%$ o $(n=8)$ that are higher than those of the contemporaneous IYSZ but markedly lower than those of modern Tibet, which average approximately 0\%o (Fig. 11). Using the Cerling (1984) diffusion model, much higher $\mathrm{pCO}_{2}(5 \mathrm{x}$ ? $>$ modern) in the mid-Eocene would add $\sim 1 \%$ to $\delta^{13} \mathrm{C}_{\mathrm{p}}$ values from Linzhou; thus, the $\mathrm{pCO}_{2}{ }^{-}$ corrected values are $-6.6 \%$, still fairly high and indicative of low respiration rates and dry conditions. For the other, post-Eocene paleosols, when $\mathrm{pCO}_{2}$ was closer to modern, lower soil respiration rates should be the sole cause of the elevated $\delta^{13} C_{p c}$ values. Hence, these values reflect semiarid conditions north of the IYSZ in the mid-Cenozoic, in contrast to moist conditions in the contemporaneous IYSZ and to arid conditions across all of Tibet today. 


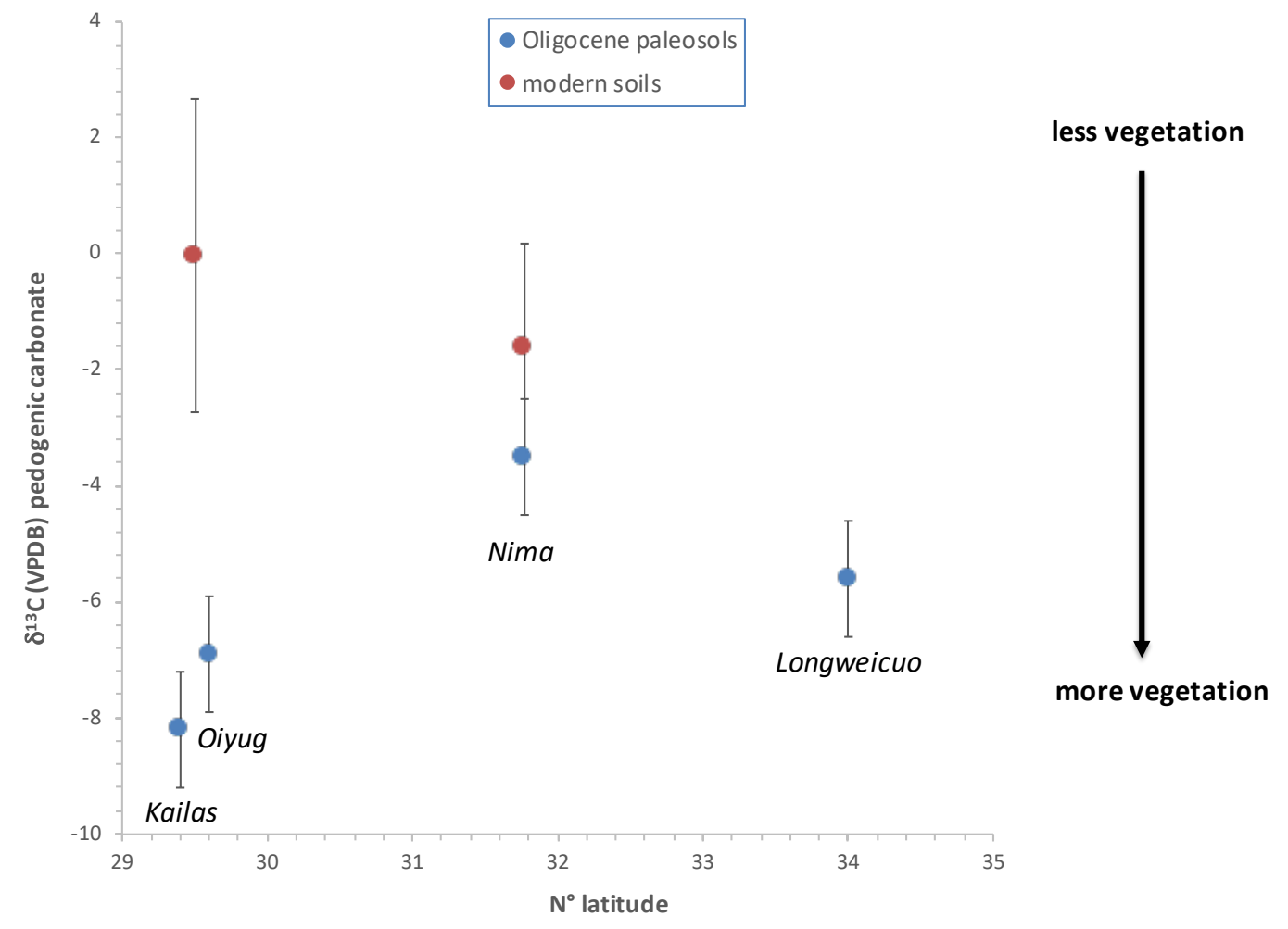

Figure 11. $\delta^{13} \mathrm{C}$ (VPDB) of soil and paleosol carbonate with latitude in Tibet. Modern soil data is from Quade et al. (2011), and Oligocene paleosol data is from Kailas (this paper); Oiyug (Currie et al., 2016) ; Nima (DeCelles et al., 2007); and Longweicuo (Xu et al., 2013).

\subsection{Oxygen and clumped isotope record}

The pattern of alteration displayed by the marine carbonates in the region is a good starting place for isolating diagenetic affects because we know the starting and ending values of the limestones. The changes in $\delta^{18} \mathrm{O}$ value that carbonates may undergo are controlled by the initial $\delta^{18} \mathrm{O}$ value of the carbonates, the $\delta^{18} \mathrm{O}$ value of the altering fluid, the water/rock ratio of 
alteration, and the alteration temperature. The initial value must be $\sim 0 \pm 4 \%$ for marine carbonate of this age, whereas the measured values today are in the range of -5 to $-10 \%$ outside the IYSZ and magmatic arc and -12 to $-22 \%$ for most limestone samples within the IYSZ/ Gandese magmatic arc (Figs. 12, 13).

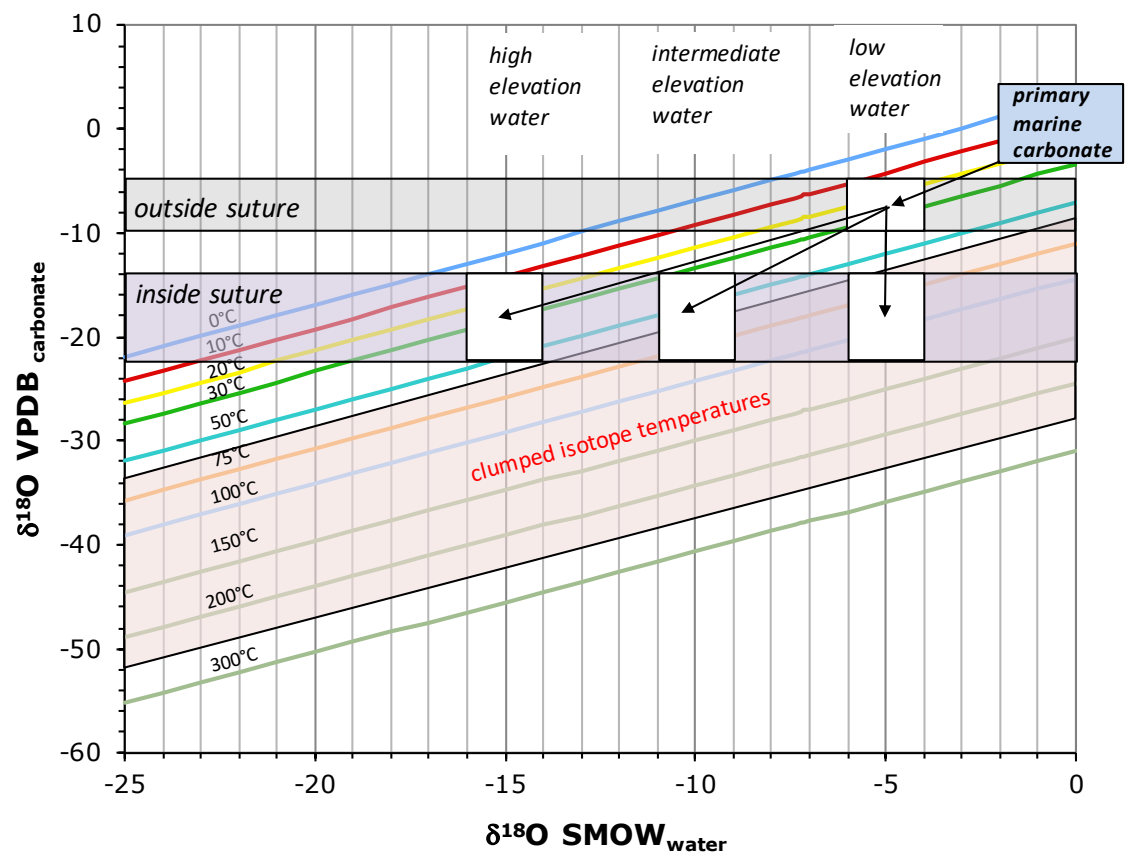

Figure 12. Modeled $\delta^{18} \mathrm{O}(\mathrm{VPDB})$ values of carbonate rock as function of temperature (using Kim and O’Neil, 1997) and the $\delta^{18} \mathrm{O}$ (VSMOW) value of parent water. Gray and purple boxes define the range of $\delta^{18} \mathrm{O}(\mathrm{VPDB})$ values of late Cretaceous/Paleogene marine carbonates inside and outside the IYSZ/Gandese arc today, respectively. The red area defines the range of temperatures reconstructed from $\Delta_{47}$ obtained by this study from the Nianbo and the Luiqu Formations. The blue box defines the range of $\delta^{18} \mathrm{O}(\mathrm{VPDB})$ values of primary marine 
carbonates from the Cretaceous and Paleogene (Veizer et. Al., 1999; Kobashi et al., 2001). Arrows and filled white boxes denote the alteration pathways of marine carbonates in the presence of low $\left(\delta^{18} \mathrm{O}(\mathrm{VSMOW})=-5 \%\right)$, intermediate $(-10 \%)$, and high elevation $(-15 \%)$ paleowater, as discussed in the text.

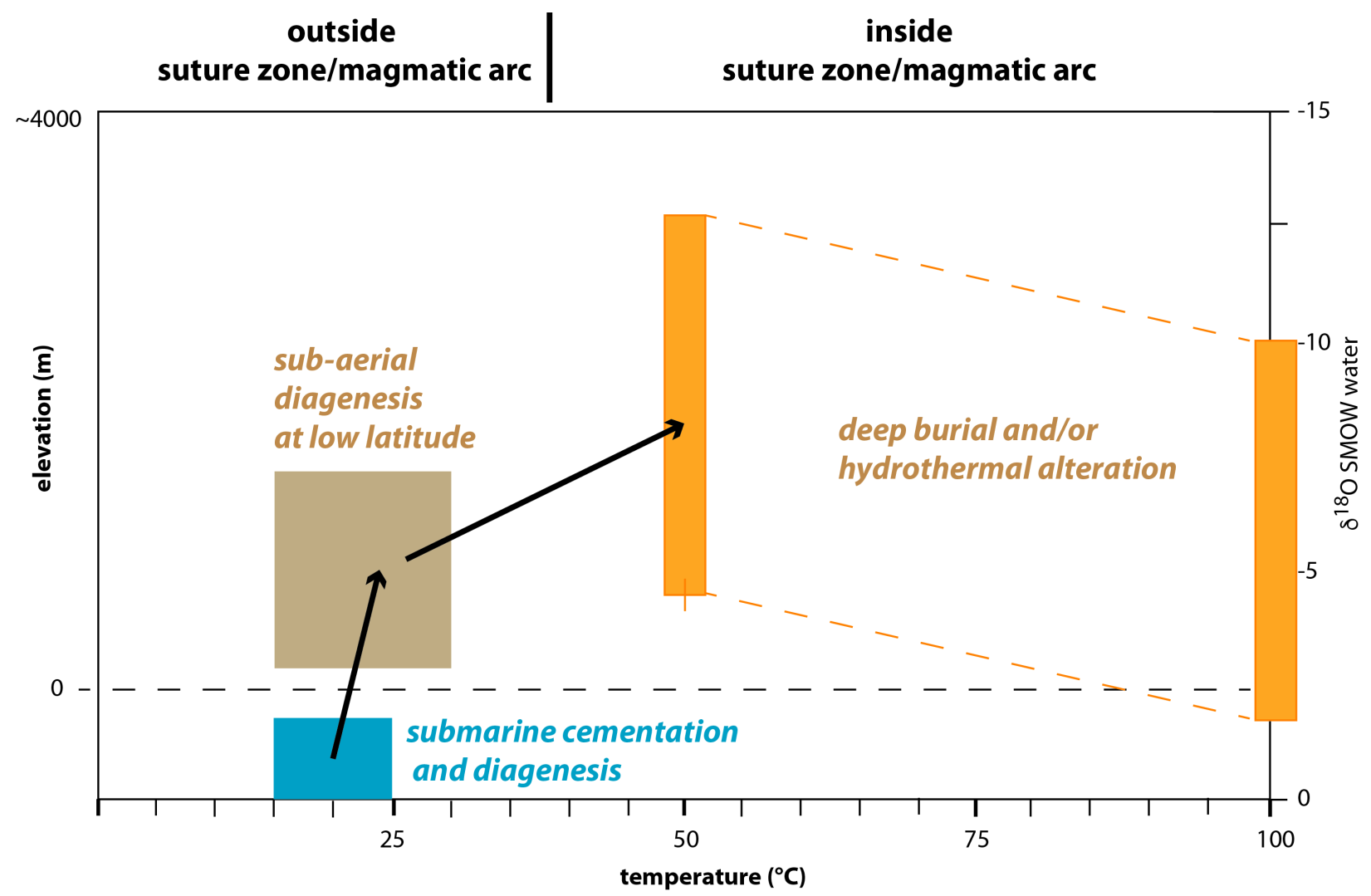

Figure 13. Summary diagram of the three stages of alteration that marine carbonates from Tibet may have undergone, the first two thoroughly described for marine carbonates in general in (see text). These three stages produce the observed ranges of $\delta^{18} \mathrm{O}_{\mathrm{ls}}$ (VPDB) values, Stage I: $\delta^{18} \mathrm{O}_{\text {ls }}$ (VPDB) $0 \pm 3 \%$; Stage II: -5 to $-10 \%$; Stage III: -10 to $-25 \%$. Stage I in blue entails precipitation and subsequent diagenesis (mainly cementation) of carbonate in a shallow submarine setting, at assumed $\mathrm{T}=15 \pm 10^{\circ} \mathrm{C}$ in the presence of seawater $\delta^{18} \mathrm{O}(\mathrm{VMOW})$ values $<-$ 2\%. Stage II in tan entails sub-aerial exposure and pedogenesis of marine carbonate at assumed $\mathrm{T}=15-30^{\circ} \mathrm{C}$ in the presence of low-latitude meteoric water with $\delta^{18} \mathrm{O}$ (VMOW) values $<-5 \pm 2 \%$. 
Stage III in orange entails heating 50 to $100^{\circ} \mathrm{C}$ (as required by most $\mathrm{T}(47$ ) results) of marine carbonate from Stage II in the presence of low to intermediate elevation water with $\delta^{18} \mathrm{O}$ (VMOW) values $>-10 \%$. Fluids with $\mathrm{T}>100^{\circ} \mathrm{C}$ and $\delta^{18} \mathrm{O}$ (SMOW) $<-10 \%$ (i.e. higher elevations) are not permitted, yielding $\delta^{18} \mathrm{O}_{1 \mathrm{~s}}$ (VPDB) values lower than any value observed ($25 \%$ ).

The existing literature suggests that $\delta^{18} \mathrm{O}$ values in many marine limestones undergo a regular series of alteration stages, starting in submarine settings that add cement, change mineralogy (e.g., dolomitization), and reduce porosity but have little effect on primary isotopic composition (Allan and Mathews, 1982). The most profound changes happen shortly after (103$10^{5}$ years) subaerial exposure and pedogenesis in the presence of meteoric water through a combination of recrystallization, replacement, and secondary cementation This vadose-zone process involves the (1) conversion of labile mineralogical phases such as aragonite, where present, and high Mg-calcite to more stable low-Mg calcite, (2) dissolution followed by reduction in primary porosity of $40-70 \%$ to $<20 \%$ as pores are cemented and compacted, and (3) decrease of $\delta^{18} \mathrm{O}_{\mathrm{ls}}$ values in the direction of equilibrium with local meteoric water (Land, 1970; Hudson, 1977; Purser, 1978; Allan and Mathews, 1982; Lohmann, 1988; Marshall, 1992). The resultant $\delta^{18} \mathrm{O}_{\mathrm{Is}}$ values altered at low latitudes by the shallow vadose zone processes fall in the -2 to $-8 \%$ range (Land, 1970; Allan and Mathews, 1982; Lohmann, 1988). This low-temperature diagenetic process greatly enhances the resistance of marine limestone to subsequent isotopic alteration. As an example, Keith and Weber (1964) found marine limestone of Mesozoic age from a range of settings to average $-5.9 \pm 3.4 \%$, very similar to the average $\delta^{18} \mathrm{O}_{\mathrm{ls}}$ values of 7.1 \pm 2.8 compiled by our study outside the IYSZ. 
The marine limestones listed in Figure 2 and Table $\mathrm{S} 1$ all formed in tropical to subtropical latitudes. They come largely from Tethyan Himalayan rocks deposited off the northern margin of India in the Neo-Tethyan Ocean before it was closed by Indo-Asian collision. These range from mid-Cretaceous to Eocene in age and were deposited between about $20^{\circ} \mathrm{S}$ to $20^{\circ} \mathrm{N}$ paleolatitude as India drifted northward (Dupont-Nivet et al., 2010). A smaller sample (published in Leier et al., 2009) comes from mid-to late Cretaceous age marine limestones deposited at $25 \pm 5^{\circ} \mathrm{N}$ in the Meso-Tethyan Ocean north of the Gangdese arc (Lippert et al., 2014; Huang et al., 2015).

We can model how the observed $\delta^{18} \mathrm{O}_{\mathrm{ls}}$ values may have been altered under these circumstances by assuming a $\delta^{18} \mathrm{O}$ (SMOW) value for low-elevation water of $-4 \pm 2 \%$ (typical of low-elevation stations, such as New Delhi $\left(28^{\circ} \mathrm{N}\right)$ or Hong Kong $\left(22^{\circ} \mathrm{N}\right)$, in the subtropics today) and a value for high-elevation water of $-16.5 \pm 1 \%$ (the average in the IYSZ today). At high water/rock ratios, the temperatures required for carbonate equilibrium with low-elevation waters $\left(10-40^{\circ} \mathrm{C}\right)$ are much more plausible sub-tropical soil temperatures than the very cold temperatures $\left(<<0^{\circ} \mathrm{C}\right)$ required by equilibrium with high-elevation water (Figs. 12, 13).

In support of this, $\delta^{18} \mathrm{O}$ values from marine limestones of the mid-Eocene Subathu Formation from NW India (Leier et al., 2009) average -7.1 $\pm 1.7 \%$ (Fig. 2b). The current elevation of the sampled outcrops is $\sim 1300 \mathrm{~m}$, and thus these carbonates have experienced neither high elevations nor interacted with diagenetic waters with very low $\delta^{18} \mathrm{O}$ values. The $\delta^{18} \mathrm{O}$ values from the marine Subathu Formation are in the same range (Fig. 2) as other marine limestones now at high elevations outside the IYSZ, suggesting that all these marine carbonates outside the IYSZ were altered early-on in the presence of low-elevation meteoric waters and not at high elevations in the presence of low- $\delta^{18} \mathrm{O}$ waters.

This is a positive outcome for paleoaltimetry reconstructions that rely on carbonates from 
outside suture zones/magmatic arcs. The pedogenic and lacustrine carbonates used for paleoaltimetric reconstructions in Tibet all overlie the older marine limestones, and therefore would not generally have been exposed to burial depths or temperatures any greater than the limestones. If the $\delta^{18} \mathrm{O}$ values of the altered marine limestones "lock in" low paleoelevations acquired during pedogenesis, the same should be true of most subsequent pedogenic mineralization of non-marine beds. Moreover, primary pedogenic carbonate takes the stable, low-Mg form of calcite, is micritic to microsparitic (Chadwick et al., 1989) in primary texture, and in many alluvial settings is encased in non-porous, argillic mudstone of the B and C horizons. This reduces the susceptibility of soil carbonate to later alteration, unlike primary marine limestone which is not stable texturally, mineralogically, and isotopically in a sub-aerial setting until it undergoes pedogenesis itself.

By contrast, limestones within the IYSZ and adjoining Gangdese arc evidently continued to experience alteration in the presence of some combination of higher temperatures and meteoric waters with variable $\delta^{18} \mathrm{O}$ values. Alteration in this setting is unsurprising given the high geothermal gradients (Francheteau et al., 1984), hydrothermal alteration and abundant modern hot spring activity (Ji-Yang et al., 1981), and deep burial and ongoing deformation (Laskowski et al., 2018) in this area. The observed range of $\delta^{18} \mathrm{O}$ (VPDB) values of -14 to $-22 \%$ could be explained by formation in the presence of intermediate-elevation waters of $\sim 10 \%$ in the 30 $100^{\circ} \mathrm{C}$ range; or alternatively, the range could be explained by formation in the presence of highelevation suture waters of -14 to $-19 \%$ in the $10-50^{\circ} \mathrm{C}$ range. Alteration in the presence of lowto intermediate-elevation water is most likely scenario given the evidence of hydrothermal alteration in suture and magmatic arc deposits and the elevated $\mathrm{T}(47)$ values of $59-257^{\circ} \mathrm{C}$ (Figs. $12,13)$. 
What are the implications of these observations from marine limestones for the alteration of $\delta^{18} \mathrm{O}$ values of nonmarine carbonates on the plateau? The implications are that for carbonates of any type in and near the IYSZ, decreases in values of up to $15 \%$ due to diagenesis are possible depending on age. Such decreases are highly probable for Eocene and older carbonates and are increasingly unlikely for increasingly younger carbonates, depending on local conditions of burial and hydrothermal alteration. In our view, this calls into serious question the reliability of

paleoelevation reconstructions using $\delta^{18} \mathrm{O}_{\mathrm{cc}}$ values from such areas as Xigaze (in agreement with Ingalls et al., 2019), Linzhou (Ding et al., 2014), quite probably the Kailas Formation and Liuqu Conglomerate (this study). On the other hand, the likelihood of preservation of near-surface isotopic conditions appears to be high for areas outside the IYSZ, such as Lunpola (Rowley and Currie, 2006), the Oligocene at Nima (DeCelles et al., 2007), and the Eocene-Oligocene (?) Kangtuo Formation in the Qiangtang terrane (Xu et al., 2013).

\subsection{Case studies from across Tibet}

\subsubsection{Alteration of the Xigaze forearc sequence and Nianbo Formation}

Our evidence from the Xigaze forearc sequence (110-53 Ma) and the Nianbo Formation (52 Ma) at Linzhou provide strong evidence in support of regional patterns of probable resetting of all $\Delta_{47}$ and $\delta^{18} \mathrm{O}_{\mathrm{ls}}$ values. Our $\delta^{18} \mathrm{O}_{\mathrm{pc}}$ and $\delta^{18} \mathrm{O}_{\mathrm{ls}}$ values from the Xigaze forearc sequence display very similar average values of $-15.5 \pm 3.8$ and $-14.1 \pm 3.1 \%$, respectively (Table S2; Fig. 3 ). This similarity and the fact that both types of carbonates had to have been deposited below or near sea level mean that the $\delta^{18} \mathrm{O}_{\mathrm{pc}}$ values are almost certainly not primary. Ingalls et al. (2019) also recognized probable alteration of $\Delta_{47}$ and $\delta^{18} \mathrm{O}_{\mathrm{ls}}$ values from the Xigaze forearc sequence at 
several points in the burial history. Orme (2017) suggest that these rocks experienced maximum burial temperatures of $140-200^{\circ} \mathrm{C}$ by $20 \mathrm{Ma}$, through burial by a combination of forearc sedimentation and later thrusting.

Two previous studies (Ding et al., 2014 and Ingalls et al., 2018) and our results all return low $\delta^{18} \mathrm{O}$ values in the $-15.4 \pm 2.4 \%$ range for terrestrial carbonates from the Nianbo and overlying Pana Formations. Our T(47) results (Table S6) from $59-105^{\circ} \mathrm{C}$ for all samples exceed plausible Earth surface temperatures, as do most but not all of those obtained by Ingalls et al. (2018). In spite of these high temperatures, micrite persists in several of the samples. On the basis of the preserved micrite, Ding et al. (2014) and Ingalls et al. (2018) interpreted their results as indicating high $(>4 \mathrm{~km})$ paleoelevations at ca. $52 \mathrm{Ma}$, during the earliest stages of Indo-Asian collision.

Recent analysis of the thermochronologic evidence from the same sections of the Linzizong Formation as those used in paleoaltimetric reconstructions shows that the Nianbo and Pana carbonates underwent several significant heating events (HE1 and HE2) related to igneous activity in this magmatic arc setting (Huang et al., in review). The first hydrothermal event (HE1) altered the Nianbo Formation and was the most intense, exceeding the biotite/muscovcite closure temperature of ${ }^{40} \mathrm{Ar} /{ }^{39} \mathrm{Ar}$ of $>300^{\circ} \mathrm{C}$ at $\sim 52 \mathrm{Ma}$. The timing of this event also coincides with the crystallization ages of dikes, granite, and ignimbrites in the lower Pana Formation. The subsequent hydrothermal event (HE2) heated the Nianbo and Pana Formations up to $130-150^{\circ} \mathrm{C}$ sometime between 42 and $26 \mathrm{Ma}$.

We argue that it is unlikely that primary $\Delta_{47}$ and $\delta^{18} \mathrm{O}$ values survived these hydrothermal events. Temperatures attained during these hydrothermal events equal or exceed the probable closure temperature of clumped isotopes of $100-125^{\circ} \mathrm{C}$ (Passey and Henkes, 2012; Quade et al., 
2013). The high temperatures of HE1, evidence for hydrothermal bleaching of the Nianbo Formation, and the abundance of secondary microspar and spar in most carbonate samples all argue against the survival of primary $\delta^{18} \mathrm{O}$ values in these rocks. Unfortunately, the Linzizong Sequence containing the Nianbo Formation contains no marine carbonates with which to decisively test for preservation of primary $\delta^{18} \mathrm{O}$ values. However, the late Cretaceous Takena Formation directly underlying the Linzizong Sequence in Linzhou contains marine carbonate that is entirely reset to low $\delta^{18} \mathrm{O}$ values, averaging $-13.2 \pm 0.9 \%$. This average is close to the average of our measurements from the Nianbo Formation of $-14.2 \pm 2.3 \%$ and to values reported by Ding et al. (2014) and Ingalls et al. (2018) (Fig. 4). This similarity reinforces our view that the $\delta^{18} \mathrm{O}$ values of the nonmarine carbonates at Linzhou are probably not primary.

\subsubsection{The Zhada Formation and other unaltered deposits}

We recognize that there are many examples from Tibet where carbonates were not reset by diagenesis and their isotopic compositions yield valid paleoelevation estimates. One example is from the Zhada Basin where Saylor et al. (2009) and Huntington et al. (2015) reconstructed late Miocene paleoelevations as high or higher than the modern basin elevation of $\sim 4000 \mathrm{~m}$. This basin is ideal for paleoaltimetric reconstruction using $\Delta_{47}$ and $\delta^{18} \mathrm{O}$ values because it is characterized by: (1) well-preserved aquatic shell made of pure aragonite and mother-of-pearl; (2) plausible surface $\mathrm{T}(47)$ values with a narrow range of approximately $9 \pm^{\circ} \mathrm{C}$; (3) low $\delta^{18} \mathrm{O}$ values from fluvial shells, intermediate values from marsh shells, and the highest values from lacustrine shells, exactly reflecting the pattern seen in modern fauna; (4) burial depths of $<1 \mathrm{~km}$, or burial heating no more than $100^{\circ} \mathrm{C}$; and (5) no evidence of hydrothermal or other major 
alteration.

Other strong examples of stand-alone isotopic records from carbonates from nearby intraHimalayan basins that probably have not undergone diagenetic alteration include the Gyirong Basin (Wang et al., 2006) and Thakkola Basin (Garzione et al., 2000). Similar to the Zhada Basin, the deposits in these basins are late Neogene in age and have experienced only modest burial.

\subsubsection{Oligo-Miocene records in the IYSZ}

Most paleoaltimetry studies in Tibet have been conducted on basins that are intermediate in age and magnitude of burial compared to the Eocene-age Linzhou and Mio-Pliocene Zhada Formation discussed above. Some of these intermediate records may have undergone resetting, whereas others have not; however, until recently, only a few studies recognized that any resetting at all had occurred in their records (e.g., Leier et al., 2009; Leary et al., 2017; Ingalls et al., 2019; Ning et al., 2019). In the end, our view is that the isotopic records from Oligo-Miocene deposits in the IYSZ should be evaluated with great caution and on an individual basis.

\subsubsection{Liuqu Conglomerate}

The $\delta^{18} \mathrm{O}_{\mathrm{pc}}$ values from 43 analyses of 25 separate soil nodules from the Liuqu Conglomerate average $-16.0 \pm 2.4 \%$ (Table S4). This low average value is comparable to the lowest values from 
modern soil carbonates in the region today, although modern values are on average much higher due to soil evaporation in the current arid conditions. Taken at face value, these values therefore suggest paleoelevations comparable to modern elevations, which are in the 4 to $4.5 \mathrm{~km}$ range.

However, the isotopic conglomerate test from section 6LQ suggests that these low $\delta^{\mathrm{s}} \mathrm{O}_{\mathrm{w}}$ values are probably not primary (Leary et al., 2017). The $\delta^{\circledR} \mathrm{O}_{\mathrm{s}}$ values of reworked marine limestone clasts found in four different sections (Table S4) average -13.0 $1.8 \%$. Two clasts of reworked soil carbonate (confirmed by petrography; see Results) returned an average $\delta^{\circledR} \mathrm{O}$ value identical to that of the reworked limestones but yielded much lower $\delta$ Cvalues of -10.6 to $11.6 \%$, consistent with $\delta{ }^{\circledR}$ Vvalues of in situ paleosol nodules in the Liuqu Conglomerate. The similarity among the $\delta^{\circledR} \mathrm{O}$ values of reworked limestone, paleosol nodules, and in situ paleosol nodules is telling evidence that marine limestone clasts and paleosol nodules were probably reset under the same burial conditions.

$\Delta_{47}$ values vary depending on the section sampled, yielding high $\mathrm{T}(47)$ values $\left(221-257^{\circ} \mathrm{C}\right)$ for $4 \mathrm{LQ}$, low $\mathrm{T}(47)$ values $\left(20-33^{\circ} \mathrm{C}\right)$ for $1 \mathrm{LQ}$, and intermediate $\mathrm{T}(47)$ values $\left(59-91^{\circ} \mathrm{C}\right)$ for $6 \mathrm{LQ}$ (Table S6). Ning et al. (2019) sampled in the vicinity of section 6LQ and obtained a similar $\mathrm{T}(47)$ range of $48-97^{\circ} \mathrm{C}$. These temperature patterns are in agreement with petrographic and thermochronologic evidence from these sections. The petrographic evidence presented in the Results and Figure 7 follows the pattern of increasing recrystallization from 1LQ (least), to 6LQ and 7LQ (intermediate), and to 4LQ (most), with the added presence of coarse diagenetic albite in 4LQ. Li et al. (2015) estimated peak burial temperatures near sections 6LQ and 7LQ to have been $<110^{\circ} \mathrm{C}$ based on AFT partial annealing, and they estimated the actual burial temperature to have been $\sim 90 \pm 5^{\circ} \mathrm{C}$ based on apatite age-composition relationships. Un-reset zircon $\mathrm{U}-\mathrm{Th} / \mathrm{He}$ 
dates from this section ( $\mathrm{Li}$ et al., 2015) also constrain the maximum burial temperature to $<\sim 175-193^{\circ} \mathrm{C}$ (e.g., Reiners et al. 2004; Reiners, 2005).

Other lines of evidence from the Liuqu Conglomerate point toward modest paleoelevations during deposition. We have already discussed the low $\delta^{13} \mathrm{C}_{\mathrm{p}}$ values $(-9.4 \pm 1.1 \%$ ) from the Liuqu Conglomerate that indicate well-vegetated conditions that contrast with the much higher and more variable $(+0.2 \pm 3.8 \%$ ) values of modern Tibetan Plateau soils (Fig. 3), a difference probably in part attributable to lower paleoelevations during Liuqu deposition. Paleobotanic and paleosol geochemical evidence reinforces this interpretation: palms and other tropical and subtropical flora point to warm moist conditions and an estimated paleoelevation of $\sim 1 \mathrm{~km}$ (Ding et al., 2017), and well-leached paleosol profiles comparable to paleosols developed in the early Miocene Himalayan foreland basin point to wet and low-elevation conditions (Leary et al., 2017).

$\delta^{18} \mathrm{O}_{p \mathrm{p}}$ and clumped isotopic data present a contradictory picture of paleoelevation for the Liuqu Conglomerate. On the one hand, the similarly low $\delta^{18} \mathrm{O}_{\mathrm{pe}}$ and $\delta^{18} \mathrm{O}_{\mathrm{ss}}$ values seem to reflect resetting, instead of primary surface conditions. The T(47) values are highly variable between high burial temperatures (Table S6: 4LQ: $221-257^{\circ} \mathrm{C}$ ) and plausible surface temperatures (1LQ: $20-33^{\circ} \mathrm{C}$ ). The latter temperatures are typical of soils forming at $0-1.5 \mathrm{~km}$ elevation in the region today (Quade et al., 2013). These temperatures cannot be primary if the bulk $\delta^{8} \mathrm{O}_{\mathrm{pc}}$ values in $1 L Q$ have been reset. If both are primary, the $\delta{ }^{18} \mathrm{O}_{\mathrm{pc}}$ values point to high paleoelevations, whereas the $\Delta_{47}$ values (as well as other paleoelevation proxies, especially lithofacies and paleosol types) 
point to low paleoelevations (Fig. 14).

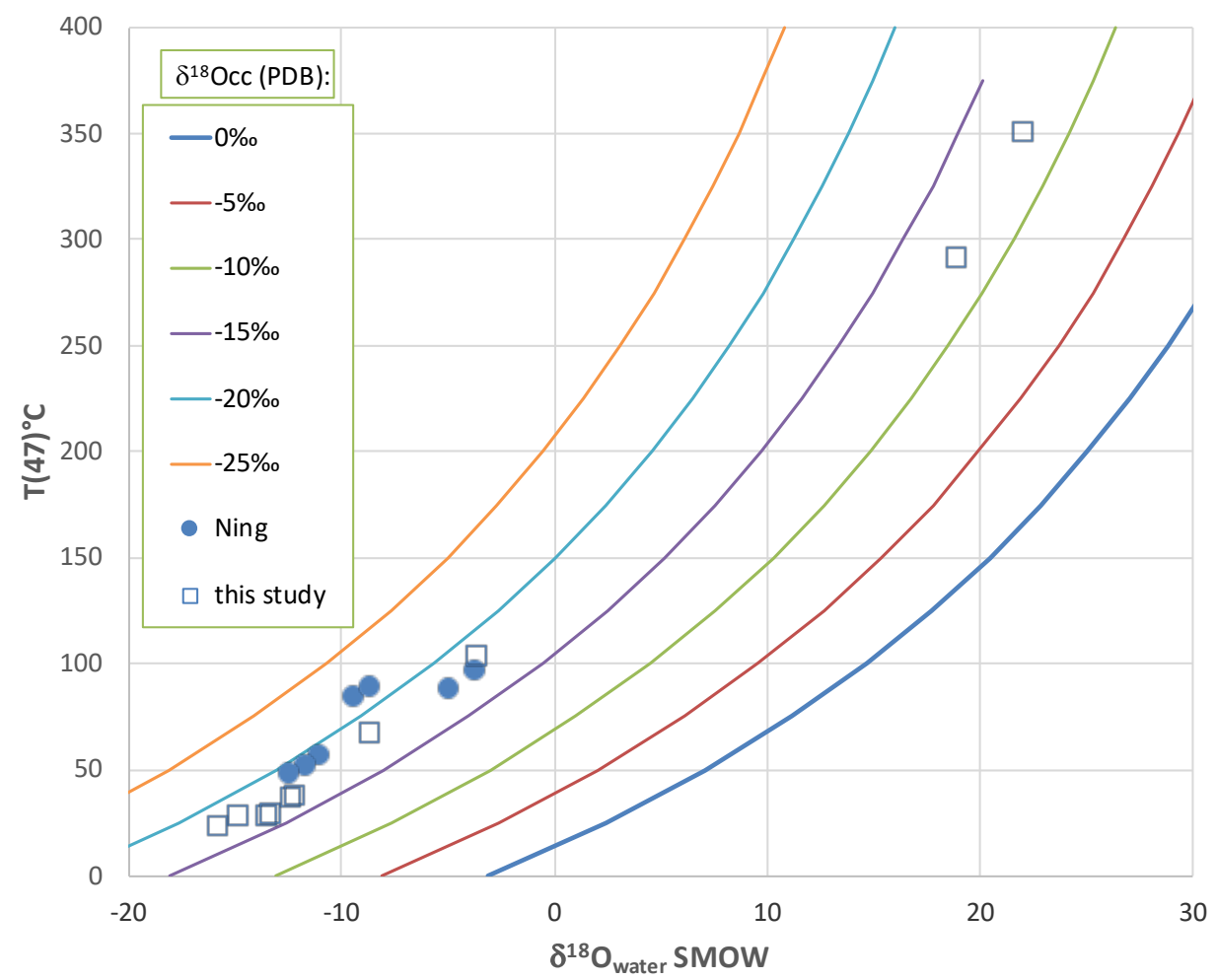

Figure 14. Modeled (lines) versus observed (solid dots (Ning et al., 2019); squares (this paper)) $\delta^{18} \mathrm{O}_{\mathrm{pc}}$ (VPDB) values of pedogenic nodules from the Luiqu Conglomerate as a function of $\delta^{18}$ Owater (SMOW) and clumped isotope temperature $\left(\mathrm{T}(47)^{\circ} \mathrm{C}\right)$, using the $\alpha_{\text {calcite-water from }}$ O’Neil (1969). Assuming isotopic equilibrium in a water-buffered system, the observed $\delta^{18} \mathrm{O}_{\mathrm{pc}}$ (VPDB) values require formation at the very wide range of measured $\mathrm{T}(47)^{\circ} \mathrm{C}$. The lowest observed $\delta^{18} \mathrm{O}_{\mathrm{pc}}$ (VPDB) values between -15 and -20\%o obtained by this study imply formation at high elevation, whereas the associated warm soil $\mathrm{T}(47)$ values of 20 to $33^{\circ} \mathrm{C}$ require low elevations of formation. 
We consider two possible scenarios to explain these apparently contradictory data. The first is that both the $\delta^{18} \mathrm{O}_{\mathrm{pc}}$ and $\Delta_{47}$ values in 1LQ record primary surface conditions. In this scenario, the low $\delta \mathrm{O}_{\mathrm{pc}}$ values can be explained by a local hydrologic cycle dominated by moisture influenced by high-elevation topography to the south in the Himalaya (e.g., Gébelin et al., 2013), even though the IYSZ itself was at low elevations. The most obvious challenge in this scenario is that it requires a range crest high enough to isotopically deplete the ${ }^{18} \mathrm{O}$ content of moisture passing over/through it but low enough to produce moist conditions during Liuqu and Kailas deposition. Moreover, to our knowledge, the influence of high-elevation moisture on rainfall falling on the lee side of orogens is not clear in modern settings (e.g., Aravena et al., 1999) due in part to mixing with moisture from other lee-side sources, although the evidence is limited.

A second possible scenario is that both $\delta^{18} \mathrm{O}_{\mathrm{p}}$ and $\Delta_{47}$ values in 1LQ have been reset at burial temperatures in the presence of high-elevation $\left(\mathrm{low}-\delta^{18} \mathrm{O}\right)$ meteoric water. No thermochronologic data have been generated from 1LQ, but AFT and AHe data from 6LQ and 7LQ 40 km west along strike suggest cooling from $>80^{\circ} \mathrm{C}$ after $10-12 \mathrm{Ma}$ (Li et al., 2015). Heat flow values of 88 $242 \mathrm{~mW} \mathrm{~m}^{-2} \sim 150 \mathrm{~km}$ to the east of 1LQ (Francheteau et al., 1984), rapid cooling at $10 \mathrm{Ma}$ and estimated paleogeothermal gradients as high as $400^{\circ} \mathrm{C} / \mathrm{km} \sim 200 \mathrm{~km}$ west of 1LQ (Mahéo et al., 2007), and abundant hot springs along the India-Asia suture zone (Ji-Yang et al., 1981) all suggest the possibility of high temperatures and/or high-temperature fluid interactions at modest burial depths. The challenge in this scenario comes in explaining the low $\mathrm{T}(47)$ and $\delta \mathrm{O}_{\mathrm{pc}}$ values from section 1LQ. Primary $\delta^{8} \mathrm{O}_{\mathrm{p}}$ values are typically retained up to temperatures of $>150^{\circ} \mathrm{C}$ (Mora et al., 1998; Leier et al., 2009; Quade et al., 2013), well above the T(47) recorded by samples in 1LQ. In this scenario $\delta^{18} \mathrm{O}_{\mathrm{pc}}$ values would have been first reset by burial, then $\Delta_{47}$ values would have been recorded during later exhumation, a scenario suggested by Ingalls et al. (2019) 
for the Xigaze forearc sequence. Alternatively, both systems could have been simultaneously reset by partial recrystallization due to fluid flow at relatively shallow depths and at the calculated T(47). This scenario would be alarming for $\delta^{18} \mathrm{O}_{\mathrm{pc}}$ carbonate studies in that it would indicate that isotopic resetting is possible at very low temperatures and that even plausible surface $\mathrm{T}(47)$ do not necessarily ensure primary $\delta^{18} \mathrm{O}_{\mathrm{pc}}$ values.

\subsubsection{Kailas Formation}

The mean and ranges of $\delta^{18} \mathrm{O}$ values from Kailas Formation carbonates in paleosols $\left(\delta^{{ }^{18}} \mathrm{O}_{\text {рсахg }}=\right.$ $-18.4 \%$, ranging from -22.4 to $-12.8 \%$ ) and sandstone cements $\left(\delta^{18} \mathrm{O}_{\text {cennen ayg }}=-18 \%\right.$, ranging from 22 to $-12.6 \%$ ) are almost identical (Table S5; Fig. 6). The similarity and homogeneity of the results are observed in most sections. For example, the 2 YA section from the Mt. Kailas region

yielded the highest $\delta^{\circledR} \mathrm{O}_{\ltimes}$ and $\delta^{\circledR} \mathrm{O}_{\text {comen }}$ values of the entire Kailas data set, averaging $-13.7 \pm 0.25$ and $-13.0 \pm 0.7 \%$, respectively. By contrast, the same values from the Gyedo section are $-20.4 \pm 0.8$ and $-19.5 \pm 1.8 \%$, respectively. At face value, these values point to generally very high paleoelevations on the order of $>4 \mathrm{~km}$. Interestingly, the highest $\delta^{18} \mathrm{O}_{\mathrm{pc}}$ values, returned by the 2YA section, coincide with the lowest $\delta^{13} \mathrm{C}$ values, a relationship we might predict for samples coming from lower, more vegetated elevations.

We can attempt some evaluation of the validity of these results by looking at the $\delta^{18} \mathrm{O}_{1 \mathrm{~s}}$ values from reworked marine limestone clasts. The $\delta^{18} \mathrm{O}_{1 \mathrm{~s}}(\mathrm{VPDB})$ values display a wide range from approximately $-21 \%$ at Dazhuka to as high as $-7 \%$ in reworked limestone clasts at Gyedo (Fig. 6; Table S5). In general, most samples are reset to very low average values of $<-10 \%$, similar to 
nearly all other $\delta^{18} \mathrm{O}_{\mathrm{is}}$ values from the IYSZ. This evidence does not prove that the $\delta^{18} \mathrm{O}_{\mathrm{pe}}$ and $\delta^{18} \mathrm{O}_{\text {cenem }}$ values are also reset since the limestones could have been altered prior to the Oligocene, but it still raises a potential red flag. At this point, we treat the $\delta^{18} \mathrm{O}_{\mathrm{pc}}$ and $\delta^{18} \mathrm{O}_{\text {cennnt }}$ results from the Kailas Formation with caution and feel that more evidence from petrography and other proxies, such as $\delta \mathrm{D}_{\text {akanes }}$ values, is needed to clarify the meaning of this record.

Caution regarding the low $\delta^{i s} \mathrm{O}_{p}$ values from the Kailas Formation is strongly warranted based on other lines of evidence and is at odds with coexisting low $\delta^{13} C_{p c}$ values. Carrapa et al. (2014) presented thermochronologic evidence from a range of Kailas Formation localities that point to burial heating in the $120-230^{\circ} \mathrm{C}$ range following deposition of the Kailas Formation from $21-26$ Ma. This heating event was followed by rapid exhumation at $\sim 17.1 \mathrm{Ma}$, the apparent result of downcutting by the ancestral Yarlung-Tsangpo River, possibly in response to rejuvenated regional uplift after break-off of the subducting Indian slab. Both modeling (Passey and Henkes, 2012) and empirical observations (Leier et al., 2009; Quade et al., 2013) suggest that temperatures at the high end of this range $\left(>200^{\circ} \mathrm{C}\right)$ could have reset the $\delta^{18} \mathrm{O}$ and $\Delta_{47}$ values of the carbonates in the Kailas Formation. Ding et al. (2017) reconstructed modest paleoelevations of $2.3 \pm 0.9 \mathrm{~km}$ based on paleofloristic evidence from several localities in the Kailas Formation. Using organic biomarker $\left(\mathrm{TEX}_{86}\right.$ and $\left.\mathrm{MBT} / \mathrm{CBT}\right)$ geothermometry evidence from Kailas lake sediments, DeCelles et al. (2018) reconstructed warm summer-season lake temperatures, consistent with low $(<1 \mathrm{~km})$ paleoelevations. Both papers pointed out the presence of significant coal in the Kailas Formation as inconsistent with high paleoelevations.

\subsubsection{Other basins outside this study}




\section{Oiyug Basin}

The Oiyug Basin lies north of the IYSZ (Fig. 1), and the deposits in this basin overlie and are interbedded with volcanic rocks of the Gangdese magmatic arc, much like the setting in the Linzhou Basin. Spicer et al. (2003), Currie et al. (2005) and Currie et al. (2016) carried out detailed paleoelevation reconstructions for this highstanding basin and concluded that it has been at elevations similar or possibly slightly higher than today $(\sim 4300 \mathrm{~m})$ since the latest Oligocene. These studies are noteworthy for their multiproxy approach; as such, in our view, they obtain some of the most robust paleoelevation reconstructions performed in Tibet to date, especially for the Mio-Pliocene portion of the record.

These studies utilize $\delta{ }^{\circledR} \mathrm{Ovalues}$ from paleosol, lacustrine, and ground-water carbonate; $\delta \mathrm{D}$ values from n-alkanes of presumed plant wax origin; and leaf physiognomy to reconstruct paleoelevation. Here, the low $\delta^{18} \mathrm{Ovalues}$ from carbonates (mostly between -10 and $-20 \%$ ) might be questioned as primary because the samples were collected from within and above ash fall and ash-flow tuffs. However, the very low $\delta \mathrm{D}$ values from n-alkanes in the -254 to $-280 \%$ range yield estimates of paleowater isotopic composition similar to those of the carbonates. Thus, high paleoelevations of $>4500 \mathrm{~m}$ are suggested by both proxies. This finding is significant because diagenesis is not expected to alter such dissimilar isotopic proxies $-\delta^{18} \mathrm{O}$ in calcite versus $\delta \mathrm{D}$ in plant wax n-alkanes - in the same way. This powerful inter-comparison is unfortunately restricted to the last $\sim 15-18 \mathrm{Ma}$; n-alkanes are not preserved in the older part of the record in the Oiyug (Currie et al., 2016). We can conclude that the Gangdese arc was standing at near-modern elevations at the same time that or slightly earlier than our carbon isotope evidence (and other lines of evidence) suggests that the adjacent IYSZ was at low to intermediate elevations. 


\subsection{Lunpola, Nima and other basins}

Several important oxygen isotopic records lying outside the IYSZ are worth including briefly in this review given their importance to paleoaltimetry in central Tibet and their potentially differing diagenetic histories from the IYSZ. The Lunpola Basin (Rowley and Currie, 2006; Polissar et al., 2009) and Nima (DeCelles et al., 2007) areas lie in the Bangong suture zone, where the Lhasa terrane sutured onto the Qiangtang terrane to the north during the early Cretaceous (Kapp et al., 2007). In the northern Qiangtang terrane, Xu et al. (2013) reconstructed

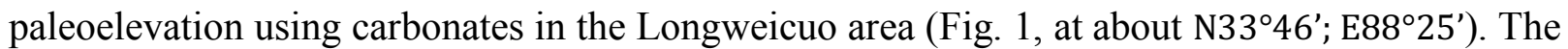
age of these deposits is a work-in-progress but constrained to be younger than $51 \mathrm{Ma}$ and older than $28 \mathrm{Ma}$ (Xu et al., 2013).

Paleosol carbonates from all three of these locations have generally yielded low $(<-10 \%)$ $\delta^{\mathrm{s}} \mathrm{O}_{\mathrm{w}}$ values consistent with the lowest values of modern soil carbonates in these areas, suggesting that the Bangong suture zone and Qiangtang terrane have been elevated since the late Eocene (?) and certainly by the late Oligocene. $\delta^{\mathrm{n}} \mathrm{O}_{\mathrm{s}}$ values from these areas are sparse (DeCelles et al., 2007; Xu et al., 2013) but show little (and in a few samples, no) offset from expected marine values, consistent with other marine limestones in south-central Tibet. As elsewhere outside the IYSZ, earlier resetting at modest temperatures and in the presence of meteoric fluids from low elevation is implied by local $\delta^{\natural} \mathrm{O}_{\mathrm{w}}$ values. If this is a valid guide, then the low $\delta^{\mathrm{s}} \mathrm{O}_{\mathrm{pc}}$ values encountered in these areas are not produced by diagenesis. The low $\delta^{\mathrm{s}} \mathrm{O}_{\mathrm{w}}$ values (and high implied paleoelevations of $>4000 \mathrm{~m}$ ) from Lunpola Basin carbonates have the added strength that they appear to be verified by low $\delta \mathrm{D}_{\text {matume }}$ values (Polissar et al., 2009) from contemporaneous leaf waxes, although the very high elevation interpretation of the Lunpola leaf wax record has 
been challenged by Jia et al. (2015). The putative presence along the Bangong suture of estuarine forams of late Eocene age, along with their low $\delta^{18} \mathrm{O}$ values, challenge the idea that the Bangong suture was elevated prior to the late Oligocene (Wei et al., 2016).

An important development is a series of recent papers relying mostly on biological evidence that have challenged the high-elevation implications of the very low $\delta^{18} \mathrm{O}$ values in nearly all the places where the two archives can be locally compared. Such locations include the Liuqu and Kailas Formations (Ding et al., 2017) and the Lunpola and Nima basins (Sun et al., 2014; Su et al., 2019; Deng et al., 2019). The one major study where paleobotanic and isotopic evidence both seem to agree on high paleoelevations is from the Namling area (Spicer et al., 2003).

Finally, clumped isotope records from central Tibet have only been published for late Oligocene deposits at Nima. T(47) estimates from paleosol carbonates are $>40^{\circ} \mathrm{C}$ (Huntington et al., 2015), too high to be primary soil temperatures. Burial depths in the Nima section are a modest 2-3 km, and the low $\delta^{18} \mathrm{O}_{\mathrm{pc}}$ values appear to be primary and unreset (DeCelles et al., 2007).

\subsection{Summary observations and future directions}

In this paper we stress the important role of $\delta^{13} \mathrm{C}_{\mathrm{k}}$ and $\delta^{18} \mathrm{O}_{\mathrm{k}}$ values from marine limestones in assessing local and regional patterns of diagenesis, in order to place some constraints on the likelihood of alteration of non-marine carbonates in overlying stratigraphic sequences. Most $\delta^{13} C_{\mathrm{s}}$ values are unaltered, allowing us to use the $\delta^{13} \mathrm{C}$ value of paleosol carbonates to trace the gradual aridification and devegetation the IYSZ sometime after $20 \mathrm{Ma}$, probably in response (at least in part) to uplift. The IYSZ was subhumid and well vegetated until $20 \mathrm{Ma}$, with conditions more 
favorable to vegetation in the west and decreasing eastward. At the same time, areas to the north as far as the central Qiangtang terrane were less vegetated and semiarid. This range of conditions from semiarid to subhumid starkly contrasts with the arid, thinly vegetated landscape of the plateau today.

By contrast, $\delta^{\mathrm{r}} \mathrm{O}_{\mathrm{k}}$ values across the Himalaya and southern Tibet show pervasive alteration, more severely in the tectonically and hydrothermally active area of the IYSZ. It is true that there are several pathways, both primary and diagenetic, that can produce the low $\delta^{\circledR} \mathrm{O}$ values observed in many of these pre-Miocene carbonates. In the non-marine limestones it is difficult to prove that alteration of terrestrial carbonate has actually occurred based on isotopic evidence alone, and we have not provided such proof in this paper. Our arguments are more circumstantial and based on isotopic evidence combined with estimates of probable burial temperatures, petrographic evidence, and alteration patterns in older or equivalent-age marine carbonates.

The higher $\delta^{\mathrm{s}} \mathrm{O}_{\mathrm{s}}$ values obtained outside the IYSZ point to alteration that begins and ends at low elevations during pedogenesis. This suggests that the $\delta^{ } \mathrm{O}$ valuesof younger pedogenic carbonates from these areas should be generally unaltered and useful for paleoelevation reconstruction. This includes the high paleoelevation reconstructions for the post-Oligocene in the northern Lhasa terrane at Lunpola and Nima and southern Qiantang terrane at Longweicuo. Inside the IYSZ /magmatic arc, the pattern of resetting is more complex. $\delta^{\text {s }} \mathrm{O}_{\text {cutomans }}$ values from late Neogene deposits such as the Zhada Basin just south of the IYSZ show that areas of the southernmost plateau were as high if not higher than today at the time, as supported by Gebelin et al. (2013) further east in the Mt. Everest region. Within the magmatic arc, evidence for high $(>4 \mathrm{~km})$ paleoelevations from Linzhou (Eocene) should be treated with caution until other locations that have experienced less burial and lower temperatures can be tested. Multi-method 
reconstructions from younger, post-Oligocene locations at Oiyug and Namling are more convincing and show high $(>4 \mathrm{~km})$ paleoelevations. At the same time, oxygen isotopic results from the nearby IYSZ in the Luiqu Conglomerate and probably the Kailas Formation appear to be reset; other proxies from these formations point to moderate paleoelevations during the early Miocene in the IYSZ.

As to the future, subsampling distinct petrographic textures in carbonates can assist in these reconstructions, although in many cases the textural variation is on too fine a scale to subsample effectively. A fruitful alternative would be $\delta^{\mathrm{B}} \mathrm{O}$ analysis of different carbonate textures at a millimeter level using secondary ionization mass spectrometry (SIMS). An equivalent means of fine-scale analysis for clumped isotopes is not yet available. Coupled $\delta^{\prime \prime s} \mathrm{O}-\Delta^{\prime 17} \mathrm{O}$ analysis of carbonates is another promising direction of research for distinguishing primary versus hydrothermally altered samples (Sharp, 2018). Paleoelevation reconstructions relying on the elemental (e.g., Leary et al., 2017) and isotopic compositions of silicates (e.g., Gébelin et al., $2013,2017)$ are an excellent alternative or complement to the use of carbonates in areas where the relevant materials can be found. The use of the $\delta \mathrm{D}$ values of plant biomarkers in paleoaltimetry is also an ongoing opportunity, since the circumstances of their alteration are so different from those of carbonates and are often testable (e.g., Polissar et al., 2009; Currie et al., 2016). Until these diagenetic concerns are more effectively addressed, we view with caution paleoelevation reconstructions based purely on analysis of older carbonates in geologically active parts of orogens such as southern Tibet.

Acknowledgments Support for this work came mainly from the NSF Continental Dynamics grant 0907885 to Paul Kapp and others. We thank Brian Currie and David Rowley for their discussion of Tibet paleoaltimetry over the years. We are greatly indebted to Dr. Ding Lin for his logistical support of the project and many scientific interactions with the Arizona tectonics 
group. Dr. Peter Scholle provided very helpful observations on the carbonate petrography of some of our samples.

\section{References}

Allan, J.R., Matthews, R.K., 1982. Isotope signatures associated with early meteoric diagenesis. Sedimentology 29, 797-817.

An, W., BouDagher-Fadel, M., Garzanti, E., Wang, J., Sun, G., 2014. Xigaze forearc basin revisited (South Tibet): Provenance changes and origin of the Xigaze Ophiolite. Geol. Soc. Am. Bull. 126 (11-12), 1595-1613.

Aravena, R., Suzuki, O., Pena, H., Pollastri, A., Fuenzalida, H., and Grilli, A., 1999. Isotopic composition and origin of precipitation in northern Chile. Applied Geochem. 14, 411-422.

Brand W. A., Assonov S. S., Coplen T. B., 2010. Correction for the ${ }^{10} \mathrm{O}$ interference in $\delta^{13} \mathrm{C}$ measurements when analyzing $\mathrm{CO}_{2}$ with stable isotope mass spectrometry (IUPAC Technical Report). Pure Appl. Chem. 82, 1719-1733.

Breecker, D, Sharp, Z., McFadden, L., 2010. Atmospheric $\mathrm{CO}_{2}$ concentrations during ancient greenhouse climates were similar to those predicted for A.D. 2100. Proc. Nat. Academy Sci. 107 (2) Proc. Natl. Academy Sci. 0902323106

Carrapa, B., Orme, D.A., DeCelles, P.G., Kapp, P., Cosca, M.A., Waldrip, R., 2014. Miocene burial and exhumation of the India-Asia collision zone in southern Tibet: response to slab dynamics and erosion. Geology 42 (5), 443-446.

Cerling, TE., 1984. The stable isotopic composition of modern soil carbonate and its relation to climate. Ear. Planet. Sci. Lett. 71: 229-240.

Cerling, T. E. and Quade, J., 1993. Stable carbon and oxygen isotopes in soil carbonates, in (P. Swart, J. A. McKenzie, K. C. Lohman Eds.), Continental Indicators of Climate, Proceedings of Chapman Conference, Jackson Hole, Wyoming, American Geophysical Union Monograph 78, 217-231.

Chadwick, O. A., J. M. Sowers, and R. G. Amundson. 1989. Morphology of calcite crystals in clast coatings from soils in the Mojave Desert region. Soil Sci. Soc. Am. J. 53:211-219. doi:10.2136/sssaj1989.03615995005300010038x.

Clayton, R. N., Degens, E.T., 1959. Use of carbon isotope analyses of carbonates for differentiating fresh water and marine sediments. Am. Assoc. Petroleum Geologists Bull. 43, 890-897.

Craig, H., 1961. Isotopic variation in meteoric waters. Science 133, 1702-1703.

Currie, B.B., 2005. Mid-Miocene paleoaltimetry of southern Tibet; implications for the role of mantle thickening and delamination in the Himalayan region. Geology 33 (3), 181-184.

Currie, B.S., Polissar, P.J., Rowley, D.B., Ingalls, M., Li, S., Olack, G., and Freeman, K.H., 2016. Multi-proxy paleoaltimetry of the late Oligocene-Pliocene Oiyug Basin, southern Tibet. Am. J. Sci. 316, 401-436.

Davis, A.M., Aitchison, J.C., Badengzhu, Luo, H., Zyabrev, S., 2002. Paleogene island arc collision-related conglomerates, Yarlung-Tsangpo suture zone, Tibet. Sed. Geol. 150, 247273. 
Davis, A.M., Aitchison, J.C., Badengzhu, Luo, H., 2004. Conglomerates record the tectonic evolution of the Yarlung-Tsangpo suture zone in southern Tibet. In: Malpas, J., Fletcher, C.J.N., Ali, J.R., Aitchison, J.C. (Eds.), Aspects of the Tectonic Evolution of China. Geological Society of London, London, Special Publication 226, pp. 235-246.

DeCelles, P. G., Quade, J., Kapp, P., Fan, M., Dettman, D. L., Ding, L., 2007. High and dry in central Tibet during the late Oligocene. Ear. Planet. Sci. Lett. 253, 389-401.

DeCelles, P. G., Kapp, P., Quade, J., Gehrels, G. E., 2011. The Oligocene-Miocene Kailas Basin, southwestern Tibet: record of post-collisional upper plate extension in the Indus-Yarlung suture zone. Geol. Soc. Am. Bull. 123 (7-8), 1337-1362. doi:10.1130/B3-258.1, 26 pages.

DeCelles, P.G., Leary, R., Kapp, P., 2018a. Cenozoic basin evolution in the Indus-Yarlung suture zone and High Himalaya. Geol. Soc Am. Spec. Pap. 540, 707-739.

DeCelles, P.G., Casteneda, I.S., Carrapa, B., Liu, J., Quade, J., Leary, R., Zhang, L., 2018b. OligoMiocene great lakes in the India-Asia collision zone. Basin Res. 30 (Suppl. 1), 228-247.

Degens, E.T., Epstein, S., 1962. Relations hsip between ${ }^{18} \mathrm{O} /{ }^{16} \mathrm{O}$ ratios in coexisting carbonates, cherts, and diatomites. Am. Assoc. Petrol. Geol. Bull. 46, 534-542.

Defliese W. F., Hren M. T., Lohmann K. C., 2015. Compositional and temperature effects of phosphoric acid fractionation on $\Delta_{47}$ analysis and implications for discrepant calibrations. Chem. Geol. 396, 51-60.

Deng, T., Ding, L., 2015. Paleoaltimetry reconstructions of the Tibetan Plateau: progress and contradictions. Natl. Sci. Rev. 2, 417-437.

Deng, T., Wang, X., Wu, F., Wang, Y., Li, Q., Wang, S., Hou, S., 2019. Review: implications of vertebrate fossils for paleo-elevations of the Tibetan Plateau. Glob. Planet, Change 174, 58-69.

Dennis K. J., Affek H. P., Passey B. H., Schrag D. P. and Eiler J. M. (2011) Defining an absolute reference frame for "clumped" isotope studies of $\mathrm{CO}_{2}$. Geochim. Cosmochim. Acta 75, 71177131.

Ding, L., Kapp, P., Wan, X., 2005. Paleocene-Eocene record of ophiolite obduction and initial Indias-Asia collision, south-central Tibet. Tectonics 24, TC3001.

Ding, L., Xu, Q., Yue, Y., Wang, H., Cai, F., Li, S., 2014. The Andean-type Gangdese Mountains: Paleoelevation record from the Paleocene-Eocene Linzhou Basin. Ear. Planet. Sci. Lett. 392, 25-264.

Ding, L.,14 others, 2017. Quantifying the rise of the Himalayan orogen and implications for the South Asian monsoon. Geology 45 (3), 215-318.

Dupont-Nivet, G., Lippert, P. C., van Hinsbergen, D. J. J., Meijers, M. J. M. and Kapp, P. (2010), Palaeolatitude and age of the Indo-Asia collision: Palaeomagnetic constraints, Geophys. J. Int., 182 (3), 1189- 1198.

Ekart, D.D., Cerling, T., Montañez, I.P., Tabor, N.J., 1999. A 400-million year record of pedogenic carbonate: implications for paleoatmospheric carbon dioxide. Am. J. Sci 299, 805-827.

Einsele, G., Liu, B., Dürr, S., Frisch, W., Liu, G., Luterbacher, H.P., Ratschbacher, L., Ricken, W., Wendt, J., Wetzel, A, Yu, G., Zheng, H., 1994. The Xigaze forearc basin; evolution and facies architecture (Cretaceous, Tibet). Sed. Geol. 90, 1-32.

Francheteau, J., Jaupart, C., Jie, S. X., Wen-Hua, K., De-Lu, L., Jia-Chi, B., Hung-Pin, W., HsiaYeu, D., 1984. High heat flow in southern Tibet: Nature, 307, 32-36.

Garzione, C. N., Quade, J., DeCelles, P. G., English, N. B., 2000. Predicting paleoelevation of Tibet and the Himalaya from $\delta^{18} \mathrm{O}$ versus altitude gradients in meteoric water across the Nepal Himalaya. Earth Planet. Sci. Lett. 183, 215-229. 
Gansser, A., 1964. The Geology of the Himalayas. Wiley, New York.

Gébelin, A., Mulch, A., Teyssier, C., Jessup, M.J., Law, R.D., Brunel, M., 2013. The Miocene elevation of Mount Everest. Geology 41 (7), 799-802.

Gébelin, A., Jessup, M.J., Teyssier, C., Cosca, M.A., Law, R.D., Brunel, M., Mulch, A., 2017. Infiltration of meteoric water in the South Tibetan detachment (Mount Everest, Himalaya): When and Why? Tectonics 36, 690-713, doi:101002/2016TC004399.

Ghosh, P.G., Prasanna, K., Banerjee, Y., Williams, IS., Gagan, M.K., Chauduri, A., Suwas, S., 2018. Rainfall seasonality on the Indian sub-continent during the Cretaceous greenhouse. Sci. Rep. DOI 10:1038/s41598-018-26272-0.

He, S., Kapp, P., DeCelles, P.G., Gehrels, G.E., Heizler, M., 2007. Cretaceous-Tertiary geology of the Gangdese Arc in the Linzhou area, southern Tibet. Tectonophysics 433 (1-2), 15-37.

He, B., Olack G. A., Colman A. S., 2012. Pressure baseline correction and high-precision $\mathrm{CO}_{2}$ clumped-isotope $\left(\Delta_{47}\right)$ measurements in bellows and micro-volume modes. Rapid Commun. Mass. Spectrom. 26, 2837-2853.

Hodges, K., 2000. Tectonics of the Himalaya and southern Tibet from two perspectives. Geol. Soc. Am. Bull. 112 (3), 324-350.

Hori M., Takashima C., Matsuoka J., Kano A., 2009. Carbon and oxygen stable isotopic measurements of carbonate and water samples using mass spectrometer with gas bench. Bulletin of the Graduate School of Social and Cultural Studies, Kyushu University 15, 51-57.

Huang, W., Dupont-Nivet, G, Lippert, P.C.,van Hinsbergen, D.J.J., Dekkers, M.J., Waldrip, R., Ganerød, M., Li, X., Guo, Z., Kapp, P., 2015. What was the Paleogene latitude of the Lhasa terrane? A reassessment of the geochronology and paleomagnetism of Linzizong volcanic rocks (Linzhou basin, Tibet). Tectonics, 34 (3), 594-622.

Huang, W., Quade, J., Lippert, P.C., Reiners, P.W., Kano, A., Kato, H., Guo, Z., Kapp, P., van Hinsbergen, D.J.J., Dupont-Nivet, G., Reassessing High Paleoelevation of the southern Tibetan Plateau in the early Paleogene. Nature, in review.

Hudson, J.D., 1977. Stable isotopes and limestone lithification. J. Geol. Soc. 133, 637-660.

Huntington, K.W., Saylor, J., Quade, J., Hudson, A., 2015. High late Miocene-Pliocene elevation of the Zhada Basin, southwestern Tibetan Plateau, from carbonate clumped isotope thermometry. Geol. Soc. Am. Bull. 127 (i-1), 181-199. doi:10.1130/B31000.1.

Hu, X., Wang, J., BouDagher-Fadel, M., Garzanti, E., An, W., 2016. New insights into the timing of the India-Asia collision from the Paleogene Quxia and Jialazi formations of the Xigaze forearc basin, South Tibet. Gondwana Res. 32, 76-92.

Ingalls, M., 2019. Reconstructing carbonate alteration histories in orogenic sedimentary basins: Xigaze forearc, southern Tibet. Geochim. Cosmochim. Acta 251, 284-300.

Ingalls, M., Rowley, D., Olack, G., Currie, B., Li, S., Schmidt, J., Trembly, M., Polissar, P., Shuster, D.L., Ding, L., Colman, A., 2018. Paleocene to Pliocene low-latitude, high elevation basins of southern Tibet: implications for tectonic models of India-Asia collision, Cenozoic climate, and geochemical weathering. Geol. Soc. Am. Bull. 130 (1/2), 307-330. https://doi.org/10.1130/B31723.

Ji-Yang, W., Mo-Xiang, C., Ji-An, W., Xiao, D., Jun, W., Hsien-Chieh, S., Liang-Ping, H., ShuZhen, Y., Zhi-Cheng, F., Xiu-Wen, L., 1981. Geothermal studies in China: J. Volcanol. Geoth. Res., 9, 57-76.

Jia, G., Bai, Y., Ma, Y., Sun, J., Peng, P., 2015. Paleoelevation of Tibetan Lunpola basin in the Oligo-Miocene transition estimated from leaf wax lipid dual isotopes. Glob. Planet. Change $126,14-22$. 
Kapp, P. and DeCelles, P.G., 2019. Mesozoic-Cenozoic geological evolution of the HimalayanTibetan orogen and working tectonic hypotheses. Am. J. Sci. 319, 159-254.

Kapp, P., DeCelles, P.G., Leier, A.L., Fabijanic, J.M., He, S., Pullen, A., Gehrels, G.E., 2007. The Gangdese retroarc thrust belt revealed. Geol. Soc. Am. Today 17 (7), 4-9.

Kato, H., Amekawa, S., Kano, A., Mori, T., Kuwahar, Y., Quade, J., 2019. Seasonal temperaturechanges obtained from carbonate clumped isotopes of annually laminated tufas from Japan: Discrepancy between natural and synthetic calcites. Geochim. Cosmochim. Acta 244, 548-564.

Keith, M.L., Weber, J.N., 1964. Carbon and oxygen isotopic composition of selected limestones and fossils. Geochim. Cosmochim. Acta 28, 1787-1816.

Kim, S., O’Neil, J.R., 1997. Equilibrium and nonequilibrium oxygen isotope effects in synthetic carbonates. Geochim. Cosmochim. Acta 61 (16), 3461-3475.

Killingley, J.S., 1983. Effects of diagenetic recrystallization on ${ }^{18} \mathrm{O} /{ }^{16} \mathrm{O}$ values od deep-sea sediments. Nature 301, 594-597.

Kobashi, T., Grossman, E. L., Yancey, T. E., Dockery, D. T., 2001. Reevaluation of conflicting Eocene tropical temperature estimates: Molluskan oxygen isotope evidence for warm low latitudes. Geology 29 (11), 983-986.

Kothari, U.C., Singh, V.P., 1996. Rainfall and temperature trends in India. Hydrol. Processes 10, 357-372.

Kumar, V., Jain, S.K., Singh, Y, 2010. Analysis of long-term rainfall trends in India. Hydrol. Sci. J. 55 (4), 484-496.

Land, L.S., 1970. Phreatic versus vadose meteoric diagenesis of limestones: evidence from as fossil water-table. Sedimentology 14, 175-185.

Laskowski, A.K., Kapp, P., Cai, F., 2018. Gandese culmination model: Oligo-Miocene duplexing along the India-Asia suture zone, Lazi region, southern Tibet. Geol. Soc. Am. Bull. 130 (7/8), 1355-1376.

Leary, R.J., DeCelles, P.G., Quade, J., Gehrels, G.E., Waanders, G., 2016. The Liuqu Conglomerate, southern Tibet: early Miocene basin development related to deformation within the Great Counter Thrust system. Lithosphere 8, 427-450.

Leary, R., Quade, J., DeCelles, P., 2017. Evidence from paleosols for low to moderate elevation of the India-Asia suture zone during mid-Cenozoic time. Geology 45 (5), 399-402.

Leier, A., Quade, J., DeCelles, P., Kapp, P., 2009. Stable isotopic results from paleosol carbonate in South Asia: paleoenvironmental reconstructions and selective alteration. Ear. Planet. Sci. Lett., 279(3-4), pp.242-254.

Lippert, P. C., van Hinsbergen, D.J.J. and Dupont-Nivet, G. 2014. The Early Cretaceous to Present latitude of the central Lhasa-plano (Tibet): A paleomagnetic synthesis with implications for Cenozoic tectonics, paleogeography and climate of Asia, in Towards an Improved Understanding of Uplift Mechanisms and the Elevation History of the Tibetan Plateau, Geol. Soc. Am. Spec. Pap., vol. 507, edited by J. S. Nie, G. D. Hoke, and B. K. Horton, pp. 1-21, Geol. Soc. of Am., Boulder, Colo.

Li, X., Jenkyns, H.C., Wang, C., Hu, X., Chen, X., Wei, Y., Huang, Y. and Cui, J., 2006. Upper Cretaceous carbon-and oxygen-isotope stratigraphy of hemipelagic carbonate facies from southern Tibet, China. J. Geol. Society, 163(2), pp.375-382.

Li, G., Kohn, B., Sandford, M., Xu, Z., Wei, L., 2015. Constraining the age of the Liuqu Conglomerate, southern Tibet: implications for evolution of the India-Asia collision zone. Ear. Planet. Sc. Lett. 426, 259-266. 
Lohmann, K.C., 1988. Geochemical patterns of meteoric diagenetic systems and their application to studies of paleokarst. In: N.P. James, N. P. and Choquette, P.W. (Eds.) Paleokarst. Berlin: Springer Verlag, pp. 58-80.

Mahéo, G., Leloup, P.H., Vsalli, F., Lacassin, R., Arnaud, N., Paquette, J.-L., Fernandez, A., Haibing, L., Farley, K.A., Tapponnier, P., 2007. Post-4 Ma initiation of normal faulting in southern Tibet. Constraints fom the Kung Co half graben. Ear. Planet. Sci. Lett. 256, 233 243.

Marshall, J.D., 1992. Climatic and oceanographic isotopic signals from the carbonate rock record and their preservation. Geol. Mag. 129, 143-160.

Mora, C. I., Sheldon, B. T., Elliott, W. C., Driese, S. G., 1998. An oxygen isotope study of illite and calcite in three Appalachian Paleozoic vertic paleosols. Jour. Sed. Res., 68, 456-464.

Najman, Y. and eleven others, 2010. Timing of India-Asia collision: geological, biostratigraphic, and paleomagnetic constraints. J. Geophys. Res. 115, B12416, doi:10.1029/2010JB007673.

Ning, Z., Zhang, L., Huntington, K.W., Wang, C., Dai, J., Han, Z., Passey, B.H., Qian, X, J. Zhang, 2019. The burial and exhumation of the Liuqu Conglomerate in the Yarlung Zangpo suture zone, southern Tibet: insights from clumped isotope thermometry. J. Asian Ear. Sci. $174,205-217$

Orme, D. A., 2017. Burial and exhumation history of the Xigaze forearc basin, Yarlung suture zone, Tibet. Geosci. Front. 10, 895-908.

Orme, D.A. and Laskowski, A.K., 2016. Basin analysis of the Albian-Santonian Xigaze forearc, Lazi region, south-central Tibet. J. Sedimentol. Res. 86(8), 894-913.

Orme, D.A., Carrapa, B., Kapp, P., 2015. Sedimentology, provenance and geochronology of the upper Cretaceous-lower Eocene western Xigase forearc basin, southern Tibet. Basin Res. 27, 387-411.

Pagani, M, Zachos, J.C., Freeman, K.H., Tipple, B., Bohaty, S., 2005. Decline in atmospheric carbon dioxide concentrations during the Paleogene. Science 309, 600-603.

Passey, B.H., Henkes, G.A., 2012. Carbonate clumped isotope bond reordering and geospeedometry. Ear. Plan. Sci. Lett. 351-352, 223-236.

Polissar, P.J., Freeman, K.H., Rowley, D.B., McInerney, F.A., Currie, B.S., 2009. Paleoaltimetry of the Tibetan Plateau from D/H ratios of lipid biomarkers. Ear. Planet. Sci. Lett. 287, 64-76.

Purser, B.H., 1978. Early diagenesis and preservation of porosity in Jurassic limestones. J. Petrol. Geol. 1(2) 83-94.

Quade, J., Cerling, T.E., and Bowman, J.R., 1989. Systematic variation in the carbon and oxygen isotopic composition of Holocene soil carbonate along elevation transects in the southern Great Basin, USA: Geol. Soc. Am. Bull. 101, 464-475.

Quade, J., Rech, J., Latorre, C., Betancourt, J., Gleason, E., Kalin-Arroyo, M., 2007. Soils at the hyperarid margin: the isotopic composition of soil carbonate from the Atacama Desert. Geochim. Cosmochim. Acta 71, 3772-3795.

Quade, J., Breecker, D., Daëron, M., Eiler, J., 2011. The Paleoaltimetry of Tibet: an isotopic perspective. Am. J. Sci. 311, 77-115.

Quade, J., Eiler, J., Daeron, M., Achyuthan, H., 2013. The clumped isotope geothermometer in soil and paleosol carbonate: Geochim. Cosmochim. Act., 105, 92-107.

Reiners, P.W., Spell, T.L., Nicolescu, S., Zanetti, K.A., 2004. Zircon (U/Th)/He thermochronometry: He diffusion and comparisons with ${ }^{40} \mathrm{Ar} /{ }^{30} \mathrm{Ar}$ dating. Geochim. Cosmochim. Acta 68(8) 1857-1887. 
Reiners, P. W., 2005. Zircon (U-Th)/He thermochronometry: Rev. Min. Geosc. 58, 151-179.

Revelle, R., Fairbridge, R., 1957. Carbonates and carbon dioxide. Chapter in Treatise on Marine Ecology and Paleoecology. Geol. Soc. Am. Mem. 67, 239.

Rohrmann, A., Kapp, P., Carrapa, B., Reiners, P.W., Guyunn, J., Ding, L., Heizler, M., Thermochronologic evidence for plateau formation in central Tibet by $45 \mathrm{Ma}$. Geology 40 (2), 187-190.

Rozanski, K., Araguas-Araguas, L., and Gonfiantini, R., 1993. Isotopic patterns in modern global precipitation. In: Swart, P., McKenzie, J.A., Lohman, K.C. (Eds.), Continental Indicators of Climate, Proceedings of Chapman Conference, Jackson Hole, Wyoming, American Geophysical Union Monograph 78, pp. 1-36.

Rowley, D., Currie, B., 2006. Paleoaltimetry of the late Eocene to Miocene Lunpola Basin, central Tibet. Nature 439,677-681.

Saylor, J. E., Quade, J., Dettman, D., DeCelles, P. G., Kapp, P. A., 2009. The rise and fall of southwestern Tibet: Oxygen and carbon isotopic evidence from the Zhada Basin. Am. J. Sci. $309,1-42$.

Sharp, Z.D., Wostock, J.A.G., Pack, A., 2018. Mass-dependent triple oxygen variations in terrestrial materials. Geochem. Perspect. Lett. 7, 27-31.

Spicer, R.A., Harris, N.B.W., Widdowson, M., Herman, A.B., Guo, S., Valdes, P.J., Wolfe, J.AS., Kelly, S.P., 2003. Constant elevation of southern Tibet over the past 15 million years. Nature $421,622-624$.

$\mathrm{Su}, \mathrm{T}$. and 16 others, 2019. No high Tibetan Plateau until the Neogene. Sci. Adv. 5, eaav2189.

Sun, J., Xu, Q., Liu, W., Zhang, Z., Xue, L., Zhao, P., 2014. Palynological evidence for the latest Oligocene-early Miocene paleoelevation estimate in the Lunpola Basin, central Tibet. Palaeogeogr. Palaeoclim., Palaeoecol. 399, 21-30.

Veizer, J., and sixteen others, 1999. ${ }^{87} \mathrm{Sr} /{ }^{86} \mathrm{Sr}, \delta^{13} \mathrm{C}$, and $\delta^{18} \mathrm{O}$ evolution of Phanerozoic seawater. Chem. Geol. 161, 59-88.

Wang, Y, Deng, T and Biasatti, D., 2006. Ancient diets indicate significant uplift of southern Tibet after ca. 7 Ma. Geology 34, 309-12.

Wang, C., Li, X., Liu, Z., Li, Y., Janssa, L., Dai, J., Wei, Y., 2012. Revision of the CretaceousPaleogene stratigraphic framework, facies architecture and provenance of the Xigaze forearc basin along the Yarlung-Zangbo suture zone, Gondwana Res. 22(2), 415-433.

Wei, Y., Zhang, K., Garzione, C.N., Xu, Y., Song, B., Ji, J., 2016. Low palaeoelevation of the northern Lhasa terrane during late Eocene: fossil foraminifera and stable isotope evidence from the Gerze Basin. Sci. Rep. 6, 27508-.

Wendler, I., Wendler, J., Gräfe, K.U., Lehmann, J., Willems, H., 2009. Turonian to Santonian carbon isotope data from the Tethys Himalaya, southern Tibet. Cretaceous Res. 30(4), pp.961-979.

Wendler, I., Willems, H., Gräfe, K.U., Ding, L., Luo, H., 2011. Upper Cretaceous interhemispheric correlation between the Southern Tethys and the Boreal: chemo-and biostratigraphy and paleoclimatic reconstructions from a new section in the Tethys Himalaya, S-Tibet. Newsl. Stratigr. 44(2), pp.137-171.

Wierzbowski, H., 2007. Effects of pre-treatments and organic matter on oxygen and carbon isotope analyses of skeletal and organic calcium carbonate. Int. J. Mass Spectrom. 268, 1629.

Xu, Q., Ding, L., Zhang., L., Cai, F., Lai, Q., Yang, D., Liu-Zeng, J., 2013. Paleogene high elevations in the Qiangtang Terrane, central Tibetan Plateau. Ear. Planet. Sc. Lett. 362, 31-42. 
Yin. A. and Harrison, T. M. 2000. Geologic evolution of the Himalyan-Tibetan orogen. Ann. Rev. Ear. Planet. Sci. 28, 211-280.

\section{List of Supplementary tables}

Table S1. A compilation of published stable isotope analyses of marine carbonates from Tibet and northern India.

Table S2. Stable isotope results from carbonates from the Xigaze forearc sequence.

Table S3. Stable isotope results from carbonates from the Nianbo Formation in the Linzhou area

Table S4 Stable isotope results from carbonates from the Liuqu Formation.

Table S5. Stable isotope results from carbonates from the Kailas Formation.

Table S6. Clumped isotope results from carbonates in southern Tibet from this study.

Table S7. Stable isotope results from natural waters in southern Tibet from this study.

Table S1 Isotopic values of marine carbonate from south Asia from published sources and this study

Outside Suture/Arc

Sample

Location

Age (Ma) $\quad \delta^{13} \mathrm{C} \quad \delta^{18} \mathrm{O}$ 
Leier et al. (2009)

INACR-14A

INACR-14B

INACR-14C

INACR-16A

INACR-16B

INACR-16C

INACR-16D

INACR-16E

INACR-16F

INACR-16G

INACR-16H

INACR-16|

INACR-16J

DB-5-246A

DB-5-246B

DB-5-246C

DB5-246

DB5-246

DB5-246

DB5-246

DB5-246A

DB5-246B

DB5-75A

DB5-75B

DB5-75D

LP-3-20A

LP-3-20B

LP-3-20C

LP-3-20D

LP3-20

LP3-20

LP3-20

LP3-20A
$\mathrm{N} 30^{\circ} 51.39, \mathrm{E}^{\circ} 7^{\circ} 00.400,1300 \mathrm{~m}$

(VPDB) (VPDB)

$\begin{array}{lrrr}\text { Subathu Fm., Northern India } & 55-45 & -0.4 & -11.07 \\ \text { Subathu Fm., Northern India } & 55-45 & -2.06 & -7.1 \\ \text { Subathu Fm., Northern India } & 55-45 & -3.37 & -9.88 \\ \text { Subathu Fm., Northern India } & 55-45 & -1.53 & -7.21 \\ \text { Subathu Fm., Northern India } & 55-45 & -1.57 & -5.79 \\ \text { Subathu Fm., Northern India } & 55-45 & -1.36 & -5.66 \\ \text { Subathu Fm., Northern India } & 55-45 & -1.21 & -6.27 \\ \text { Subathu Fm., Northern India } & 55-45 & -1.44 & -7.79 \\ \text { Subathu Fm., Northern India } & 55-45 & -1.99 & -7.31 \\ \text { Subathu Fm., Northern India } & 55-45 & -1.2 & -7.13 \\ \text { Subathu Fm., Northern India } & 55-45 & -1.23 & -6.58 \\ \text { Subathu Fm., Northern India } & 55-45 & -1 & -5.3 \\ \text { Subathu Fm., Northern India } & 55-45 & -1.02 & -5.31\end{array}$

\section{N31 ${ }^{\circ} 25 ; W 89^{\circ} 40$}

Duba, South Tibet

122-98

$4.79 \quad-5.4$

Duba, South Tibet

$122-98$

$4.87 \quad-4.86$

Duba, South Tibet

$122-98$

$4.75 \quad-5.52$

Duba, South Tibet

$122-98$

$4.49 \quad-5.74$

Duba, South Tibet

$4.85 \quad-4.41$

Duba, South Tibet

122-98

$4.8 \quad-4.82$

Duba, South Tibet

$4.69 \quad-5.6$

Duba, South Tibet

$4.65 \quad-5.07$

Duba, South Tibet

4.76

$-4.95$

Duba, South Tibet

$2.51-10.76$

Duba, South Tibet

$4.27 \quad-7.01$

Duba, South Tibet

$4.14-8.16$

\section{N31 ${ }^{\circ} 52 ; \mathrm{W}^{\circ} 9^{\circ} 36$}

$\begin{array}{lrrr}\text { Langshan Fm, South Tibet } & 122-98 & 3.19 & -11.73 \\ \text { Langshan Fm, South Tibet } & 122-98 & 3.1 & -11.46 \\ \text { Langshan Fm, South Tibet } & 122-98 & 2.98 & -10.11 \\ \text { Langshan Fm, South Tibet } & 122-98 & 3.52 & -4.34 \\ \text { Langshan Fm, South Tibet } & 122-98 & 1.95 & -13.09 \\ \text { Langshan Fm, South Tibet } & 122-98 & 2.74 & -10.45 \\ \text { Langshan Fm, South Tibet } & 122-98 & 3.08 & -8.38 \\ \text { Langshan Fm, South Tibet } & 122-98 & 3.18 & -11.98\end{array}$




$\begin{array}{lllrr}\text { LP1.15 } & \text { Langshan Fm, South Tibet } & 122-98 & -5.71 & -9.69 \\ \text { LP4-27A } & \text { Langshan Fm, South Tibet } & 122-98 & -3.12 & -13 \\ \text { LP4-27B } & \text { Langshan Fm, South Tibet } & 122-98 & -3.99 & -13.31 \\ \text { LP5-48A } & \text { Langshan Fm, South Tibet } & 122-98 & 3.5 & -11.87\end{array}$

Wendler et al. $2011 \quad$ N2806'14"; E89¹2'36", 4970m

$\begin{array}{lrrr}\text { Guru, South Tibet } & 92-70 & 0.94 & -8.85 \\ \text { Guru, South Tibet } & 92-70 & 0.89 & -7.75 \\ \text { Guru, South Tibet } & 92-70 & 1.11 & -8.58 \\ \text { Guru, South Tibet } & 92-70 & 1.29 & -8.37 \\ \text { Guru, South Tibet } & 92-70 & 0.54 & -8.4 \\ \text { Guru, South Tibet } & 92-70 & 0.96 & -8.13 \\ \text { Guru, South Tibet } & 92-70 & 0.98 & -8.36 \\ \text { Guru, South Tibet } & 92-70 & 1.12 & -8.63 \\ \text { Guru, South Tibet } & 92-70 & 0.66 & -8.48 \\ \text { Guru, South Tibet } & 92-70 & 0.63 & -8.23 \\ \text { Guru, South Tibet } & 92-70 & 0.6 & -8.53 \\ \text { Guru, South Tibet } & 92-70 & 0.71 & -8.22 \\ \text { Guru, South Tibet } & 92-70 & 0.76 & -8.47 \\ \text { Guru, South Tibet } & 92-70 & 0.49 & -8.71 \\ \text { Guru, South Tibet } & 92-70 & -2.72 & -6.14 \\ \text { Guru, South Tibet } & 92-70 & 0.18 & -7.84 \\ \text { Guru, South Tibet } & 92-70 & 0.57 & -8.31 \\ \text { Guru, South Tibet } & 92-70 & 0.53 & -7.61 \\ \text { Guru, South Tibet } & 92-70 & 0.71 & -7.86 \\ \text { Guru, South Tibet } & 92-70 & 0.74 & -8.37 \\ \text { Guru, South Tibet } & 92-70 & 1.75 & -8.32 \\ \text { Guru, South Tibet } & 92-70 & 1.04 & -7.86 \\ \text { Guru, South Tibet } & 92-70 & 0.78 & -8.03 \\ \text { Guru, South Tibet } & 92-70 & 0.68 & -7.84 \\ \text { Guru, South Tibet } & 92-70 & 1.79 & -9.68 \\ \text { Guru, South Tibet } & 92-70 & 1.36 & -8.22 \\ \text { Guru, South Tibet } & 1.07 & -8.14 \\ \text { Guru, South Tibet } & 1.21 & -8.15 \\ \text { Guru, South Tibet } & 1.17 & -7.94 \\ \text { Guru, South Tibet } & 9.06 & -8.29 \\ \text { Guru, South Tibet } & 9.33 \\ \text { Guru, South Tibet } & -6.44 \\ \text { Guru, South Tibet } & -6.15 \\ \text { Guru, South Tibet } & 9.12\end{array}$




\begin{tabular}{|c|c|c|c|}
\hline Guru, South Tibet & $92-70$ & 0.99 & -7.5 \\
\hline Guru, South Tibet & $92-70$ & 1.43 & -8.28 \\
\hline Guru, South Tibet & $92-70$ & 1.23 & -7.66 \\
\hline Guru, South Tibet & $92-70$ & 1.65 & -8.46 \\
\hline Guru, South Tibet & $92-70$ & 1.75 & -9.82 \\
\hline Guru, South Tibet & $92-70$ & 1.6 & -9.08 \\
\hline Guru, South Tibet & $92-70$ & 1.05 & -8.03 \\
\hline Guru, South Tibet & $92-70$ & 1.62 & -12.95 \\
\hline Guru, South Tibet & $92-70$ & 1.92 & -8.46 \\
\hline Guru, South Tibet & $92-70$ & 1.52 & -8.66 \\
\hline Guru, South Tibet & $92-70$ & 1.92 & -8.76 \\
\hline Guru, South Tibet & $92-70$ & 1.25 & -7.49 \\
\hline Guru, South Tibet & $92-70$ & 1.43 & -7.84 \\
\hline Guru, South Tibet & $92-70$ & 1.78 & -8.26 \\
\hline Guru, South Tibet & $92-70$ & 1.84 & -8.31 \\
\hline Guru, South Tibet & $92-70$ & 1.91 & -8.01 \\
\hline Guru, South Tibet & $92-70$ & 2.97 & -8.42 \\
\hline Guru, South Tibet & $92-70$ & 1.57 & -8.1 \\
\hline Guru, South Tibet & $92-70$ & 0.65 & -7.91 \\
\hline Guru, South Tibet & $92-70$ & 1.57 & -8.2 \\
\hline Guru, South Tibet & $92-70$ & 0.65 & -7.91 \\
\hline Guru, South Tibet & $92-70$ & 1.57 & -8.2 \\
\hline Guru, South Tibet & $92-70$ & -0.69 & -8.57 \\
\hline Guru, South Tibet & $92-70$ & 1.5 & -8.8 \\
\hline Guru, South Tibet & $92-70$ & 1.3 & -8.37 \\
\hline Guru, South Tibet & $92-70$ & 1.22 & -7.63 \\
\hline Guru, South Tibet & $92-70$ & 2.13 & -7.89 \\
\hline Guru, South Tibet & $92-70$ & 1.39 & -6.7 \\
\hline Guru, South Tibet & $92-70$ & 1.32 & -6.53 \\
\hline Guru, South Tibet & $92-70$ & 1.68 & -8.15 \\
\hline Guru, South Tibet & $92-70$ & 1.82 & -7.81 \\
\hline Guru, South Tibet & $92-70$ & 1.67 & -7.52 \\
\hline Guru, South Tibet & $92-70$ & 1.45 & -7.43 \\
\hline Guru, South Tibet & $92-70$ & 1.51 & -8.05 \\
\hline Guru, South Tibet & $92-70$ & 1.58 & -8.45 \\
\hline Guru, South Tibet & $92-70$ & 1.32 & -7.48 \\
\hline Guru, South Tibet & $92-70$ & 1.4 & -8.68 \\
\hline Guru, South Tibet & $92-70$ & 1.54 & -7.73 \\
\hline Guru, South Tibet & $92-70$ & 1.06 & -8.32 \\
\hline Guru, South Tibet & $92-70$ & 0.75 & -7.54 \\
\hline
\end{tabular}




\begin{tabular}{|c|c|c|c|}
\hline Guru, South Tibet & $92-70$ & 0.97 & -7.39 \\
\hline Guru, South Tibet & $92-70$ & 0.82 & -7.34 \\
\hline Guru, South Tibet & $92-70$ & 1.23 & -8.26 \\
\hline Guru, South Tibet & $92-70$ & 0.91 & -7.33 \\
\hline Guru, South Tibet & $92-70$ & 0.76 & -6.84 \\
\hline Guru, South Tibet & $92-70$ & 1.12 & -7.3 \\
\hline Guru, South Tibet & $92-70$ & 1.25 & -8.04 \\
\hline Guru, South Tibet & $92-70$ & 1.28 & -8.44 \\
\hline Guru, South Tibet & $92-70$ & 1 & -7.51 \\
\hline Guru, South Tibet & $92-70$ & 1.05 & -7.62 \\
\hline Guru, South Tibet & $92-70$ & 1.19 & -8.04 \\
\hline Guru, South Tibet & $92-70$ & 1.22 & -8.03 \\
\hline Guru, South Tibet & $92-70$ & 1 & -7.58 \\
\hline Guru, South Tibet & $92-70$ & 1.04 & -7.61 \\
\hline Guru, South Tibet & $92-70$ & 0.98 & -7.76 \\
\hline Guru, South Tibet & $92-70$ & 1.11 & -8.06 \\
\hline Guru, South Tibet & $92-70$ & 0.68 & -6.74 \\
\hline Guru, South Tibet & $92-70$ & 1.38 & -8.24 \\
\hline Guru, South Tibet & $92-70$ & 0.88 & -7.24 \\
\hline Guru, South Tibet & $92-70$ & 0.72 & -7.82 \\
\hline Guru, South Tibet & $92-70$ & 0.96 & -7.37 \\
\hline Guru, South Tibet & $92-70$ & 0.99 & -7.68 \\
\hline Guru, South Tibet & $92-70$ & 1.16 & -7.89 \\
\hline Guru, South Tibet & $92-70$ & 1.14 & -8.48 \\
\hline Guru, South Tibet & $92-70$ & 0.53 & -8.15 \\
\hline Guru, South Tibet & $92-70$ & 0.48 & -7.76 \\
\hline Guru, South Tibet & $92-70$ & 0.64 & -7.61 \\
\hline Guru, South Tibet & $92-70$ & 0.79 & -7.72 \\
\hline Guru, South Tibet & $92-70$ & 0.54 & -7.03 \\
\hline Guru, South Tibet & $92-70$ & 0.42 & -6.96 \\
\hline Guru, South Tibet & $92-70$ & 0.47 & -7.2 \\
\hline Guru, South Tibet & $92-70$ & 0.56 & -7.6 \\
\hline Guru, South Tibet & $92-70$ & 0.49 & -7.35 \\
\hline Guru, South Tibet & $92-70$ & 0.68 & -8.53 \\
\hline Guru, South Tibet & $92-70$ & 0.24 & -7.53 \\
\hline Guru, South Tibet & $92-70$ & 0.34 & -7.64 \\
\hline Guru, South Tibet & $92-70$ & 0.5 & -8.01 \\
\hline Guru, South Tibet & $92-70$ & 0.18 & -7.37 \\
\hline Guru, South Tibet & $92-70$ & 0.96 & -9.41 \\
\hline Guru, South Tibet & $92-70$ & 0.82 & -8.25 \\
\hline
\end{tabular}




\begin{tabular}{|c|c|c|c|}
\hline Guru, South Tibet & $92-70$ & 0.67 & -7.7 \\
\hline Guru, South Tibet & $92-70$ & 0.77 & -7.55 \\
\hline Guru, South Tibet & $92-70$ & 0.72 & -7.07 \\
\hline Guru, South Tibet & $92-70$ & 1.04 & -7.75 \\
\hline Guru, South Tibet & $92-70$ & 0.99 & -7.62 \\
\hline Guru, South Tibet & $92-70$ & 1.13 & -7.91 \\
\hline Guru, South Tibet & $92-70$ & 1.31 & -7.77 \\
\hline Guru, South Tibet & $92-70$ & 1.29 & -7.16 \\
\hline Guru, South Tibet & $92-70$ & 1.36 & -6.55 \\
\hline Guru, South Tibet & $92-70$ & 1.45 & -6.37 \\
\hline Guru, South Tibet & $92-70$ & 1.58 & -6.73 \\
\hline Guru, South Tibet & $92-70$ & 1.71 & -6.71 \\
\hline Guru, South Tibet & $92-70$ & 1.92 & -7.37 \\
\hline Guru, South Tibet & $92-70$ & 1.94 & -7.61 \\
\hline Guru, South Tibet & $92-70$ & 1.85 & -6.02 \\
\hline Guru, South Tibet & $92-70$ & 2.01 & -7.83 \\
\hline Guru, South Tibet & $92-70$ & 1.98 & -8.06 \\
\hline Guru, South Tibet & $92-70$ & 2.05 & -7.94 \\
\hline Guru, South Tibet & $92-70$ & 2.09 & -7.84 \\
\hline Guru, South Tibet & $92-70$ & 2.03 & -7.74 \\
\hline Guru, South Tibet & $92-70$ & 2.04 & -6.57 \\
\hline Guru, South Tibet & $92-70$ & 2.31 & -6.12 \\
\hline Guru, South Tibet & $92-70$ & 1.73 & -6.91 \\
\hline Guru, South Tibet & $92-70$ & 1.75 & -6.66 \\
\hline Guru, South Tibet & $92-70$ & 1.82 & -6.22 \\
\hline Guru, South Tibet & $92-70$ & 1.78 & -6.39 \\
\hline Guru, South Tibet & $92-70$ & 1.69 & -6.17 \\
\hline Guru, South Tibet & $92-70$ & 1.58 & -6.2 \\
\hline Guru, South Tibet & $92-70$ & 1.57 & -6.24 \\
\hline Guru, South Tibet & $92-70$ & 1.67 & -6.41 \\
\hline Guru, South Tibet & $92-70$ & 1.52 & -6 \\
\hline Guru, South Tibet & $92-70$ & 1.62 & -6.33 \\
\hline Guru, South Tibet & $92-70$ & 1.44 & -5.96 \\
\hline Guru, South Tibet & $92-70$ & 1.51 & -6.2 \\
\hline Guru, South Tibet & $92-70$ & 1.54 & -6.03 \\
\hline Guru, South Tibet & $92-70$ & 1.36 & -5.67 \\
\hline Guru, South Tibet & $92-70$ & 1.31 & -5.84 \\
\hline Guru, South Tibet & $92-70$ & 1.01 & -5.79 \\
\hline Guru, South Tibet & $92-70$ & 1.31 & -6.38 \\
\hline Guru, South Tibet & $92-70$ & 1.09 & -6.03 \\
\hline
\end{tabular}




\begin{tabular}{|c|c|c|c|}
\hline Guru, South Tibet & $92-70$ & 1.31 & -6.9 \\
\hline Guru, South Tibet & $92-70$ & 0.93 & -6.04 \\
\hline Guru, South Tibet & $92-70$ & 0.87 & -6.42 \\
\hline Guru, South Tibet & $92-70$ & 0.61 & -6.18 \\
\hline Guru, South Tibet & $92-70$ & 0.81 & -6.08 \\
\hline Guru, South Tibet & $92-70$ & 0.59 & -6.11 \\
\hline Guru, South Tibet & $92-70$ & 0.25 & -5.54 \\
\hline Guru, South Tibet & $92-70$ & 0.54 & -5.7 \\
\hline Guru, South Tibet & $92-70$ & 0.64 & -5.62 \\
\hline Guru, South Tibet & $92-70$ & 0.58 & -5.52 \\
\hline Guru, South Tibet & $92-70$ & 0.79 & -6.1 \\
\hline Guru, South Tibet & $92-70$ & 0.67 & -5.26 \\
\hline Guru, South Tibet & $92-70$ & 0.82 & -6.1 \\
\hline Guru, South Tibet & $92-70$ & 0.85 & -5.73 \\
\hline Guru, South Tibet & $92-70$ & 0.42 & -5.73 \\
\hline Guru, South Tibet & $92-70$ & 0.46 & -5.74 \\
\hline Guru, South Tibet & $92-70$ & 0.68 & -5.43 \\
\hline Guru, South Tibet & $92-70$ & -3.43 & -4.77 \\
\hline Guru, South Tibet & $92-70$ & 0.48 & -5.13 \\
\hline Guru, South Tibet & $92-70$ & -6.46 & -4.72 \\
\hline Guru, South Tibet & $92-70$ & -5.59 & -4.54 \\
\hline Guru, South Tibet & $92-70$ & 0.66 & -5.2 \\
\hline Guru, South Tibet & $92-70$ & 0.81 & -5.06 \\
\hline Guru, South Tibet & $92-70$ & 1.15 & -5.26 \\
\hline Guru, South Tibet & $92-70$ & 0.74 & -5.5 \\
\hline Guru, South Tibet & $92-70$ & 0.86 & -5.38 \\
\hline Guru, South Tibet & $92-70$ & 1.18 & -5.66 \\
\hline Guru, South Tibet & $92-70$ & 0.87 & -5 \\
\hline Guru, South Tibet & $92-70$ & 1.4 & -5.27 \\
\hline Guru, South Tibet & $92-70$ & 1.09 & -5.12 \\
\hline Guru, South Tibet & $92-70$ & 1.5 & -5.2 \\
\hline Guru, South Tibet & $92-70$ & 1.71 & -5.14 \\
\hline Guru, South Tibet & $92-70$ & 1.94 & -4.97 \\
\hline Guru, South Tibet & $92-70$ & 1.84 & -5.03 \\
\hline Guru, South Tibet & $92-70$ & 2 & -5.02 \\
\hline Guru, South Tibet & $92-70$ & 1.91 & -5.06 \\
\hline Guru, South Tibet & $92-70$ & 2.07 & -5.2 \\
\hline Guru, South Tibet & $92-70$ & 2.04 & -5.12 \\
\hline Guru, South Tibet & $92-70$ & 2.14 & -5.08 \\
\hline Guru, South Tibet & $92-70$ & 2.22 & -5.32 \\
\hline
\end{tabular}




\begin{tabular}{|c|c|c|c|}
\hline Guru, South Tibet & $92-70$ & 2.35 & -5.23 \\
\hline Guru, South Tibet & $92-70$ & 2.38 & -5.32 \\
\hline Guru, South Tibet & $92-70$ & 2.53 & -5.1 \\
\hline Guru, South Tibet & $92-70$ & 2.45 & -5.38 \\
\hline Guru, South Tibet & $92-70$ & 2.68 & -5.25 \\
\hline Guru, South Tibet & $92-70$ & 2.8 & -5.4 \\
\hline Guru, South Tibet & $92-70$ & 2.88 & -5.66 \\
\hline Guru, South Tibet & $92-70$ & 2.7 & -7.17 \\
\hline Guru, South Tibet & $92-70$ & 2.81 & -5.43 \\
\hline Guru, South Tibet & $92-70$ & 2.59 & -5.94 \\
\hline Guru, South Tibet & $92-70$ & 2.72 & -5.64 \\
\hline Guru, South Tibet & $92-70$ & 2.78 & -6.06 \\
\hline Guru, South Tibet & $92-70$ & 2.59 & -5.55 \\
\hline Guru, South Tibet & $92-70$ & 2.59 & -5.47 \\
\hline Guru, South Tibet & $92-70$ & 2.78 & -5.16 \\
\hline Guru, South Tibet & $92-70$ & 2.66 & -5.48 \\
\hline Guru, South Tibet & $92-70$ & 2.77 & -5.59 \\
\hline Guru, South Tibet & $92-70$ & 2.55 & -5.36 \\
\hline Guru, South Tibet & $92-70$ & 2.25 & -5.49 \\
\hline Guru, South Tibet & $92-70$ & 2.51 & -5.11 \\
\hline Guru, South Tibet & $92-70$ & 2.61 & -5.07 \\
\hline Guru, South Tibet & $92-70$ & 2.54 & -5.09 \\
\hline Guru, South Tibet & $92-70$ & 2.65 & -5.48 \\
\hline Guru, South Tibet & $92-70$ & 2.35 & -5.19 \\
\hline Guru, South Tibet & $92-70$ & 2.31 & -5.52 \\
\hline Guru, South Tibet & $92-70$ & 2.88 & -5.3 \\
\hline Guru, South Tibet & $92-70$ & 2.61 & -6.45 \\
\hline Guru, South Tibet & $92-70$ & 2.31 & -5.17 \\
\hline Guru, South Tibet & $92-70$ & 2.35 & -5.53 \\
\hline Guru, South Tibet & $92-70$ & 2.19 & -5.2 \\
\hline Guru, South Tibet & $92-70$ & 2.43 & -5.02 \\
\hline Guru, South Tibet & $92-70$ & 2.42 & -4.93 \\
\hline Guru, South Tibet & $92-70$ & 2.49 & -5.24 \\
\hline Guru, South Tibet & $92-70$ & 2.46 & -6.22 \\
\hline Guru, South Tibet & $92-70$ & 2.38 & -6.66 \\
\hline Guru, South Tibet & $92-70$ & 2.36 & -6.13 \\
\hline Guru, South Tibet & $92-70$ & 2.26 & -5.03 \\
\hline Guru, South Tibet & $92-70$ & 2.26 & -5.3 \\
\hline Guru, South Tibet & $92-70$ & 2.28 & -5.36 \\
\hline Guru, South Tibet & $92-70$ & 2.12 & -5.47 \\
\hline
\end{tabular}




\begin{tabular}{|c|c|c|c|}
\hline Guru, South Tibet & $92-70$ & 2.22 & -6.17 \\
\hline Guru, South Tibet & $92-70$ & 1.78 & -6.01 \\
\hline Guru, South Tibet & $92-70$ & 1.62 & -5.31 \\
\hline Guru, South Tibet & $92-70$ & 1.44 & -5.54 \\
\hline Guru, South Tibet & $92-70$ & 0.87 & -5.24 \\
\hline Guru, South Tibet & $92-70$ & 1.64 & -6.92 \\
\hline Guru, South Tibet & $92-70$ & 1.49 & -6.63 \\
\hline Guru, South Tibet & $92-70$ & -0.17 & -5.23 \\
\hline Guru, South Tibet & $92-70$ & 1.33 & -6.65 \\
\hline Guru, South Tibet & $92-70$ & 1 & -6.65 \\
\hline Guru, South Tibet & $92-70$ & 0.5 & -5.42 \\
\hline Guru, South Tibet & $92-70$ & 0.86 & -5.86 \\
\hline Guru, South Tibet & $92-70$ & 0.37 & -6.75 \\
\hline Guru, South Tibet & $92-70$ & 1.24 & -5.93 \\
\hline Guru, South Tibet & $92-70$ & 0.33 & -5.59 \\
\hline Guru, South Tibet & $92-70$ & 1.31 & -5.71 \\
\hline Guru, South Tibet & $92-70$ & 1.32 & -6.09 \\
\hline Guru, South Tibet & $92-70$ & 1.4 & -5.72 \\
\hline Guru, South Tibet & $92-70$ & 1.32 & -6.03 \\
\hline Guru, South Tibet & $92-70$ & 1.17 & -5.84 \\
\hline Guru, South Tibet & $92-70$ & 1.07 & -6.15 \\
\hline Guru, South Tibet & $92-70$ & 1.54 & -7.58 \\
\hline Guru, South Tibet & $92-70$ & 1.52 & -6.28 \\
\hline Guru, South Tibet & $92-70$ & 1.58 & -6.3 \\
\hline Guru, South Tibet & $92-70$ & 1.06 & -5.79 \\
\hline Guru, South Tibet & $92-70$ & 0.89 & -5.28 \\
\hline Guru, South Tibet & $92-70$ & 1.51 & -5.57 \\
\hline Guru, South Tibet & $92-70$ & 1.66 & -5.94 \\
\hline Guru, South Tibet & $92-70$ & 0.7 & -5.29 \\
\hline Guru, South Tibet & $92-70$ & 1.88 & -5.11 \\
\hline Guru, South Tibet & $92-70$ & 1.74 & -5.07 \\
\hline Guru, South Tibet & $92-70$ & 1.67 & -5.53 \\
\hline Guru, South Tibet & $92-70$ & 1.58 & -5.31 \\
\hline Guru, South Tibet & $92-70$ & 1.4 & -4.69 \\
\hline Guru, South Tibet & $92-70$ & 1.81 & -5.03 \\
\hline Guru, South Tibet & $92-70$ & 1.84 & -4.94 \\
\hline Guru, South Tibet & $92-70$ & 1.84 & -5.48 \\
\hline Guru, South Tibet & $92-70$ & 1.77 & -5.35 \\
\hline Guru, South Tibet & $92-70$ & 1.79 & -4.65 \\
\hline Guru, South Tibet & $92-70$ & 2.01 & -4.81 \\
\hline
\end{tabular}




\begin{tabular}{|c|c|c|c|}
\hline Guru, South Tibet & $92-70$ & 1.84 & -4.9 \\
\hline Guru, South Tibet & $92-70$ & 2.24 & -4.73 \\
\hline Guru, South Tibet & $92-70$ & 2.13 & -4.54 \\
\hline Guru, South Tibet & $92-70$ & 2.09 & -4.36 \\
\hline Guru, South Tibet & $92-70$ & 2.1 & -4.58 \\
\hline Guru, South Tibet & $92-70$ & 1.92 & -4.9 \\
\hline Guru, South Tibet & $92-70$ & 2.13 & -4.54 \\
\hline Guru, South Tibet & $92-70$ & 2.09 & -4.72 \\
\hline Guru, South Tibet & $92-70$ & 1.97 & -5.17 \\
\hline Guru, South Tibet & $92-70$ & 2.08 & -4.85 \\
\hline Guru, South Tibet & $92-70$ & 2.08 & -6.51 \\
\hline Guru, South Tibet & $92-70$ & 2.09 & -4.77 \\
\hline Guru, South Tibet & $92-70$ & 1.81 & -6.54 \\
\hline Guru, South Tibet & $92-70$ & 2.17 & -5.11 \\
\hline Guru, South Tibet & $92-70$ & 2.13 & -5.08 \\
\hline Guru, South Tibet & $92-70$ & 2.13 & -4.95 \\
\hline Guru, South Tibet & $92-70$ & 2.04 & -5.02 \\
\hline Guru, South Tibet & $92-70$ & 2.05 & -5.12 \\
\hline Guru, South Tibet & $92-70$ & 2.16 & -5.37 \\
\hline Guru, South Tibet & $92-70$ & 2.18 & -5.3 \\
\hline Guru, South Tibet & $92-70$ & 2.1 & -5.31 \\
\hline Guru, South Tibet & $92-70$ & 2.23 & -4.74 \\
\hline Guru, South Tibet & $92-70$ & 2.1 & -4.76 \\
\hline Guru, South Tibet & $92-70$ & 2.15 & -5.02 \\
\hline Guru, South Tibet & $92-70$ & 1.92 & -6.53 \\
\hline Guru, South Tibet & $92-70$ & 1.77 & -5.36 \\
\hline Guru, South Tibet & $92-70$ & 1.7 & -5.21 \\
\hline Guru, South Tibet & $92-70$ & 1.52 & -5.16 \\
\hline Guru, South Tibet & $92-70$ & 1.36 & -5.32 \\
\hline Guru, South Tibet & $92-70$ & 1.52 & -5.27 \\
\hline Guru, South Tibet & $92-70$ & 1.67 & -5.02 \\
\hline Guru, South Tibet & $92-70$ & 1.75 & -5.16 \\
\hline Guru, South Tibet & $92-70$ & 1.95 & -5.11 \\
\hline Guru, South Tibet & $92-70$ & 2.22 & -5.14 \\
\hline Guru, South Tibet & $92-70$ & 2.05 & -4.96 \\
\hline Guru, South Tibet & $92-70$ & 2.28 & -4.77 \\
\hline Guru, South Tibet & $92-70$ & 2.19 & -5.04 \\
\hline Guru, South Tibet & $92-70$ & 2.16 & -7.01 \\
\hline Guru, South Tibet & $92-70$ & 2.17 & -4.74 \\
\hline Guru, South Tibet & $92-70$ & 2.1 & -4.83 \\
\hline
\end{tabular}




\begin{tabular}{|c|c|c|c|}
\hline Guru, South Tibet & $92-70$ & 2.13 & -4.99 \\
\hline Guru, South Tibet & $92-70$ & 2.21 & -4.97 \\
\hline Guru, South Tibet & $92-70$ & 2.03 & -5.11 \\
\hline Guru, South Tibet & $92-70$ & 2.13 & -5.46 \\
\hline Guru, South Tibet & $92-70$ & 1.96 & -4.89 \\
\hline Guru, South Tibet & $92-70$ & 2.23 & -5.13 \\
\hline Guru, South Tibet & $92-70$ & 2.16 & -4.95 \\
\hline Guru, South Tibet & $92-70$ & 2.32 & -5.14 \\
\hline Guru, South Tibet & $92-70$ & 1.75 & -4.41 \\
\hline Guru, South Tibet & $92-70$ & 2.32 & -4.81 \\
\hline Guru, South Tibet & $92-70$ & 2.26 & -5.28 \\
\hline Guru, South Tibet & $92-70$ & 2.32 & -5.07 \\
\hline Guru, South Tibet & $92-70$ & 2.21 & -5.03 \\
\hline Guru, South Tibet & $92-70$ & 2.3 & -7.21 \\
\hline Guru, South Tibet & $92-70$ & 2.18 & -4.13 \\
\hline Guru, South Tibet & $92-70$ & 2.44 & -7.41 \\
\hline Guru, South Tibet & $92-70$ & 2.06 & -4.46 \\
\hline Guru, South Tibet & $92-70$ & 2.2 & -5.1 \\
\hline Guru, South Tibet & $92-70$ & 2.18 & -5.39 \\
\hline Guru, South Tibet & $92-70$ & 2.26 & -5.07 \\
\hline Guru, South Tibet & $92-70$ & 2.5 & -5.04 \\
\hline Guru, South Tibet & $92-70$ & 2.62 & -5.24 \\
\hline Guru, South Tibet & $92-70$ & 2.6 & -4.7 \\
\hline Guru, South Tibet & $92-70$ & 2.58 & -5.27 \\
\hline Guru, South Tibet & $92-70$ & 2.74 & -5.19 \\
\hline Guru, South Tibet & $92-70$ & 2.67 & -4.99 \\
\hline Guru, South Tibet & $92-70$ & 2.72 & -4.93 \\
\hline Guru, South Tibet & $92-70$ & 2.71 & -4.72 \\
\hline Guru, South Tibet & $92-70$ & 2.66 & -5.62 \\
\hline Guru, South Tibet & $92-70$ & 2.48 & -5.47 \\
\hline Guru, South Tibet & $92-70$ & 2.52 & -6.72 \\
\hline Guru, South Tibet & $92-70$ & 2.15 & -4.75 \\
\hline Guru, South Tibet & $92-70$ & 2 & -4.68 \\
\hline Guru, South Tibet & $92-70$ & 2.66 & -5.29 \\
\hline Guru, South Tibet & $92-70$ & 2.73 & -5.47 \\
\hline Guru, South Tibet & $92-70$ & 2.49 & -4.51 \\
\hline Guru, South Tibet & $92-70$ & 2.84 & -5.42 \\
\hline Guru, South Tibet & $92-70$ & 2.87 & -5.09 \\
\hline Guru, South Tibet & $92-70$ & 2.86 & -4.58 \\
\hline Guru, South Tibet & $92-70$ & 3 & -5.15 \\
\hline
\end{tabular}




$\begin{array}{lrrr}\text { Guru, South Tibet } & 92-70 & 2.6 & -4.73 \\ \text { Guru, South Tibet } & 92-70 & 2.46 & -4.43 \\ \text { Guru, South Tibet } & 92-70 & 2.67 & -5.82 \\ \text { Guru, South Tibet } & 92-70 & 2.45 & -4.36 \\ \text { Guru, South Tibet } & 92-70 & 2.37 & -4.8 \\ \text { Guru, South Tibet } & 92-70 & 2.09 & -5.34 \\ \text { Guru, South Tibet } & 92-70 & 2.3 & -4.86 \\ \text { Guru, South Tibet } & 92-70 & 2.37 & -5.14 \\ \text { Guru, South Tibet } & 92-70 & 2.27 & -5.44 \\ \text { Guru, South Tibet } & 92-70 & 2.13 & -6.3 \\ \text { Guru, South Tibet } & 92-70 & 1.99 & -5.91 \\ \text { Guru, South Tibet } & 92-70 & 1.64 & -5.7 \\ \text { Guru, South Tibet } & 92-70 & 1.69 & -5.81 \\ \text { Guru, South Tibet } & 92-70 & 1.35 & -6.8 \\ \text { Guru, South Tibet } & 92-70 & 1.29 & -7.38 \\ \text { Guru, South Tibet } & 92-70 & 1.37 & -5.9 \\ \text { Guru, South Tibet } & 92-70 & 1.87 & -6.23\end{array}$

Wendler et al. (2009) N284' $\quad \mathrm{N} 60^{\prime \prime}, \mathrm{E} 86^{\circ} 44^{\prime} 915^{\prime \prime}, 4765 \mathrm{~m}$

\begin{tabular}{|c|c|c|c|}
\hline & \\
\hline Tingri, South Tibet & $90-85$ & 1.43 & -7.48 \\
\hline Tingri, South Tibet & $90-85$ & 1.72 & -9.62 \\
\hline Tingri, South Tibet & $90-85$ & 1.64 & -6.9 \\
\hline Tingri, South Tibet & $90-85$ & 1.88 & -6.9 \\
\hline Tingri, South Tibet & $90-85$ & 1.72 & -7.45 \\
\hline Tingri, South Tibet & $90-85$ & 1.63 & -7.2 \\
\hline Tingri, South Tibet & $90-85$ & 1.57 & -7.65 \\
\hline Tingri, South Tibet & $90-85$ & 1.5 & -6.89 \\
\hline Tingri, South Tibet & $90-85$ & 1.52 & -7.14 \\
\hline Tingri, South Tibet & $90-85$ & 1.6 & -7.21 \\
\hline Tingri, South Tibet & $90-85$ & 1.56 & -7.35 \\
\hline Tingri, South Tibet & $90-85$ & 1.27 & -6.51 \\
\hline Tingri, South Tibet & $90-85$ & 1.23 & -7.59 \\
\hline Tingri, South Tibet & $90-85$ & 1.42 & -6.79 \\
\hline Tingri, South Tibet & $90-85$ & 1.23 & -6.85 \\
\hline Tingri, South Tibet & $90-85$ & 0.78 & -6.82 \\
\hline Tingri, South Tibet & $90-85$ & 1.26 & -5.94 \\
\hline Tingri, South Tibet & $90-85$ & 1.27 & -6.97 \\
\hline Tingri, South Tibet & $90-85$ & 1.24 & -6.45 \\
\hline
\end{tabular}




\begin{tabular}{|c|c|c|c|}
\hline Tingri, South Tibet & $90-85$ & 1.31 & -6.43 \\
\hline Tingri, South Tibet & $90-85$ & 1.2 & -6.46 \\
\hline Tingri, South Tibet & $90-85$ & 1.06 & -6.58 \\
\hline Tingri, South Tibet & $90-85$ & 1.11 & -6.27 \\
\hline Tingri, South Tibet & $90-85$ & 1.15 & -6.38 \\
\hline Tingri, South Tibet & $90-85$ & 1.26 & -7.97 \\
\hline Tingri, South Tibet & $90-85$ & 1.36 & -6.39 \\
\hline Tingri, South Tibet & $90-85$ & 1.34 & -6.64 \\
\hline Tingri, South Tibet & $90-85$ & 1.17 & -5.99 \\
\hline Tingri, South Tibet & $90-85$ & 1.12 & -6.04 \\
\hline Tingri, South Tibet & $90-85$ & 1.22 & -5.95 \\
\hline Tingri, South Tibet & $90-85$ & 1.14 & -8.06 \\
\hline Tingri, South Tibet & $90-85$ & 1.17 & -6.14 \\
\hline Tingri, South Tibet & $90-85$ & 1.2 & -6.28 \\
\hline Tingri, South Tibet & $90-85$ & 1.13 & -6.12 \\
\hline Tingri, South Tibet & $90-85$ & 1.17 & -5.75 \\
\hline Tingri, South Tibet & $90-85$ & 1.19 & -5.91 \\
\hline Tingri, South Tibet & $90-85$ & 1.38 & -6.01 \\
\hline Tingri, South Tibet & $90-85$ & 1.08 & -6.2 \\
\hline Tingri, South Tibet & $90-85$ & 1.27 & -5.92 \\
\hline Tingri, South Tibet & $90-85$ & 1.29 & -5.61 \\
\hline Tingri, South Tibet & $90-85$ & 1.14 & -5.98 \\
\hline Tingri, South Tibet & $90-85$ & 0.99 & -6.4 \\
\hline Tingri, South Tibet & $90-85$ & 1.31 & -5.83 \\
\hline Tingri, South Tibet & $90-85$ & 1.27 & -6.01 \\
\hline Tingri, South Tibet & $90-85$ & 1.2 & -5.96 \\
\hline Tingri, South Tibet & $90-85$ & 1.26 & -6.5 \\
\hline Tingri, South Tibet & $90-85$ & 1.25 & -6.01 \\
\hline Tingri, South Tibet & $90-85$ & 1.19 & -6.73 \\
\hline Tingri, South Tibet & $90-85$ & 1.45 & -6.12 \\
\hline Tingri, South Tibet & $90-85$ & 1.28 & -6.66 \\
\hline Tingri, South Tibet & $90-85$ & 1.18 & -7.08 \\
\hline Tingri, South Tibet & $90-85$ & 1.32 & -7.35 \\
\hline Tingri, South Tibet & $90-85$ & 1.35 & -6.35 \\
\hline Tingri, South Tibet & $90-85$ & 1.16 & -6.29 \\
\hline Tingri, South Tibet & $90-85$ & 1.24 & -6.12 \\
\hline
\end{tabular}




\begin{tabular}{|c|c|c|c|}
\hline Tingri, South Tibet & $90-85$ & 1.21 & -6.03 \\
\hline Tingri, South Tibet & $90-85$ & 1.31 & -6.64 \\
\hline Tingri, South Tibet & $90-85$ & 1.26 & -6.44 \\
\hline Tingri, South Tibet & $90-85$ & 1.42 & -6.01 \\
\hline Tingri, South Tibet & $90-85$ & 1.28 & -5.92 \\
\hline Tingri, South Tibet & $90-85$ & 1.26 & -5.99 \\
\hline Tingri, South Tibet & $90-85$ & 1.31 & -5.69 \\
\hline Tingri, South Tibet & $90-85$ & 1.27 & -6.09 \\
\hline Tingri, South Tibet & $90-85$ & 1.27 & -5.85 \\
\hline Tingri, South Tibet & $90-85$ & 1.29 & -5.97 \\
\hline Tingri, South Tibet & $90-85$ & 1.34 & -6.04 \\
\hline Tingri, South Tibet & $90-85$ & 1.48 & -6.16 \\
\hline Tingri, South Tibet & $90-85$ & 1.19 & -5.87 \\
\hline Tingri, South Tibet & $90-85$ & 1.16 & -6.1 \\
\hline Tingri, South Tibet & $90-85$ & 1.11 & -6.74 \\
\hline Tingri, South Tibet & $90-85$ & 1.16 & -6.33 \\
\hline Tingri, South Tibet & $90-85$ & 1.25 & -6.07 \\
\hline Tingri, South Tibet & $90-85$ & 1.17 & -6.19 \\
\hline Tingri, South Tibet & $90-85$ & 1.3 & -5.97 \\
\hline Tingri, South Tibet & $90-85$ & 1.28 & -6.32 \\
\hline Tingri, South Tibet & $90-85$ & 1.17 & -6.79 \\
\hline Tingri, South Tibet & $90-85$ & 1.14 & -5.92 \\
\hline Tingri, South Tibet & $90-85$ & 1.32 & -6.53 \\
\hline Tingri, South Tibet & $90-85$ & 1.35 & -5.95 \\
\hline Tingri, South Tibet & $90-85$ & 1.3 & -5.94 \\
\hline Tingri, South Tibet & $90-85$ & 1.33 & -6.5 \\
\hline Tingri, South Tibet & $90-85$ & 1.4 & -6.16 \\
\hline Tingri, South Tibet & $90-85$ & 1.42 & -6.66 \\
\hline Tingri, South Tibet & $90-85$ & 1.43 & -7.3 \\
\hline Tingri, South Tibet & $90-85$ & 1.34 & -6.09 \\
\hline Tingri, South Tibet & $90-85$ & 1.5 & -5.83 \\
\hline Tingri, South Tibet & $90-85$ & 1.48 & -6.03 \\
\hline Tingri, South Tibet & $90-85$ & 1.5 & -6.04 \\
\hline Tingri, South Tibet & $90-85$ & 1.65 & -5.65 \\
\hline Tingri, South Tibet & $90-85$ & 1.65 & -5.66 \\
\hline Tingri, South Tibet & $90-85$ & 1.67 & -5.73 \\
\hline
\end{tabular}




\begin{tabular}{|c|c|c|c|}
\hline Tingri, South Tibet & $90-85$ & 1.64 & -6.42 \\
\hline Tingri, South Tibet & $90-85$ & 1.71 & -7.84 \\
\hline Tingri, South Tibet & $90-85$ & 1.67 & -6.95 \\
\hline Tingri, South Tibet & $90-85$ & 1.59 & -5.89 \\
\hline Tingri, South Tibet & $90-85$ & 1.7 & -5.77 \\
\hline Tingri, South Tibet & $90-85$ & 1.69 & -6.1 \\
\hline Tingri, South Tibet & $90-85$ & 1.7 & -7.48 \\
\hline Tingri, South Tibet & $90-85$ & 1.74 & -5.99 \\
\hline Tingri, South Tibet & $90-85$ & 1.84 & -7.61 \\
\hline Tingri, South Tibet & $90-85$ & 1.91 & -6.41 \\
\hline Tingri, South Tibet & $90-85$ & 1.92 & -6.35 \\
\hline Tingri, South Tibet & $90-85$ & 1.92 & -5.83 \\
\hline Tingri, South Tibet & $90-85$ & 1.98 & -5.69 \\
\hline Tingri, South Tibet & $90-85$ & 2.01 & -5.8 \\
\hline Tingri, South Tibet & $90-85$ & 2.01 & -7.49 \\
\hline Tingri, South Tibet & $90-85$ & 2.16 & -7.95 \\
\hline Tingri, South Tibet & $90-85$ & 1.97 & -6.13 \\
\hline Tingri, South Tibet & $90-85$ & 2.11 & -6.26 \\
\hline Tingri, South Tibet & $90-85$ & 2.25 & -5.77 \\
\hline Tingri, South Tibet & $90-85$ & 2.06 & -6.4 \\
\hline Tingri, South Tibet & $90-85$ & 2.08 & -10.31 \\
\hline Tingri, South Tibet & $90-85$ & 2.03 & -7.35 \\
\hline Tingri, South Tibet & $90-85$ & 2.13 & -6.72 \\
\hline Tingri, South Tibet & $90-85$ & 2.04 & -5.82 \\
\hline Tingri, South Tibet & $90-85$ & 2 & -6.03 \\
\hline Tingri, South Tibet & $90-85$ & 2.06 & -5.4 \\
\hline Tingri, South Tibet & $90-85$ & 1.99 & -6.69 \\
\hline Tingri, South Tibet & $90-85$ & 1.94 & -6.54 \\
\hline Tingri, South Tibet & $90-85$ & 2.02 & -5.92 \\
\hline Tingri, South Tibet & $90-85$ & 1.98 & -6.56 \\
\hline Tingri, South Tibet & $90-85$ & 1.99 & -8.83 \\
\hline Tingri, South Tibet & $90-85$ & 1.98 & -5.63 \\
\hline Tingri, South Tibet & $90-85$ & 1.93 & -5.47 \\
\hline Tingri, South Tibet & $90-85$ & 1.94 & -5.54 \\
\hline Tingri, South Tibet & $90-85$ & 2 & -5.94 \\
\hline Tingri, South Tibet & $90-85$ & 1.95 & -8.76 \\
\hline
\end{tabular}




\begin{tabular}{|c|c|c|c|}
\hline Tingri, South Tibet & $90-85$ & 2.08 & -6.12 \\
\hline Tingri, South Tibet & $90-85$ & 2.03 & -5.46 \\
\hline Tingri, South Tibet & $90-85$ & 1.93 & -6.21 \\
\hline Tingri, South Tibet & $90-85$ & 2 & -6.77 \\
\hline Tingri, South Tibet & $90-85$ & 2.01 & -5.99 \\
\hline Tingri, South Tibet & $90-85$ & 2.02 & -5.83 \\
\hline Tingri, South Tibet & $90-85$ & 2.03 & -6.34 \\
\hline Tingri, South Tibet & $90-85$ & 1.8 & -5.46 \\
\hline Tingri, South Tibet & $90-85$ & 2 & -5.8 \\
\hline Tingri, South Tibet & $90-85$ & 1.95 & -5.42 \\
\hline Tingri, South Tibet & $90-85$ & 1.98 & -5.4 \\
\hline Tingri, South Tibet & $90-85$ & 1.88 & -5.63 \\
\hline Tingri, South Tibet & $90-85$ & 1.92 & -6.23 \\
\hline Tingri, South Tibet & $90-85$ & 1.77 & -5.44 \\
\hline Tingri, South Tibet & $90-85$ & 1.82 & -5.29 \\
\hline Tingri, South Tibet & $90-85$ & 1.87 & -8.87 \\
\hline Tingri, South Tibet & $90-85$ & 1.91 & -5.96 \\
\hline Tingri, South Tibet & $90-85$ & 1.89 & -6.78 \\
\hline Tingri, South Tibet & $90-85$ & 1.9 & -6.56 \\
\hline Tingri, South Tibet & $90-85$ & 1.88 & -9.17 \\
\hline Tingri, South Tibet & $90-85$ & 1.88 & -10.5 \\
\hline Tingri, South Tibet & $90-85$ & 1.78 & -6.31 \\
\hline Tingri, South Tibet & $90-85$ & 1.69 & -5.46 \\
\hline Tingri, South Tibet & $90-85$ & 1.66 & -6.5 \\
\hline Tingri, South Tibet & $90-85$ & 1.6 & -5.85 \\
\hline Tingri, South Tibet & $90-85$ & 1.64 & -5.44 \\
\hline Tingri, South Tibet & $90-85$ & 1.86 & -5.9 \\
\hline Tingri, South Tibet & $90-85$ & 1.8 & -5.44 \\
\hline Tingri, South Tibet & $90-85$ & 1.75 & -5.59 \\
\hline Tingri, South Tibet & $90-85$ & 1.77 & -5.73 \\
\hline Tingri, South Tibet & $90-85$ & 1.82 & -6.02 \\
\hline Tingri, South Tibet & $90-85$ & 1.83 & -5.64 \\
\hline Tingri, South Tibet & $90-85$ & 1.83 & -6.13 \\
\hline Tingri, South Tibet & $90-85$ & 1.89 & -5.75 \\
\hline Tingri, South Tibet & $90-85$ & 1.82 & -5.74 \\
\hline Tingri, South Tibet & $90-85$ & 1.56 & -12.29 \\
\hline
\end{tabular}




\begin{tabular}{|c|c|c|c|}
\hline Tingri, South Tibet & $90-85$ & 1.87 & -5.65 \\
\hline Tingri, South Tibet & $90-85$ & 1.84 & -6.02 \\
\hline Tingri, South Tibet & $90-85$ & 1.79 & -5.9 \\
\hline Tingri, South Tibet & $90-85$ & 1.74 & -5.76 \\
\hline Tingri, South Tibet & $90-85$ & 1.57 & -6.71 \\
\hline Tingri, South Tibet & $90-85$ & 1.65 & -5.28 \\
\hline Tingri, South Tibet & $90-85$ & 1.66 & -6.12 \\
\hline Tingri, South Tibet & $90-85$ & 1.13 & -5.81 \\
\hline Tingri, South Tibet & $90-85$ & 1.21 & -5.82 \\
\hline Tingri, South Tibet & $90-85$ & 1.43 & -7.22 \\
\hline Tingri, South Tibet & $90-85$ & 1.46 & -7.06 \\
\hline Tingri, South Tibet & $90-85$ & 1.26 & -5.23 \\
\hline Tingri, South Tibet & $90-85$ & 1.55 & -7.51 \\
\hline Tingri, South Tibet & $90-85$ & 1.51 & -5.38 \\
\hline Tingri, South Tibet & $90-85$ & 1.33 & -5.16 \\
\hline Tingri, South Tibet & $90-85$ & 1.18 & -6.58 \\
\hline Tingri, South Tibet & $90-85$ & 1.39 & -5.75 \\
\hline Tingri, South Tibet & $90-85$ & 1.49 & -7 \\
\hline Tingri, South Tibet & $90-85$ & 1.48 & -6.64 \\
\hline Tingri, South Tibet & $90-85$ & 1.34 & -5.31 \\
\hline Tingri, South Tibet & $90-85$ & 1.1 & -5.1 \\
\hline Tingri, South Tibet & $90-85$ & 1.5 & -5.69 \\
\hline Tingri, South Tibet & $90-85$ & 1.11 & -5.24 \\
\hline Tingri, South Tibet & $90-85$ & 0.97 & -5.34 \\
\hline Tingri, South Tibet & $90-85$ & 0.87 & -5.17 \\
\hline Tingri, South Tibet & $90-85$ & 1.51 & -7.27 \\
\hline Tingri, South Tibet & $90-85$ & 1.26 & -5.5 \\
\hline Tingri, South Tibet & $90-85$ & 1.35 & -5.36 \\
\hline Tingri, South Tibet & $90-85$ & 1.18 & -5.43 \\
\hline Tingri, South Tibet & $90-85$ & 1.29 & -5.18 \\
\hline Tingri, South Tibet & $90-85$ & 1.42 & -5.53 \\
\hline Tingri, South Tibet & $90-85$ & 1.51 & -6.51 \\
\hline Tingri, South Tibet & $90-85$ & 1.29 & -5.57 \\
\hline Tingri, South Tibet & $90-85$ & 1.32 & -5.19 \\
\hline Tingri, South Tibet & $90-85$ & 1.32 & -5.19 \\
\hline Tingri, South Tibet & $90-85$ & 1.66 & -5.43 \\
\hline
\end{tabular}


Tingri, South Tibet

Tingri, South Tibet

Tingri, South Tibet

Tingri, South Tibet

Tingri, South Tibet

Tingri, South Tibet

Tingri, South Tibet

Tingri, South Tibet

Tingri, South Tibet

Tingri, South Tibet
$90-85$
$90-85$
$90-85$
$90-85$
$90-85$
$90-85$
$90-85$
$90-85$
$90-85$
$90-85$

\begin{tabular}{|r|r|}
\hline 1.36 & -5.44 \\
\hline 1.14 & -5.45 \\
\hline 1.11 & -5.17 \\
\hline 1.19 & -6.94 \\
\hline 0.96 & -5.23 \\
\hline 1.09 & -5.49 \\
\hline 0.89 & -5.54 \\
\hline 1.48 & -6.15 \\
\hline 1.35 & -5.66 \\
\hline 2.7 & -6.61 \\
\hline
\end{tabular}

Inside Suture/Arc

Sample

Area

Leier et al. ( 2009)
Penbo, South Tibet

Penbo, South Tibet

PB-3-8B

PB-3-8C

PB-3-8D

PB3-8

PB3-8

PB3-8

PB3-8

PB-5-32A

PB-5-32B

PB-5-32C

PB-5-32D
Penbo, South Tibet

Penbo, South Tibet

Penbo, South Tibet

Penbo, South Tibet

Penbo, South Tibet

Penbo, South Tibet

Penbo, South Tibet

Penbo, South Tibet

Penbo, South Tibet

Penbo, South Tibet
Age

$\delta^{13} \mathrm{C}$ (VPDB)
$\mathbf{N}$

E 


\begin{tabular}{|c|c|c|c|c|c|c|}
\hline & & & & & 29 & 91 \\
\hline \multirow[t]{2}{*}{ JPB-1A } & Penbo, South Tibet & $100-90$ & 2.58 & -13.12 & 55.700 & 21.2 \\
\hline & & & & & 29 & 91 \\
\hline \multirow[t]{2}{*}{ JPB-1B } & Penbo, South Tibet & $100-90$ & 0.64 & -13.99 & 55.700 & 21.2 \\
\hline & & & & & 30 & 92 \\
\hline \multirow[t]{2}{*}{ JPB-2A } & Penbo, South Tibet & $100-90$ & 1.46 & -13.1 & 55.700 & 21.2 \\
\hline & & & & & 31 & 93 \\
\hline \multirow[t]{2}{*}{ JPB-2A } & Penbo, South Tibet & $100-90$ & 0.14 & -13.5 & 55.700 & 21.2 \\
\hline & & & & & 32 & 94 \\
\hline \multirow[t]{2}{*}{ JPB-2C } & Penbo, South Tibet & $100-90$ & 1.26 & -13.04 & 55.700 & 21.2 \\
\hline & & & & & 29 & 91 \\
\hline \multirow[t]{2}{*}{ JPB-16A } & Penbo, South Tibet & $100-90$ & -2.47 & -12.03 & 58.321 & 16.5 \\
\hline & & & & & 29 & 91 \\
\hline \multirow[t]{2}{*}{ JPB-16B } & Penbo, South Tibet & $100-90$ & 0.5 & -12.81 & 58.321 & 16.5 \\
\hline & & & & & 30 & 91 \\
\hline \multirow[t]{2}{*}{ AB5A } & Penbo, South Tibet & Jurassic & 3.23 & -7.54 & 02.259 & 16.3 \\
\hline & & & & & 30 & 91 \\
\hline \multirow[t]{2}{*}{$A B 5 B$} & Penbo, South Tibet & Jurassic & 3.37 & -7.91 & 02.259 & 16.3 \\
\hline & & & & & 30 & 91 \\
\hline \multirow[t]{2}{*}{$A B 5 C$} & Penbo, South Tibet & Jurassic & 3.27 & -8.58 & 02.259 & 16.3 \\
\hline & & & & & 30 & 91 \\
\hline \multirow[t]{2}{*}{$A B 5 D$} & Penbo, South Tibet & Jurassic & 3.14 & -8.39 & 02.259 & 16.3 \\
\hline & & & & & 29 & 90 \\
\hline \multirow[t]{2}{*}{$M Q-3 X-2 A$} & Penbo, South Tibet & $100-90$ & -3.9 & -14.72 & 58.326 & 45.73 \\
\hline & & & & & 29 & 90 \\
\hline \multirow[t]{2}{*}{$M Q-3 X-2 B$} & Penbo, South Tibet & $100-90$ & -4.09 & -14.85 & 58.326 & 45.739 \\
\hline & & & & & 29 & 90 \\
\hline \multirow[t]{2}{*}{$M Q-3 X-2 C$} & Penbo, South Tibet & $100-90$ & -3.97 & -14.87 & 58.326 & 45.73 \\
\hline & & & & & 29 & 90 \\
\hline \multirow[t]{2}{*}{$M Q-3 X-2 D$} & Penbo, South Tibet & $100-90$ & -4.12 & -20.92 & 58.326 & 45.73 \\
\hline & & & & & 29 & 90 \\
\hline \multirow[t]{2}{*}{ MQ3X-2 } & Penbo, South Tibet & $100-90$ & -3.38 & -14.43 & 58.326 & 45.739 \\
\hline & & & & & 29 & 90 \\
\hline \multirow[t]{2}{*}{ MQ3X-2 } & Penbo, South Tibet & $100-90$ & -4.03 & -14.58 & 58.326 & 45.73 \\
\hline & & & & & 29 & 90 \\
\hline \multirow[t]{2}{*}{ MQ3X-2 } & Penbo, South Tibet & $100-90$ & -3.8 & -14.62 & 58.326 & 45.73 \\
\hline & & & & & 29 & 90 \\
\hline \multirow[t]{2}{*}{ MQ3X-2 } & Penbo, South Tibet & $100-90$ & -6.26 & -21.76 & 58.326 & 45.739 \\
\hline & & & & & 29 & 90 \\
\hline \multirow[t]{2}{*}{ MQ3X-2 } & Penbo, South Tibet & $100-90$ & -4.64 & -19.63 & 58.326 & 45.73 \\
\hline & & & & & 29 & 90 \\
\hline \multirow[t]{2}{*}{ MQ3X-2 } & Penbo, South Tibet & $100-90$ & -4.37 & -14.64 & 58.326 & 45.7 \\
\hline & & & & & 30 & 91 \\
\hline NM2-410A & Penbo, South Tibet & $100-90$ & 0.32 & -12.85 & 42.511 & 05.3 \\
\hline
\end{tabular}




\begin{tabular}{|c|c|c|c|c|c|c|}
\hline & & & & & 31 & 92 \\
\hline \multirow[t]{2}{*}{ NM2-410B } & Penbo, South Tibet & $100-90$ & 0.4 & -13.33 & 42.511 & 05.389 \\
\hline & & & & & 32 & 93 \\
\hline \multirow[t]{2}{*}{ NM2-410C } & Penbo, South Tibet & $100-90$ & 0.43 & -13.25 & 42.511 & $05.3 \varepsilon$ \\
\hline & & & & & 33 & 94 \\
\hline \multirow{6}{*}{$\begin{array}{l}\text { AB-10 } \\
\text { this paper }\end{array}$} & Langshan Fm, South Tibet & $120-100$ & 0.97 & -15.45 & 42.511 & 05.38 \\
\hline & & & & & & \\
\hline & South Tibet & Paleogene & -7.25 & -11.37 & & \\
\hline & South Tibet & Paleogene & -7.07 & -12.55 & & \\
\hline & South Tibet & Paleogene & -3.3 & -17.51 & & \\
\hline & South Tibet & Paleogene & -3.93 & -16.83 & & \\
\hline L 95A-2 & South Tibet & 83 & -1.19 & -18.2 & 29.86 & 84. \\
\hline L 95B-1 & South Tibet & 83 & -5.47 & -18.37 & 29.86 & 84 \\
\hline L 95C-1 & South Tibet & 83 & -7.47 & -17.08 & 29.86 & \\
\hline L 95A-1 & South Tibet & 83 & -1.21 & -18.95 & 29.86 & 84 \\
\hline L97 A-2 & South Tibet & 83 & -11.27 & -15.43 & 29.86 & 84 \\
\hline L97 B-3 & South Tibet & 83 & -9.93 & -16.68 & 29.86 & 84 \\
\hline L97 C-2 & South Tibet & 83 & -10.21 & -15.16 & 29.86 & 84 \\
\hline L97 C-3 & South Tibet & 83 & -10.4 & -15.14 & 29.86 & 84 \\
\hline L97 C-1 & South Tibet & 83 & -2.83 & -17.74 & 29.86 & \\
\hline L97 B-1 & South Tibet & 83 & -10.25 & -16.88 & 29.86 & 84 \\
\hline L97 B-2 & South Tibet & 83 & -8.74 & -17.2 & 29.86 & \\
\hline L97 A-1 & South Tibet & 83 & -10.12 & -17.2 & 29.86 & \\
\hline L565 A-4 & South Tibet & 79 & -4.55 & -17.6 & 29.86 & \\
\hline L565 A-5 & South Tibet & 79 & -3.4 & -13.26 & 29.86 & 84 \\
\hline L565 A-1 & South Tibet & 79 & -1.14 & -16.53 & 29.86 & \\
\hline L565 A-2 & South Tibet & 79 & -2.18 & -17.8 & 29.86 & \\
\hline L565 A-3 & South Tibet & 79 & -1.9 & -12.45 & 29.86 & \\
\hline L652 A-1 & South Tibet & 79 & -0.23 & -17.17 & 29.86 & \\
\hline L652 A-2 & South Tibet & 79 & -2.78 & -17.6 & 29.86 & \\
\hline L652 A-3 & South Tibet & 79 & -2.56 & -17.29 & 29.86 & \\
\hline L703 A-1 & South Tibet & 79 & 0.86 & -9.49 & 29.86 & \\
\hline L703 A-2 & South Tibet & 79 & 0.6 & -13.63 & 29.86 & \\
\hline L703 A-3 & South Tibet & 79 & 0.15 & -15.65 & 29.86 & \\
\hline L703 A-4 & South Tibet & 79 & 0.51 & -14.52 & 29.86 & \\
\hline L757 A-2 & South Tibet & 79 & -0.14 & -14.47 & 29.86 & \\
\hline
\end{tabular}




\begin{tabular}{|c|c|c|c|c|c|}
\hline L757 A-3 & South Tibet & 79 & -0.23 & -14.33 & 29.86 \\
\hline L757 A-4 & South Tibet & 79 & -0.1 & -14.93 & 29.86 \\
\hline L757 A-1 & South Tibet & 79 & -0.48 & -16.12 & 29.86 \\
\hline L800 A-1 & South Tibet & 78 & 0.31 & -14.39 & 29.86 \\
\hline L800 A-2 & South Tibet & 78 & 1.45 & -12.43 & 29.86 \\
\hline L800 A-3 & South Tibet & 78 & -0.03 & -12.48 & 29.86 \\
\hline L800 A-4 & South Tibet & 78 & 0.97 & -11.71 & 29.86 \\
\hline L800 A-5 & South Tibet & 78 & 0.07 & -12.15 & 29.86 \\
\hline LH25-16(1) & Lhazi, South Tibet & 110 & -0.48 & -8.42 & 29.89 \\
\hline LH25-16(2) & Lhazi, South Tibet & 110 & -0.1 & -9.56 & 29.89 \\
\hline LP-3(1) & Lopu Kangri, South Tibet & 80 & -3.71 & -15.64 & 29.89 \\
\hline LP-3(2) & Lopu Kangri, South Tibet & 80 & -3.45 & -14.71 & 29.89 \\
\hline LP-5(1) & Lopu Kangri, South Tibet & 80 & 3.25 & -6.97 & 29.20 \\
\hline LP-5(2) & Lopu Kangri, South Tibet & 80 & 3.16 & -7.26 & 29.20 \\
\hline LP-5(3) & Lopu Kangri, South Tibet & 80 & 3.21 & -10.82 & 29.86 \\
\hline LH-29-110(1) & Lhazi, South Tibet & 99 & -0.89 & -10.39 & 29.21 \\
\hline LH29-110(2) & Lhazi, South Tibet & 99 & 0.63 & -9.24 & 29.21 \\
\hline LH25-FOSS-1A & Lhazi, South Tibet & 100 & 0.46 & -10.96 & 29.21 \\
\hline LH25-FOSS-1B & Lhazi, South Tibet & 100 & 0.34 & -11.29 & 29.21 \\
\hline LH25-FOSS-2A & Lhazi, South Tibet & 100 & 0.45 & -12.52 & 29.21 \\
\hline LH25-FOSS-2B & Lhazi, South Tibet & 100 & 1.2 & -10.09 & 29.21 \\
\hline LH25FOSS(3) & Lhazi, South Tibet & 100 & 0.4 & -12.76 & 29.21 \\
\hline LH25FOSS(4) & Lhazi, South Tibet & 100 & 0.44 & -12.45 & 29.21 \\
\hline GYEDOJQ 8-A1 & Gyedo, Kailas & NA & 2.5 & -6.7 & 29.542 \\
\hline GYEDOJQ 8-A2 & Gyedo, Kailas & NA & 2.9 & -7.2 & 29.542 \\
\hline GYEDOJQ 8-B1 & Gyedo, Kailas & NA & 2.1 & -7.4 & 29.542 \\
\hline GYEDOJQ 8-B2 & Gyedo, Kailas & NA & 1.9 & -9.3 & 29.542 \\
\hline GYEDOJQ 8-C1 & Gyedo, Kailas & NA & 3.2 & -7.7 & 29.542 \\
\hline 1DK-18-A1 & Dazhuka & NA & 3.3 & -20.8 & 29.308 \\
\hline 1DK-18-B1 & Dazhuka & NA & 1.1 & -20.3 & 29.308 \\
\hline 1DK-18-A2 & Dazhuka & NA & 2.9 & -20.7 & 29.308 \\
\hline 1DK-18-C1 & Dazhuka & NA & 3.2 & -16.1 & 29.308 \\
\hline 1DK-18-D1 & Dazhuka & NA & -1.0 & -20.5 & 29.308 \\
\hline 1DK-426-A1 & Dazhuka & NA & 4.3 & -20.9 & 29.305 \\
\hline 1DK-426-A2 & Dazhuka & NA & 4.4 & -20.5 & 29.305 \\
\hline
\end{tabular}




\begin{tabular}{|c|c|c|c|c|c|c|}
\hline 1DK-426-A3 & Dazhuka & NA & 2.8 & -17.1 & 29.305 & 89.82 \\
\hline 6.17.12.1-B1 & Kailas, Mt. Kailas region & NA & 4.3 & -15.5 & 30.861 & 81 \\
\hline 6.17.12.1-C1 & Kailas, Mt. Kailas region & NA & 0.3 & -12.2 & 30.861 & 81. \\
\hline 6.17.12.1-D1 & Kailas, Mt. Kailas region & NA & 0.3 & -16.0 & 30.861 & 81. \\
\hline 6.17.12.1-A1 & Kailas, Mt. Kailas region & NA & 0.9 & -11.0 & 30.861 & \\
\hline 4YA-219-A1 & Kailas, Mt. Kailas region & NA & 2.2 & -18.4 & 30.789 & 81. \\
\hline 4YA-219-B1 & Kailas, Mt. Kailas region & NA & 1.8 & -14.7 & 30.789 & 81. \\
\hline 4YA-219-C1 & Kailas, Mt. Kailas region & NA & 2.0 & -17.9 & 30.789 & 81. \\
\hline 4YA-389-A1 & Kailas, Mt. Kailas region & NA & 1.6 & -16.0 & 30.787 & 81. \\
\hline 4YA-389-B1 & Kailas, Mt. Kailas region & NA & 2.1 & -16.0 & 30.787 & \\
\hline 4YA-389-B2 & Kailas, Mt. Kailas region & NA & 4.0 & -10.9 & 30.787 & 81. \\
\hline 4YA-389-C1 & Kailas, Mt. Kailas region & NA & 1.3 & -16.0 & 30.787 & 81. \\
\hline $4 Y A-471 A-A 1$ & Kailas, Mt. Kailas region & NA & -1.9 & -17.0 & 30.786 & 81. \\
\hline 4YA-471A-B1 & Kailas, Mt. Kailas region & NA & -1.6 & -16.7 & 30.786 & 81. \\
\hline 4YA-471B-A1 & Kailas, Mt. Kailas region & NA & 1.6 & -17.2 & 30.786 & 81. \\
\hline 4YA-471B-B1 & Kailas, Mt. Kailas region & NA & 0.9 & -17.7 & 30.786 & 81. \\
\hline \multirow[t]{2}{*}{ 4YA-471B-C1 } & Kailas, Mt. Kailas region & NA & 1.4 & -17.1 & 30.786 & \\
\hline & Kailas, Mt. Kailas region & NA & & & & \\
\hline 4YA-13-A1 & Kailas, Mt. Kailas region & NA & -2.6 & -23.6 & 30.793 & 81. \\
\hline 4YA-13-B1 & Kailas, Mt. Kailas region & NA & -2.2 & -21.1 & 30.793 & 81. \\
\hline 4YA-13-C1 & Kailas, Mt. Kailas region & NA & 0.6 & -21.6 & 30.793 & \\
\hline TP12-5-A1 & Kailas, Mt. Kailas region & NA & 0.1 & -16.1 & 31.198 & 80.5 \\
\hline TP12-5-B1 & Kailas, Mt. Kailas region & NA & -0.1 & -14.2 & 31.198 & 80. \\
\hline TP12-5-C1 & Kailas, Mt. Kailas region & NA & 0.9 & -16.3 & 31.198 & 80. \\
\hline TP12-5-E1 & Kailas, Mt. Kailas region & NA & 1.4 & -15.3 & 31.198 & 80. \\
\hline TP12-5-G1 & Kailas, Mt. Kailas region & NA & 1.9 & -16.1 & 31.198 & 80 \\
\hline TP12-5-I1 & Kailas, Mt. Kailas region & NA & 1.1 & -14.5 & 31.198 & 80. \\
\hline TP12-5-J1 & Kailas, Mt. Kailas region & NA & 0.3 & -16.5 & 31.198 & \\
\hline D1 TP12-5 & Kailas, Mt. Kailas region & NA & 1.9 & -15.7 & 31.198 & \\
\hline F1 TP12-5 & Kailas, Mt. Kailas region & NA & 1.6 & -15.5 & 31.198 & 80. \\
\hline
\end{tabular}


Table S2 Isotopic results from the Xigaze forearc sequence

\begin{tabular}{|c|c|c|c|c|c|c|}
\hline SAMPLE ID & $\mathbf{N}^{\circ}$ & $E^{\circ}$ & $\begin{array}{c}\delta^{13} \mathrm{C} \\
\text { VPDB }\end{array}$ & $\begin{array}{c}\delta^{18} 0 \\
\text { VPDB }\end{array}$ & area & material \\
\hline L14 A-2 & 29.86 & 84.83 & -11.1 & -13.3 & Lopu Kangri & paleosol car \\
\hline L14 B-1 & 29.86 & 84.83 & -10.1 & -14.5 & Lopu Kangri & paleosol car \\
\hline L14 B-2 & 29.86 & 84.83 & -10.2 & -14.8 & Lopu Kangri & paleosol car \\
\hline L14 C-1 & 29.86 & 84.83 & -10.2 & -13.8 & Lopu Kangri & paleosol ca \\
\hline L14 A-3 & 29.86 & 84.83 & -9.4 & -15.5 & Lopu Kangri & paleosol ca \\
\hline L14 B-3 & 29.86 & 84.83 & -9.4 & -15.3 & Lopu Kangri & paleosol ca \\
\hline L14 C-2 & 29.86 & 84.83 & -9.9 & -15.4 & Lopu Kangri & paleosol carbo \\
\hline L14 C-3 & 29.86 & 84.83 & -10.1 & -15.7 & Lopu Kangri & paleosol car \\
\hline LP-2(1) & 29.89 & 84.74 & -10.2 & -19.8 & Lopu Kangri & paleosol car \\
\hline LP-2(2) & 29.89 & 84.74 & -9.9 & -22.8 & Lopu Kangri & paleosol car \\
\hline LP-2(3) & 29.89 & 84.74 & -10.8 & -22.2 & Lopu Kangri & paleosol car \\
\hline $\mathrm{H}-57(1)$ & 29.89 & 84.72 & -11.2 & -11.7 & Lopu Kangri & paleosol car \\
\hline $\mathrm{H}-57(2)$ & 29.89 & 84.72 & -11.2 & -10.8 & Lopu Kangri & paleosol car \\
\hline$H-57(3)$ & 29.89 & 84.72 & -11.5 & -11.0 & Lopu Kangri & paleosol car \\
\hline L 95A-2 & 29.86 & 84.83 & -1.2 & -18.2 & Lopu Kangri & wackest \\
\hline L 95B-1 & 29.86 & 84.83 & -5.5 & -18.4 & Lopu Kangri & wackest \\
\hline L 95C-1 & 29.86 & 84.83 & -7.5 & -17.1 & Lopu Kangri & wackest \\
\hline L 95A-1 & 29.86 & 84.83 & -1.2 & -19.0 & Lopu Kangri & wackest \\
\hline L97 A-2 & 29.86 & 84.83 & -11.3 & -15.4 & Lopu Kangri & intraclastic pa \\
\hline L97 B-3 & 29.86 & 84.83 & -9.9 & -16.7 & Lopu Kangri & intraclastic pa \\
\hline L97 C-2 & 29.86 & 84.83 & -10.2 & -15.2 & Lopu Kangri & intraclastic pa \\
\hline L97 C-3 & 29.86 & 84.83 & -10.4 & -15.1 & Lopu Kangri & intraclastic pa \\
\hline L97 C-1 & 29.86 & 84.83 & -2.8 & -17.7 & Lopu Kangri & intraclastic pa \\
\hline L97 B-1 & 29.86 & 84.83 & -10.2 & -16.9 & Lopu Kangri & intraclastic pa \\
\hline L97 B-2 & 29.86 & 84.83 & -8.7 & -17.2 & Lopu Kangri & intraclastic pa \\
\hline L97 A-1 & 29.86 & 84.83 & -10.1 & -17.2 & Lopu Kangri & intraclastic pa \\
\hline L565 A-4 & 29.86 & 84.83 & -4.6 & -17.6 & Lopu Kangri & fossiliferous lim \\
\hline L565 A-5 & 29.86 & 84.83 & -3.4 & -13.3 & Lopu Kangri & fossiliferous lim \\
\hline L565 A-1 & 29.86 & 84.83 & -1.1 & -16.5 & Lopu Kangri & fossiliferous lir \\
\hline L565 A-2 & 29.86 & 84.83 & -2.2 & -17.8 & Lopu Kangri & fossiliferous li \\
\hline
\end{tabular}




\begin{tabular}{|c|c|c|c|c|c|}
\hline L565 A-3 & 29.86 & 84.83 & -1.9 & -12.4 & Lopu Kangri \\
\hline L652 A-1 & 29.86 & 84.83 & -0.2 & -17.2 & Lopu Kangri \\
\hline L652 A-2 & 29.86 & 84.83 & -2.8 & -17.6 & Lopu Kangri \\
\hline L652 A-3 & 29.86 & 84.83 & -2.6 & -17.3 & Lopu Kangri \\
\hline L703 A-1 & 29.86 & 84.83 & 0.9 & -9.5 & Lopu Kangri \\
\hline L703 A-2 & 29.86 & 84.83 & 0.6 & -13.6 & Lopu Kangri \\
\hline L703 A-3 & 29.86 & 84.83 & 0.1 & -15.6 & Lopu Kangri \\
\hline L703 A-4 & 29.86 & 84.83 & 0.5 & -14.5 & Lopu Kangri \\
\hline L757 A-2 & 29.86 & 84.83 & -0.1 & -14.5 & Lopu Kangri \\
\hline L757 A-3 & 29.86 & 84.83 & -0.2 & -14.3 & Lopu Kangri \\
\hline L757 A-4 & 29.86 & 84.83 & -0.1 & -14.9 & Lopu Kangri \\
\hline L757 A-1 & 29.86 & 84.83 & -0.5 & -16.1 & Lopu Kangri \\
\hline L800 A-1 & 29.86 & 84.83 & 0.3 & -14.4 & Lopu Kangri \\
\hline L800 A-2 & 29.86 & 84.83 & 1.4 & -12.4 & Lopu Kangri \\
\hline L800 A-3 & 29.86 & 84.83 & 0.0 & -12.5 & Lopu Kangri \\
\hline L800 A-4 & 29.86 & 84.83 & 1.0 & -11.7 & Lopu Kangri \\
\hline L800 A-5 & 29.86 & 84.83 & 0.1 & -12.1 & Lopu Kangri \\
\hline LP-9(1) & 29.89 & 84.74 & -7.3 & -11.4 & Lopu Kangri \\
\hline LP-9(2) & 29.89 & 84.74 & -7.1 & -12.6 & Lopu Kangri \\
\hline LP-12(1) & 29.89 & 84.74 & -3.3 & -17.5 & Lopu Kangri \\
\hline LP-12(2) & 29.89 & 84.74 & -3.9 & -16.8 & Lopu Kangri \\
\hline LH25-16(1) & 29.20 & 87.91 & -0.5 & -8.4 & Lazi \\
\hline LH25-16(2) & 29.20 & 87.91 & -0.1 & -9.6 & Lazi \\
\hline LP-3(1) & 29.86 & 84.83 & -3.7 & -15.6 & Lopu Kangri \\
\hline LP-3(2) & 29.86 & 84.83 & -3.5 & -14.7 & Lopu Kangri \\
\hline
\end{tabular}

fossiliferous lim

dirty limestc dirty limesto dirty limesto

wackeston wackeston wackeston wackeston

algal ? limest algal ? limest algal ? limest algal ? limest

fossiliferou mudstone fossiliferou mudstone fossiliferou mudstone fossiliferou mudstone fossiliferou mudstone

fossiliferou sandstone fossiliferou sandstone limestone limestone

wackeston wackeston limestone limestone 


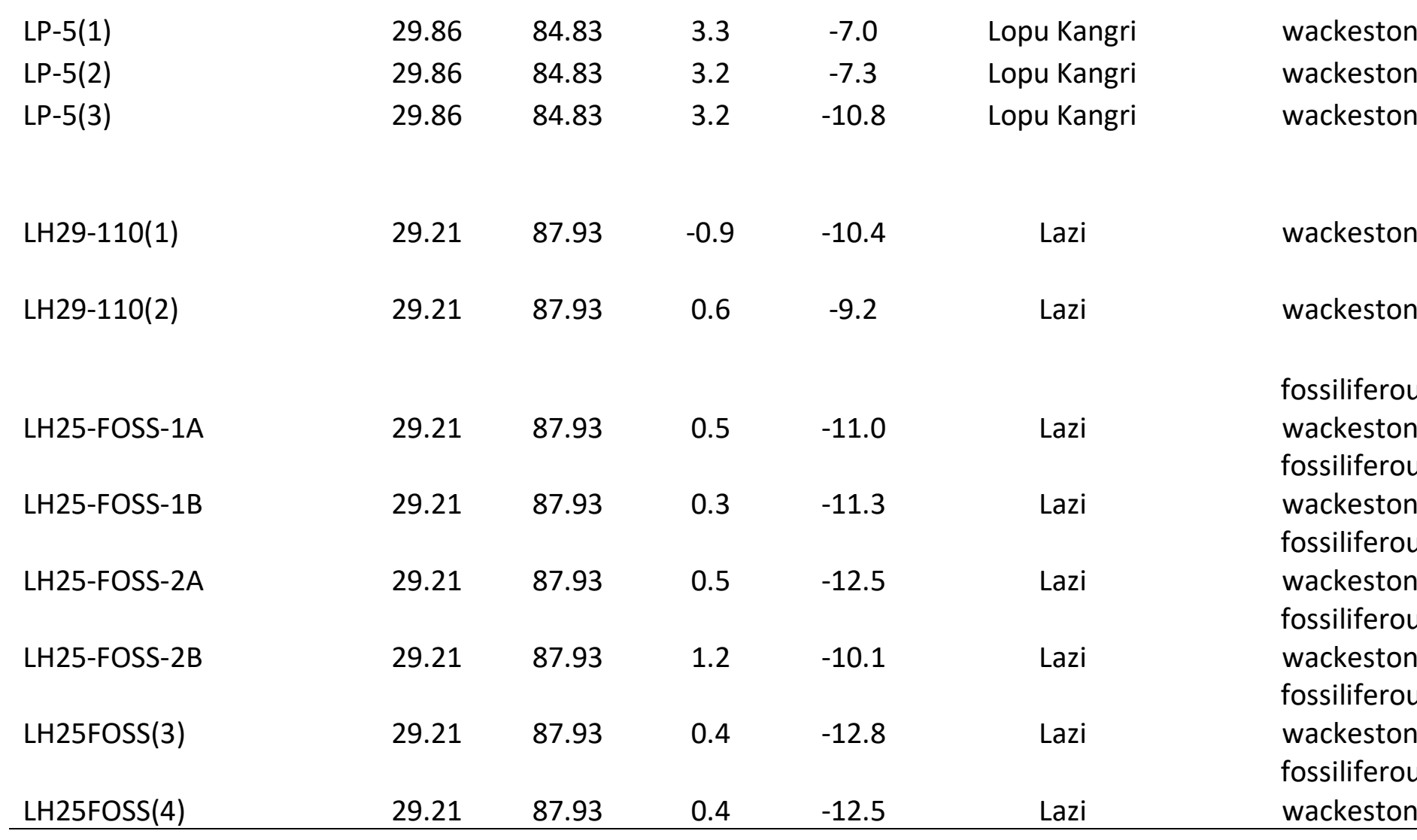

* capital letter refers to section, and number to stratigraphuic height in sections shiown in Orme and Laskowsl 
Table S3 Stable isotope results from fresh-water carbonates from the Nianbo Formation at Linzhou.

\begin{tabular}{lcccccl}
\multicolumn{1}{c}{ sample \# } & ${ }^{\mathbf{}} \mathbf{N}$ & ${ }^{\circ} \mathbf{E}$ & $\begin{array}{c}\text { elevation } \\
(\mathbf{m})\end{array}$ & $\begin{array}{c}\boldsymbol{\delta}^{\mathbf{1 3}} \mathbf{C} \\
\text { VPDB }\end{array}$ & $\begin{array}{c}\boldsymbol{\delta}^{\mathbf{1 8} \mathbf{O}} \\
\text { VPDB }\end{array}$ & material \\
PENBO 21 (1) & 29.972 & 91.194 & 3993 & -3.81 & -13.77 & matrix \\
PENBO 19A (1) & 29.971 & 91.213 & 4083 & -0.76 & -8.82 & matrix \\
PENBO-19A(2) & 29.971 & 91.213 & 4083 & -0.50 & -15.36 & matrix \\
PENBO 19B (1) & 29.971 & 91.213 & 4083 & -0.70 & -15.33 & matrix \\
PENBO 19C (1) & 29.971 & 91.213 & 4083 & -1.60 & -13.59 & matrix \\
PENBO 23 (1) & 29.971 & 91.203 & 4136 & -2.85 & -13.56 & matrix \\
PENBO 23 (2) & 29.971 & 91.203 & 4136 & -2.42 & -19.81 & spar \\
PENBO 24 (1) & 29.979 & 91.205 & 4080 & -1.35 & -17.63 & red matrix \\
PENBO 24 (2) & 29.979 & 91.205 & 4080 & -1.37 & -20.80 & spar \\
SHAR1-146(1) & 29.974 & 91.915 & 4031 & -2.16 & -16.69 & tuffaceous \\
SHAR1-68(1) & 29.973 & 91.237 & 4038 & -2.57 & -12.43 & matrix \\
SHAR1-4.7(1) & 29.973 & 91.237 & 4038 & -1.16 & -14.57 & matrix \\
SHAR1-12.5(1) & 29.972 & 91.194 & 3993 & -3.06 & -13.78 & matrix \\
SHAR1-2M(1) & 29.972 & 91.194 & 3993 & -0.12 & -14.56 & matrix \\
SHAR1-16(1) & 29.972 & 91.194 & 3993 & -1.63 & -15.56 & matrix \\
SHAR1-20(1) & 29.972 & 91.194 & 3993 & -0.84 & -16.93 & calcareous tuff \\
SHAR1-0.5(1) & 29.972 & 91.194 & 3993 & -1.88 & -11.15 & Matrix
\end{tabular}


Table S4 Stable isotope results from carbonates of the Luiqu Conglomerate

\begin{tabular}{|c|c|c|c|c|c|c|}
\hline sample \# & $\mathbf{N}^{\circ}$ & $\mathbf{E}^{\circ}$ & $\begin{array}{c}\text { elevation } \\
(\mathrm{m})\end{array}$ & $\begin{array}{c}\delta^{13} \mathrm{C} \\
\text { VPDB }\end{array}$ & $\begin{array}{c}\delta^{18} O \\
\text { VPDB }\end{array}$ & material \\
\hline 1LQ473 A1 & 29.12652 & 88.56059 & & -10.2 & -16.9 & paleosol carbonate \\
\hline 1LQ473 A2 & 29.12652 & 88.56059 & & -10.3 & -16.3 & paleosol carbonate \\
\hline 1LQ473 B1 & 29.12652 & 88.56059 & & -11.3 & -16.5 & paleosol carbonate \\
\hline 1LQ473 C1 & 29.12652 & 88.56059 & & -10.2 & -16.7 & paleosol carbonate \\
\hline 1LQ473 C2 & 29.12652 & 88.56059 & & -10.3 & -17.0 & paleosol carbonate \\
\hline 1LQ474 A1 & 29.12652 & 88.56059 & & -10.4 & -16.5 & paleosol carbonate \\
\hline 1LQ474 B1 & 29.12652 & 88.56059 & & -10.7 & -16.6 & paleosol carbonate \\
\hline 1LQ474 B2 & 29.12652 & 88.56059 & & -10.7 & -16.8 & paleosol carbonate \\
\hline 1LQ475 A2 & 29.12652 & 88.56059 & & -9.9 & -16.9 & paleosol carbonate \\
\hline 1LQ475 A3 & 29.12652 & 88.56059 & & -10.9 & -17.3 & paleosol carbonate \\
\hline 1LQ475 B1 & 29.12652 & 88.56059 & & -9.7 & -16.8 & paleosol carbonate \\
\hline 1LQ475 C1 & 29.12652 & 88.56059 & & -10.2 & -16.6 & paleosol carbonate \\
\hline 1LQ475 C2 & 29.12652 & 88.56059 & & -11.9 & -17.8 & paleosol carbonate \\
\hline 1LQ730 B1 & 29.12652 & 88.56059 & & -9.2 & -17.0 & paleosol carbonate \\
\hline 1LQ730 B2 & 29.12652 & 88.56059 & & -9.1 & -17.0 & paleosol carbonate \\
\hline 1LQ730 C1 & 29.12652 & 88.56059 & & -9.1 & -16.7 & paleosol carbonate \\
\hline 1LQ730 C2 & 29.12652 & 88.56059 & & -9.7 & -17.3 & paleosol carbonate \\
\hline 1LQ821 A1 & 29.12652 & 88.56059 & & -8.7 & -17.8 & paleosol carbonate \\
\hline 1LQ821 A2 & 29.12652 & 88.56059 & & -9.1 & -18.0 & paleosol carbonate \\
\hline 1LQ821 B1 & 29.12652 & 88.56059 & & -9.3 & -17.8 & paleosol carbonate \\
\hline 1LQ821 B2 & 29.12652 & 88.56059 & & -9.9 & -18.2 & paleosol carbonate \\
\hline 1LQ821 C1 & 29.12652 & 88.56059 & & -9.4 & -17.8 & paleosol carbonate \\
\hline 1LQ821 C2 & 29.12652 & 88.56059 & & -9.4 & -18.0 & paleosol carbonate \\
\hline 1LQ705-A-1 & 29.12652 & 88.56059 & & -8.5 & -17.3 & paleosol carbonate \\
\hline 1LQ705-B-1 & 29.12652 & 88.56059 & & -9.4 & -16.2 & paleosol carbonate \\
\hline 1LQ705-B-2 & 29.12652 & 88.56059 & & -8.1 & -15.9 & paleosol carbonate \\
\hline 10LQ-84-A1 & 29.19395 & 87.91682 & & -7.3 & -9.9 & paleosol carbonate \\
\hline 10LQ-84-A2 & 29.19395 & 87.91682 & & -7.6 & -9.1 & paleosol carbonate \\
\hline 10LQ-84-B1 & 29.19395 & 87.91682 & & -7.2 & -14.3 & paleosol carbonate \\
\hline 10LQ-84-B2 & 29.19395 & 87.91682 & & -7.6 & -14.3 & paleosol carbonate \\
\hline 10LQ-84-C1 & 29.19395 & 87.91682 & & -7.9 & -13.6 & paleosol carbonate \\
\hline 10LQ-84-C2 & 29.19395 & 87.91682 & & -8.6 & -14.0 & paleosol carbonate \\
\hline 10LQ-84-D1 & 29.19395 & 87.91682 & & -7.5 & -14.7 & paleosol carbonate \\
\hline 10LQ-84-D2 & 29.19395 & 87.91682 & & -7.8 & -14.5 & paleosol carbonate \\
\hline 6LQ130-A-1 & 29.16222 & 88.15038 & & -9.9 & -20.1 & paleosol carbonate \\
\hline 6LQ130-A-2 & 29.16222 & 88.15038 & & -9.0 & -18.1 & paleosol carbonate \\
\hline
\end{tabular}




$\begin{array}{cccccl}\text { 6LQ130-B-1 } & 29.16222 & 88.15038 & -9.5 & -19.4 & \text { paleosol carbonate } \\ \text { 6LQ130-B-2 } & 29.16222 & 88.15038 & -9.2 & -18.2 & \text { paleosol carbonate } \\ \text { 7LQ165-A-1 } & 29.16373 & 88.13858 & -9.4 & -17.7 & \text { paleosol carbonate } \\ \text { 4LQ47-A-1 } & 29.20077 & 87.65878 & -10.6 & -11.7 & \text { paleosol carbonate } \\ \text { 4LQ47-A-2 } & 29.20077 & 87.65878 & -10.8 & -12.4 & \text { paleosol carbonate } \\ \text { 4LQ47-B-1 } & 29.20077 & 87.65878 & -10.2 & -12.5 & \text { paleosol carbonate } \\ \text { 4LQ47-B-2 } & 29.20077 & 87.65878 & -8.5 & -12.0 & \text { paleosol carbonate } \\ & & & & & \\ \text { 7LQ150-A-1 } & 29.16373 & 88.13858 & 1.2 & -14.0 & \text { limestone clast } \\ \text { 7LQ150-A-3 } & 29.16373 & 88.13858 & -0.7 & -14.9 & \text { limestone clast } \\ \text { 6LQ63-A-1 } & 29.16222 & 88.15038 & 0.7 & -8.5 & \text { limestone clast } \\ \text { 6LQ63-A-2 } & 29.16222 & 88.15038 & 0.2 & -9.8 & \text { limestone clast } \\ \text { 6LQ63-B-1 } & 29.16222 & 88.15038 & 0.7 & -13.5 & \text { limestone clast } \\ \text { 6LQ63-B-2 } & 29.16222 & 88.15038 & 0.8 & -13.7 & \text { limestone clast } \\ \text { 6LQ63-C-1 } & 29.16222 & 88.15038 & -0.1 & -13.1 & \text { limestone clast } \\ \text { 6LQ63-C-2 } & 29.16222 & 88.15038 & -0.9 & -13.5 & \text { limestone clast } \\ \text { 5LQ150-A-2 } & 29.17368 & 88.15565 & 1.8 & -13.3 & \text { limestone clast } \\ \text { 5LQ636-A-1 } & 29.17368 & 88.15565 & 0.9 & -13.2 & \text { limestone clast } \\ \text { 5LQ636-A-2 } & 29.17368 & 88.15565 & 1.4 & -13.5 & \text { limestone clast } \\ \text { 5LQ636-B-1 } & 29.17368 & 88.15565 & 1.0 & -13.5 & \text { limestone clast } \\ \text { 5LQ636-B-2 } & 29.17368 & 88.15565 & -8.2 & -11.8 & \text { limestone clast } \\ \text { 5LQ636-C-1 } & 29.17368 & 88.15565 & -0.3 & -12.1 & \text { limestone clast } \\ \text { 5LQ636-C-2 } & 29.17368 & 88.15565 & -0.3 & -11.7 & \text { limestone clast } \\ \text { 5LQ636-D-1 } & 29.17368 & 88.15565 & -6.8 & -15.6 & \text { limestone clast } \\ \text { 5LQ636-D-2 } & 29.17368 & 88.15565 & -14.7 & \text { limestone clast } \\ \text { 4LQ115-A-1 } & 29.20077 & 87.65878 & -13.0 & \text { paleosol clast } \\ \text { 4LQ115-A-2 } & 29.20077 & 87.65878 & -12.8 & \text { paleosol clast } \\ & & & & \end{array}$


Table S5 Carbon and oxygen isotope results from the Kailas Formation

\begin{tabular}{|c|c|c|c|c|c|c|}
\hline sample \# & $\mathbf{N}^{\circ}$ & $E^{\circ}$ & $\begin{array}{c}\text { elevation } \\
(\mathrm{m}) \\
\end{array}$ & $\begin{array}{c}\delta^{13} \mathrm{C} \\
\text { VPDB } \\
\end{array}$ & $\begin{array}{r}\delta^{18} O \\
\text { VPDB } \\
\end{array}$ & mate \\
\hline \multicolumn{7}{|l|}{ Gyedo } \\
\hline GYEDOJQ 1-B1 & 29.528 & 86.542 & 4738 & -7.0 & -19.6 & carb \\
\hline GYEDOJQ1-1A & 29.528 & 86.542 & 4738 & -7.2 & -20.3 & carb \\
\hline GYEDOJQ 1-A2 & 29.528 & 86.542 & 4738 & -6.8 & -19.9 & cark \\
\hline GYEDOJQ 1-A3 & 29.528 & 86.542 & 4738 & -7.2 & -20.3 & car \\
\hline GYED JQ 1-B1 & 29.528 & 86.542 & 4738 & -7.1 & -19.7 & car \\
\hline GYEDOJQ-1-C1 & 29.528 & 86.542 & 4738 & -6.8 & -19.8 & cark \\
\hline GYEDOJQ 3-A1 & 29.526 & 86.542 & 4713 & -8.2 & -21.6 & car \\
\hline GYEDOJQ 3-A2 & 29.526 & 86.542 & 4713 & -8.2 & -20.1 & \\
\hline GYEDOJQ 3-A3 & 29.526 & 86.542 & 4713 & -8.1 & -19.9 & \\
\hline GYEDOJQ 3-B1 & 29.526 & 86.542 & 4713 & -8.5 & -20.1 & \\
\hline GYEDOJQ 3-C1 & 29.526 & 86.542 & 4713 & -8.2 & -19.9 & car \\
\hline GYEDO-JQ-10-A1 & 29.541 & 86.465 & 4801 & -7.5 & -11.3 & fres \\
\hline GYEDO-JQ-10-A2 & 29.541 & 86.465 & 4801 & -10.1 & -8.7 & fres \\
\hline GYEDO-JQ-10-A3 & 29.541 & 86.465 & 4801 & -14.5 & -10.6 & fres \\
\hline GYEDO-JQ-10-B1 & 29.541 & 86.465 & 4801 & -9.8 & -7.3 & fres \\
\hline GYEDO-JQ-10-C1 & 29.541 & 86.465 & 4801 & -13.4 & -11.5 & fres \\
\hline GYEDOJQ 8-A1 & 29.542 & 86.463 & 4881 & 2.5 & -6.7 & lime \\
\hline GYEDOJQ 8-A2 & 29.542 & 86.463 & 4881 & 2.9 & -7.2 & lime \\
\hline GYEDOJQ 8-B1 & 29.542 & 86.463 & 4881 & 2.1 & -7.4 & lime \\
\hline GYEDOJQ 8-B2 & 29.542 & 86.463 & 4881 & 1.9 & -9.3 & lime \\
\hline GYEDOJQ 8-C1 & 29.542 & 86.463 & 4881 & 3.2 & -7.7 & lime \\
\hline GY-MD-4-A1 & 29.529 & 86.542 & 4744 & -6.4 & -20.6 & san \\
\hline GY-MD-4-A2 & 29.529 & 86.542 & 4744 & -6.2 & -20.0 & san \\
\hline GY-MD-4-B1 & 29.529 & 86.542 & 4744 & -6.7 & -21.2 & sanc \\
\hline GY-MD-4-B2 & 29.529 & 86.542 & 4744 & -6.7 & -20.2 & san \\
\hline GY-MD-4-C1 & 29.529 & 86.542 & 4744 & -6.4 & -20.1 & san \\
\hline GY-MD-5-A1 & NA & NA & & -8.9 & -22.3 & \\
\hline
\end{tabular}


GY-MD-5-A3

3GY-144-B1

3GY-144-B2

3GY-144-A1

3GY-144-A2

3GY-144-A3

3GY-375-A1

3GY-375-A2

3GY-375-A3

3GY-375-B1

3GY-375-C1

6GY-29.6-A1

6GY-29.6-A2

6GY-29.6-A3

6GY-29.6-B1

6GY-29.6-C1

6GY-28.5-A1

6GY-28.5-A2

6GY-28.5-A3

6GY-28.5-B1

6GY-28.5-C1

6GY-17.5-A1

6GY-17.5-A2

6GY-17.5-A3

6GY-17.5-B1

6GY-17.5-C1

6GY-2.8-A3

6GY-2.8-B1

GYEDOJQ 2-A1

GYEDOJQ 2-A1

GYEDOJQ 2-A2

GYEDOJQ 2-A3
NA NA

NA

NA

29.528

29.528

29.528

29.528

29.528

29.528

29.528

29.528

29.528

29.528

29.528

29.528

29.528

29.528

29.528

29.528

29.528

29.528

29.528

29.528

29.528

29.528

29.528

29.528

29.528

29.528

29.528

29.528

29.528

29.528

29.528
$-8.8$

$-9.1$

4738

4738

4738

4738

4738

4738

4738

4738

4738

4738

4738

4738

4738

4738

4738

4738

4738

4738

4738

4738

4738

4738

4738

4738

4738

4738

4738

4738

4738

4738

4738
-20.8 sandst

-21.5 sandst

$3.2 \quad-17.0$ sands

$3.2 \quad-17.7$ sands

$2.2 \quad-20.3 \quad$ sands

$4.0 \quad-18.5$ sands

$\begin{array}{lll}1.8 & -20.9 & \text { sands }\end{array}$

$\begin{array}{lll}-1.3 & -15.5 & \text { sands }\end{array}$

$-1.3 \quad-16.5$ sands

$-1.2 \quad-15.6$ sands

$-2.4 \quad-18.0$ sands

-2.1 $\quad-15.4$ sands

$-7.8 \quad-20.4 \quad$ sands

$-7.9 \quad-20.4 \quad$ sands

$-6.9 \quad-18.8$ sands

$-7.6 \quad-20.5$ sands

-7.6 -20.3 sands

$\begin{array}{lll}-7.9 & -20.7 & \text { sands }\end{array}$

$-6.9 \quad-19.1$ sands

$-7.4 \quad-20.3$ sands

$-7.5 \quad-20.0$ sands

$-7.2 \quad-19.9$ sands

$-7.1 \quad-19.1$ sands

$\begin{array}{lll}-7.0 & -19.2 & \text { sands }\end{array}$

$-7.1 \quad-21.2$ sands

$-7.6 \quad-20.6$ sands

$-7.2 \quad-19.3$ sands

$-7.1 \quad-21.2 \quad$ sands

$\begin{array}{lll}-7.9 & -20.2 & \text { sands }\end{array}$

-6.8 -20.4 rhizol

$-6.5 \quad-20.3$ rhizol

$-6.6 \quad-20.0$ rhizoli

$\begin{array}{lll}-6.9 & -20.2 \quad \text { rhizol }\end{array}$ 
GYEDOJQ 2-B1

GYEDOJQ 2-C1

GYEDOJQ 5-A1

GYEDOJQ 5-A2

GYEDOJQ 5-B1

GYEDO JQ 5-C1

GYEDOJQ 6A-A1

GYEDOJQ 6A-A2

GYEDOJQ 6A-A3

GYEDOJQ 6A-B1

GYEDOJQ 6A-C1

GYEDOJQ 6B-A1

GYEDOJQ 6B-A2

GYEDOJQ 6B-B1

GYEDOJQ 6B-C1

GYEDO JQ-6b-A3

4GY-425-B1

4GY-425-C1

4GY-461.7-A3

4GY-461.7-A2

4GY-461.7-B1

4GY-467.1-B2

4GY-425-A3

4GY-425-A1

5GY-20.8-A1

5GY-20.8-A1

5GY-20.8-A2

5GY-20.8-B1

5GY-20.8-B2

5GY-20.8-C1

6GY-20.5-B1

6GY-20.5-C1

6GY-20.5-A3
29.528

29.528

29.529

29.529

29.529

29.529

29.529

29.529

29.529

29.529

29.529

29.529

29.529

29.529

29.529

29.529

29.528

29.528

29.528

29.528

29.528

29.528

29.528

29.528

29.528

29.528

29.528

29.528

29.528

29.528

29.528

29.528

29.528
86.542

86.542

86.496

86.496

86.496

86.496

86.496

86.496

86.496

86.496

86.496

86.496

86.496

86.496

86.496

86.496

86.542

86.542

86.542

86.542

86.542

86.542

86.542

86.542

86.542

86.542

86.542

86.542

86.542

86.542

86.542

86.542

86.542
4738

4738

4735

4735

4735

4735

4735

4735

4735

4735

4735

4735

4735

4735

4735

4735

4738

4738

4738

4738

4738

4738

4738

4738

4738

4738

4738

4738

4738

4738

4738

4738

4738
$-7.9$

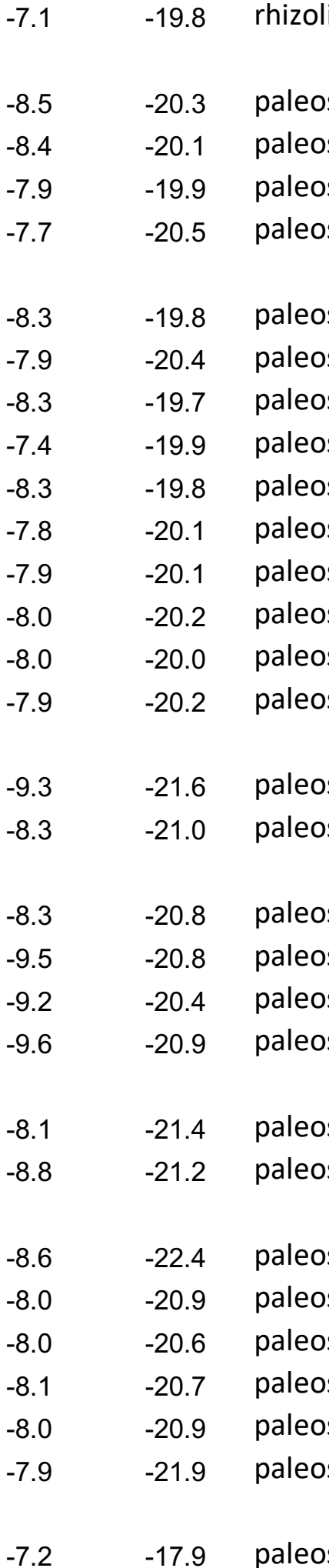

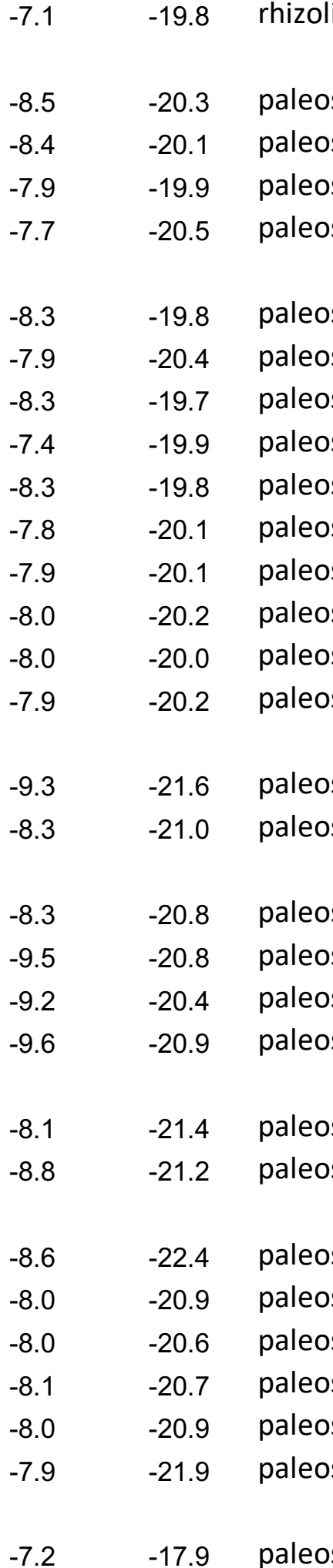

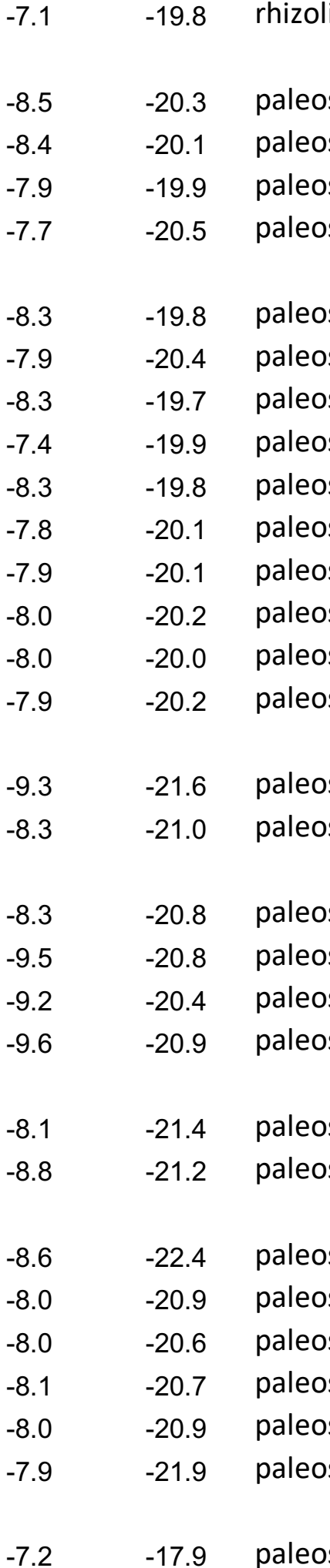

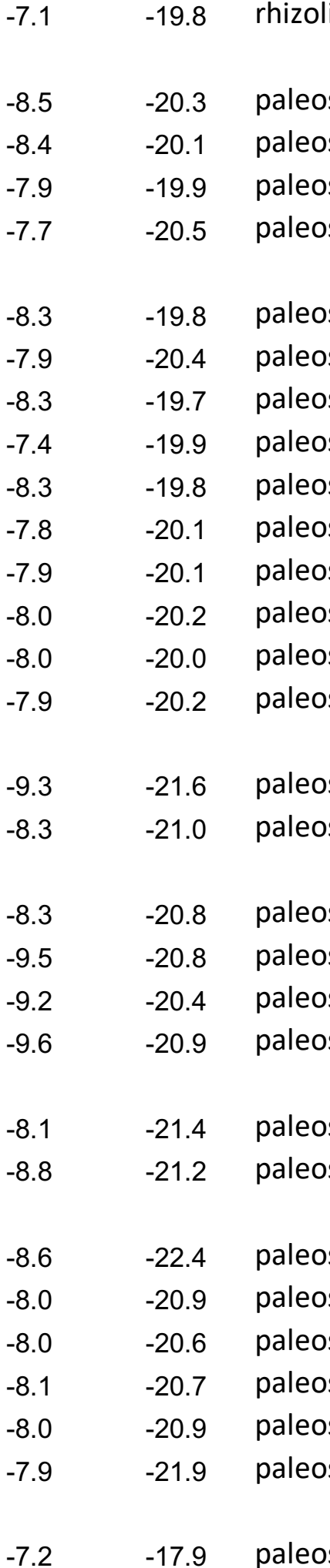

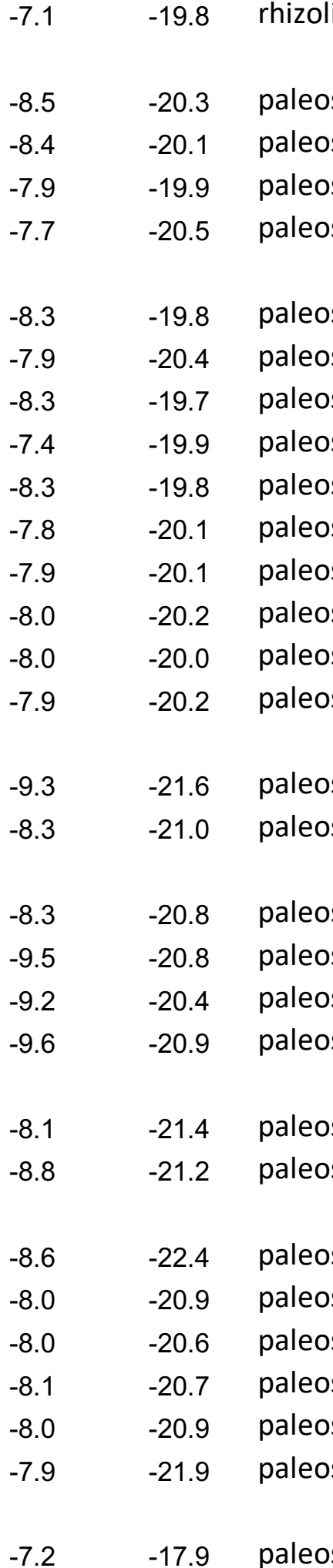

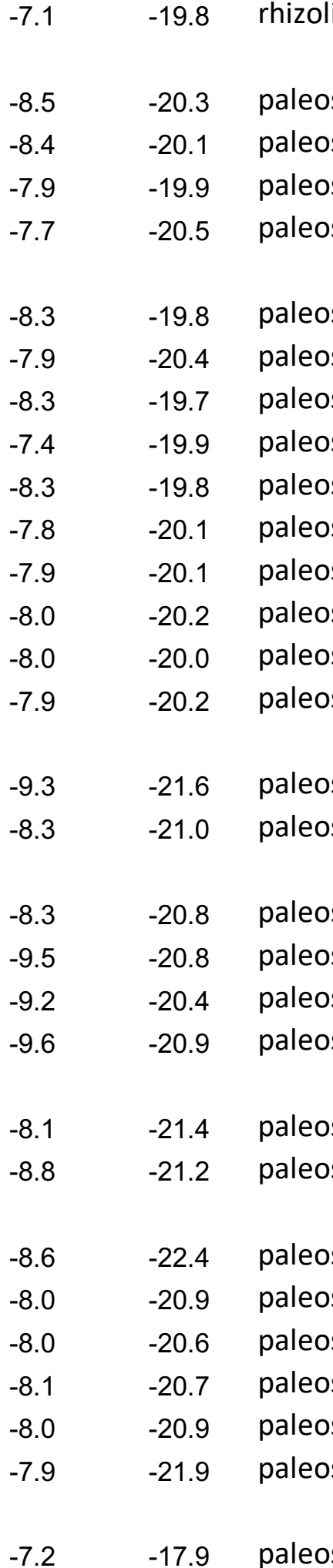

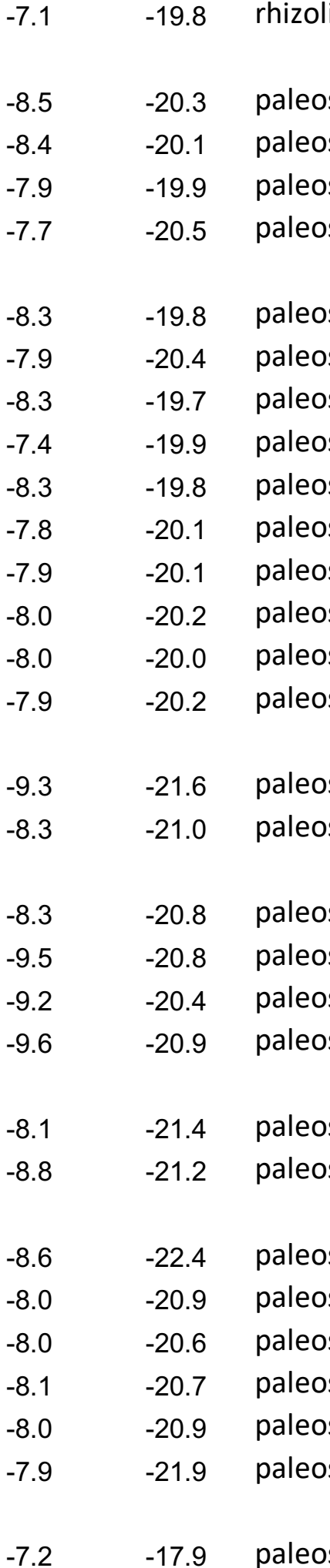

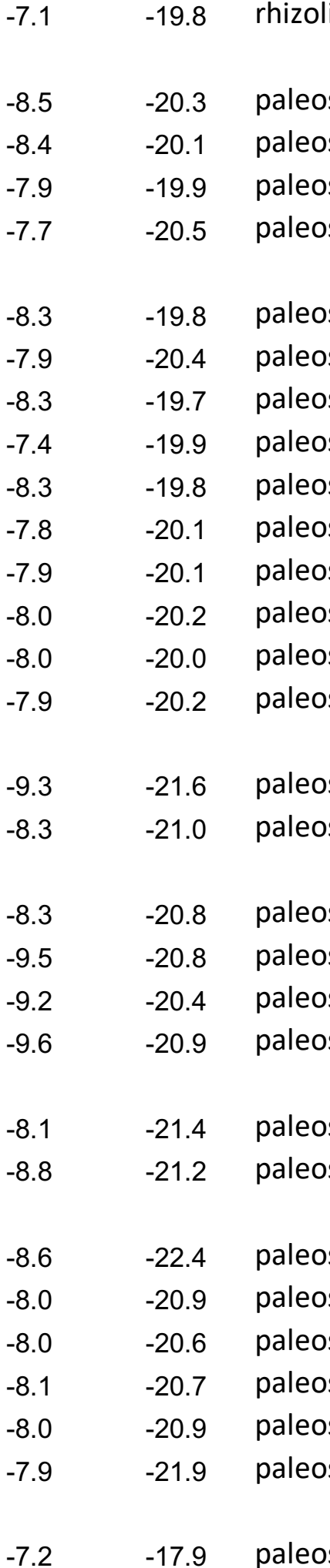

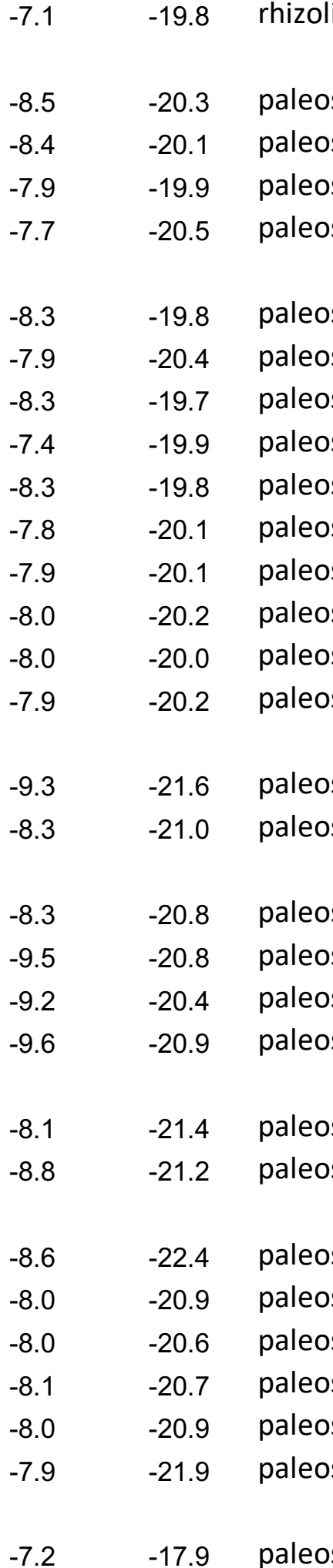

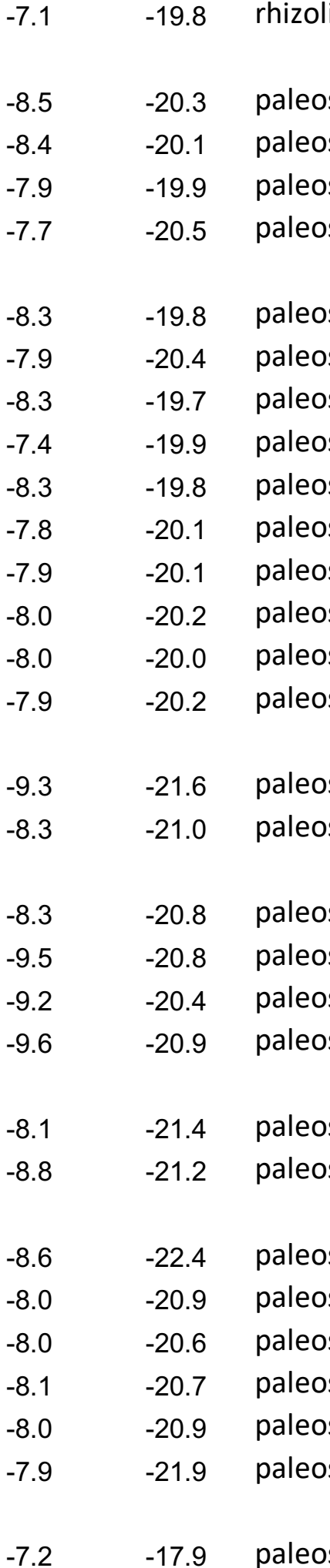

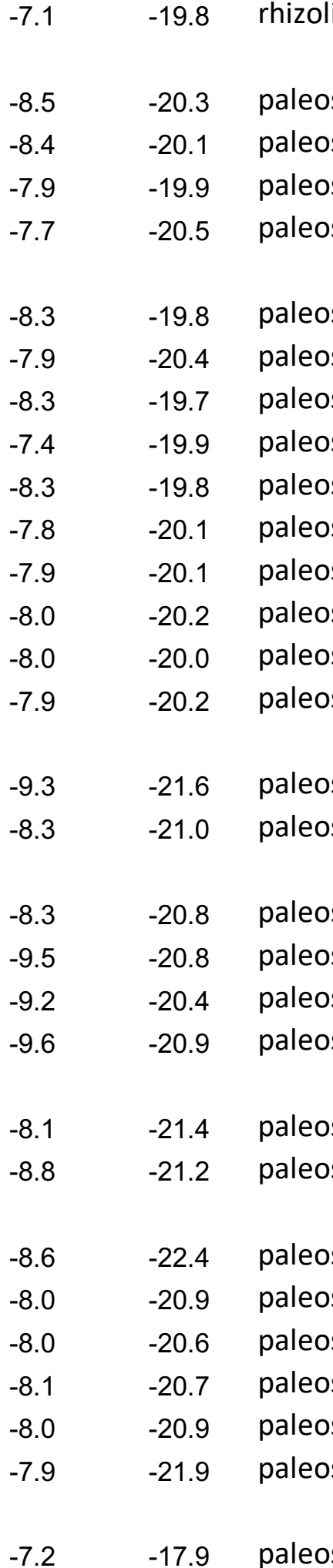

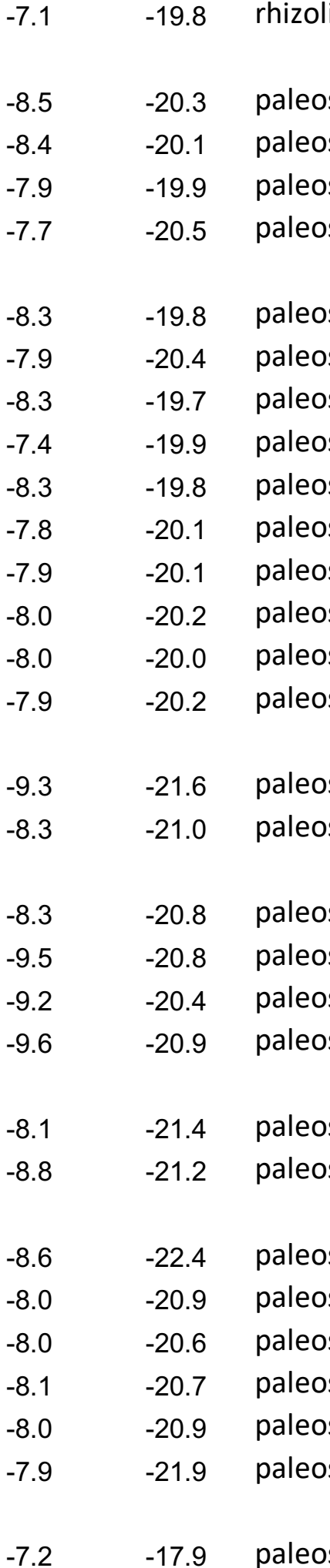

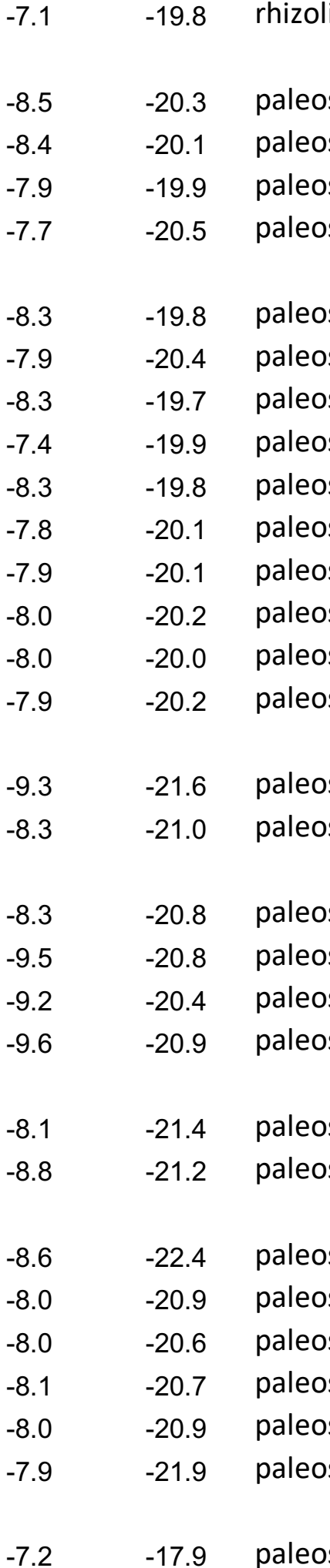

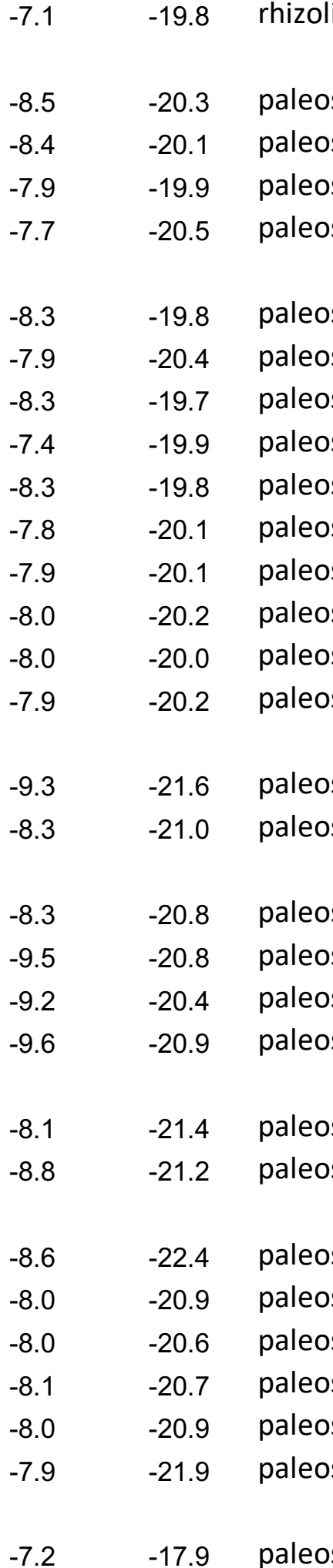

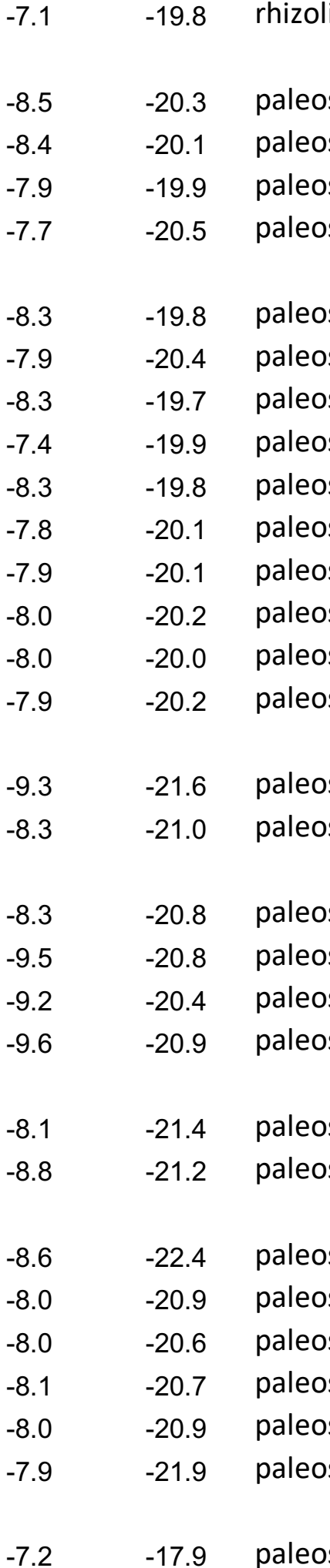

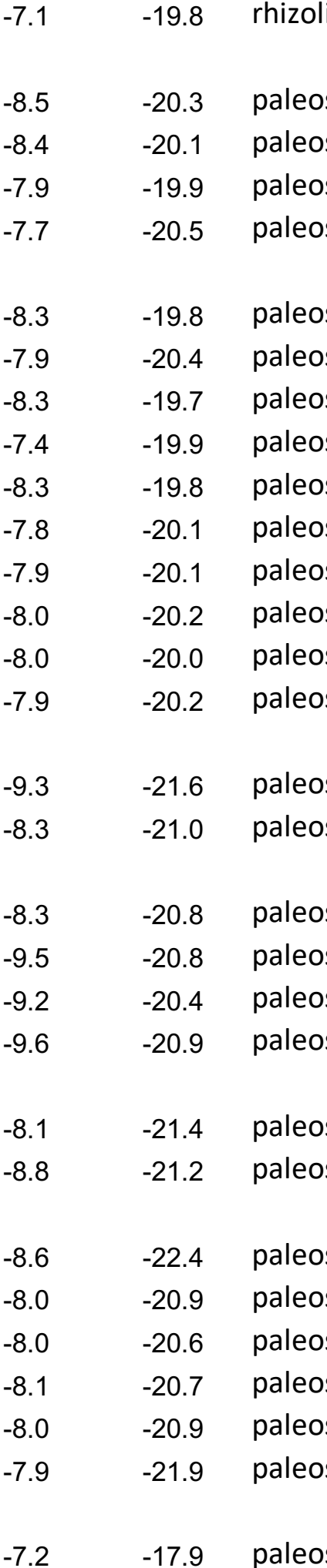

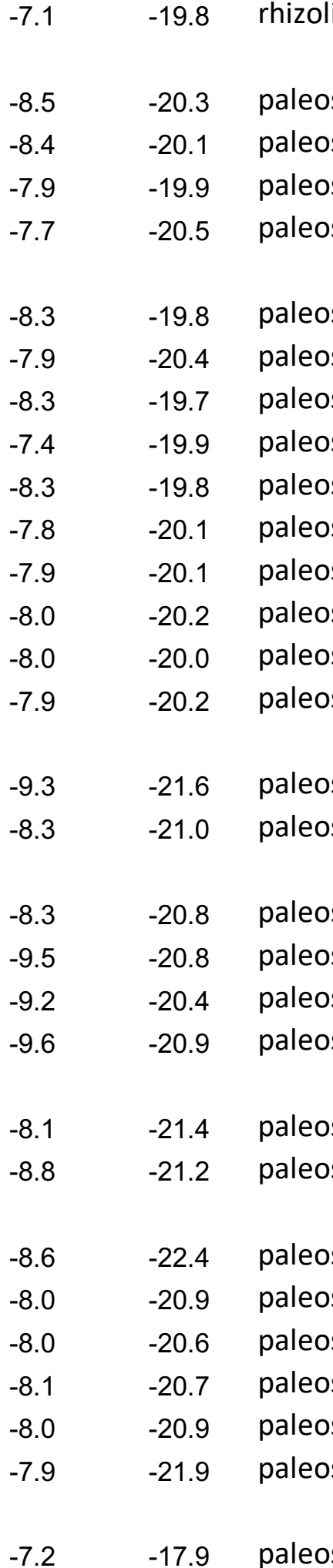

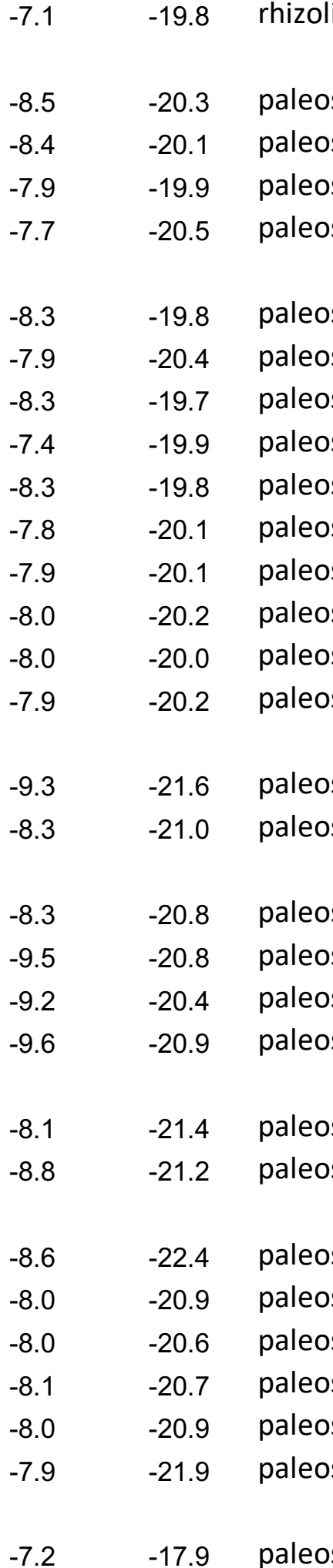

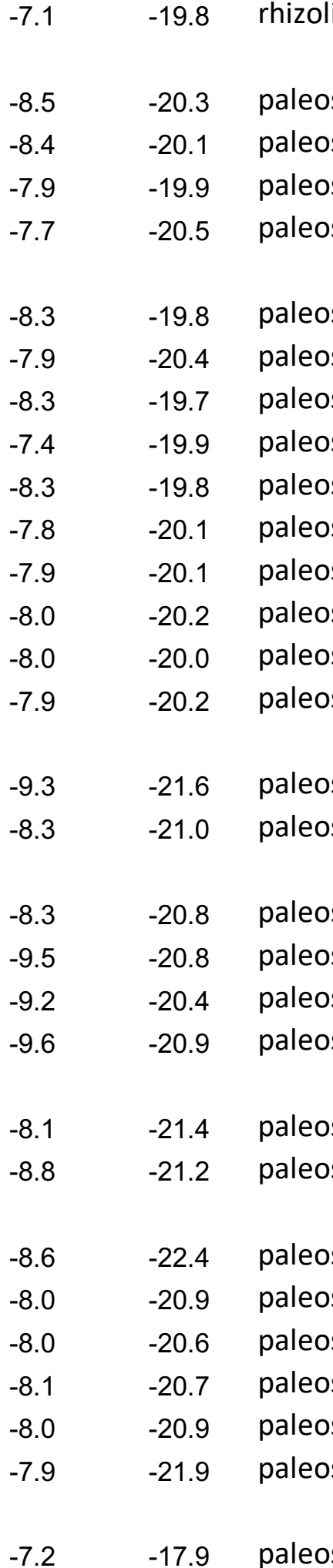

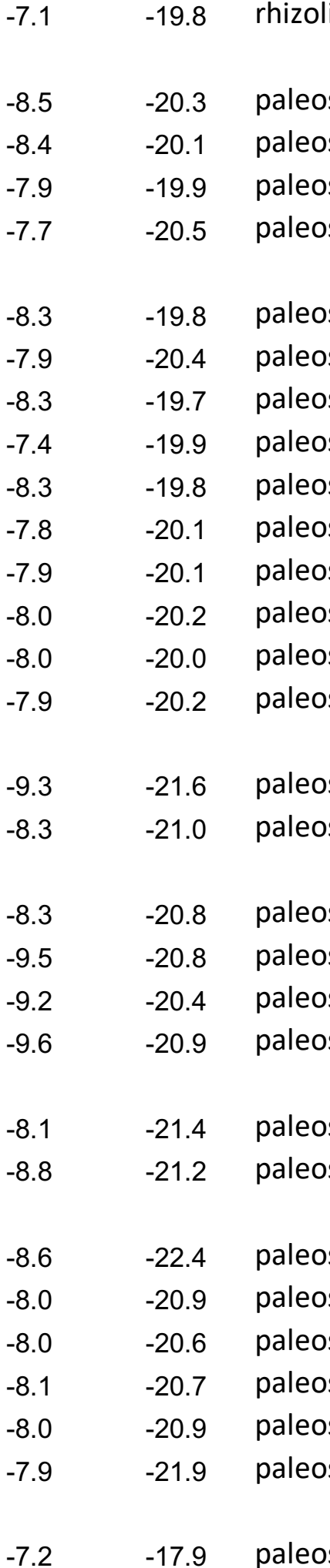

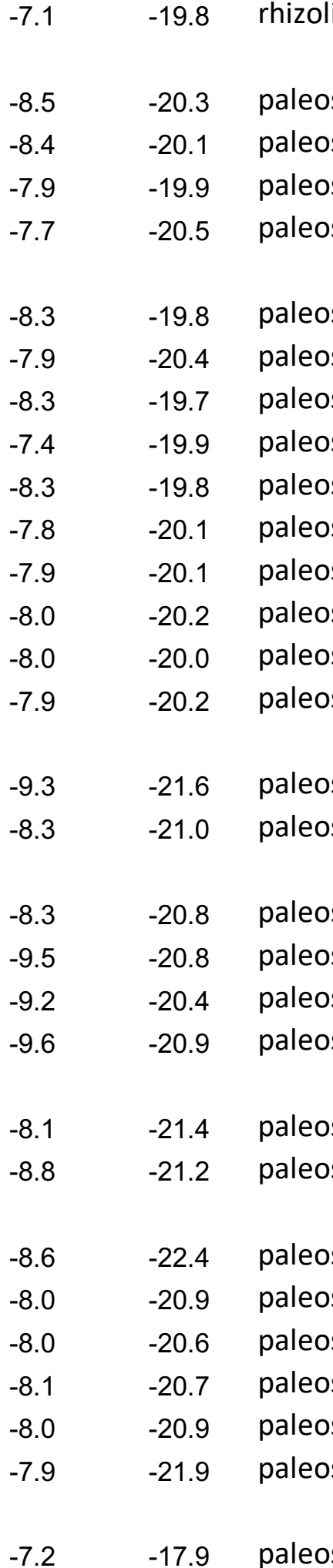

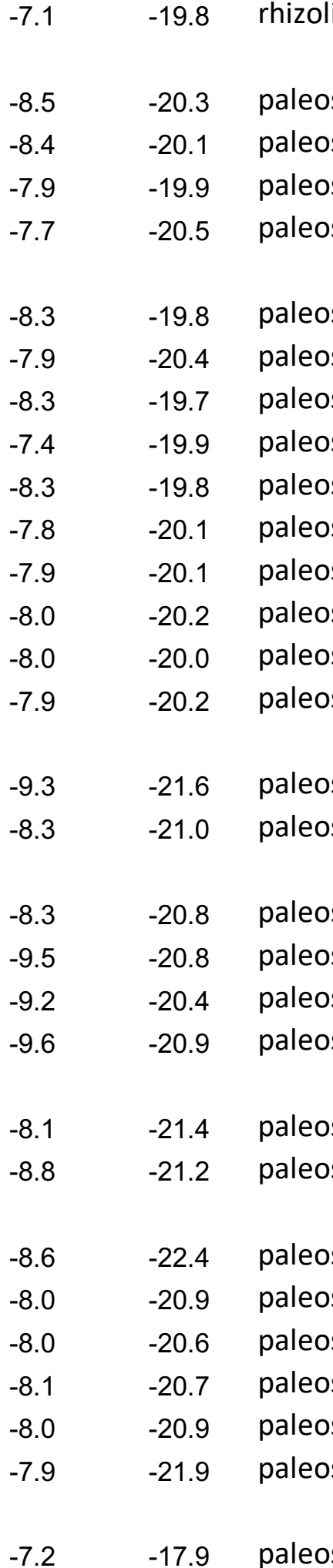

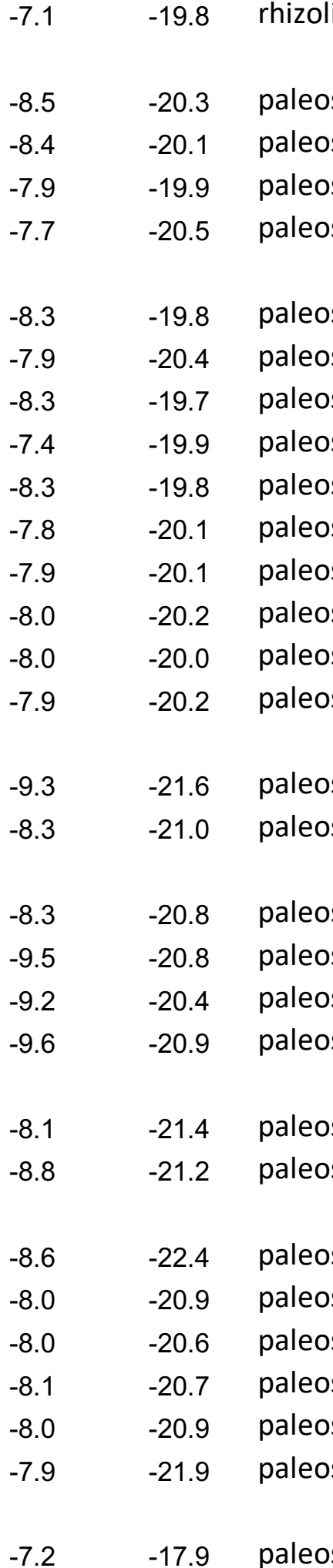

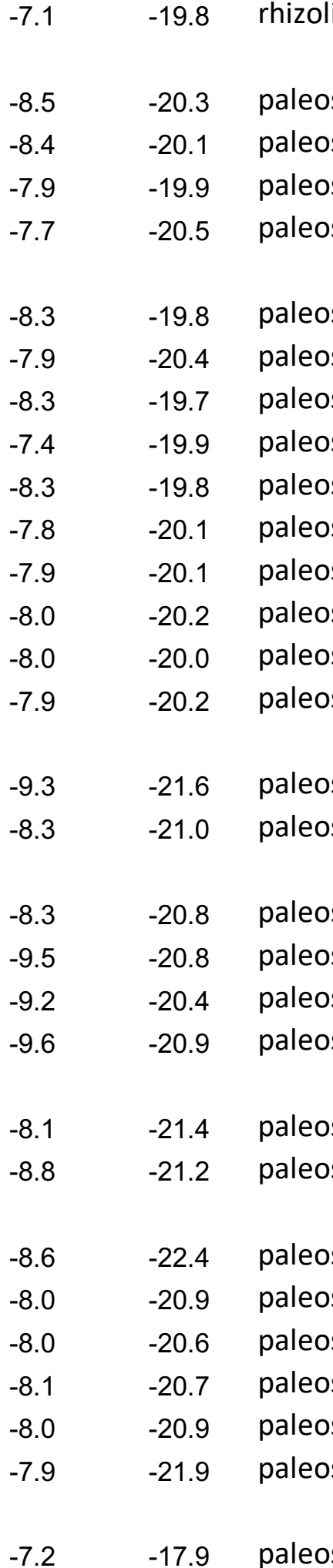

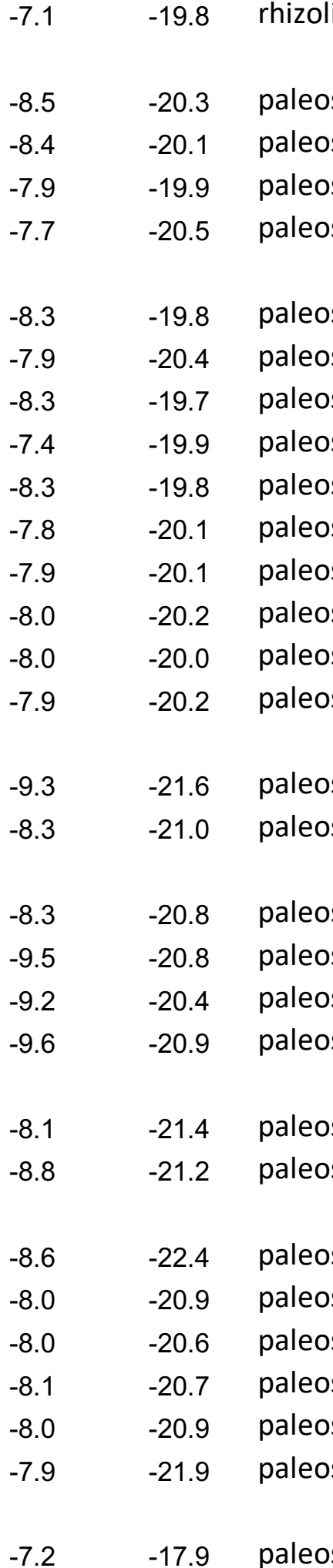

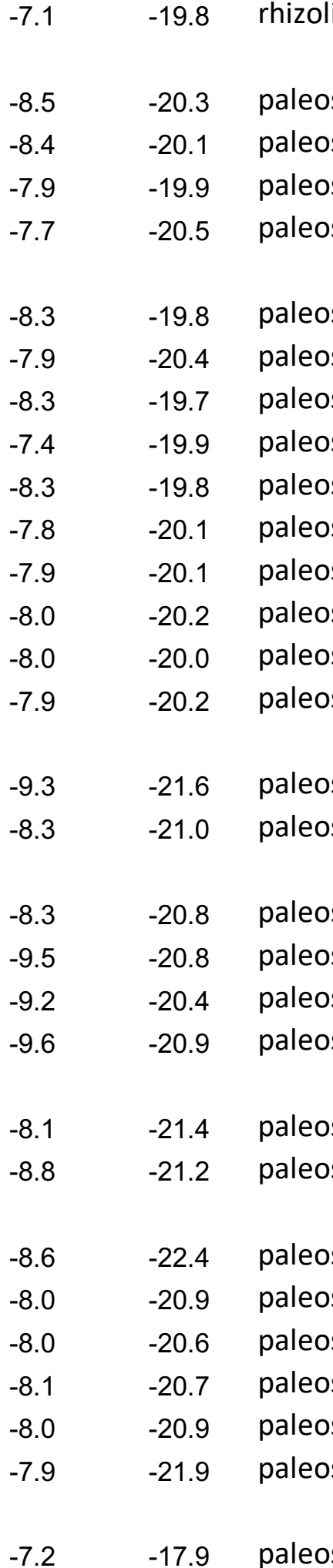

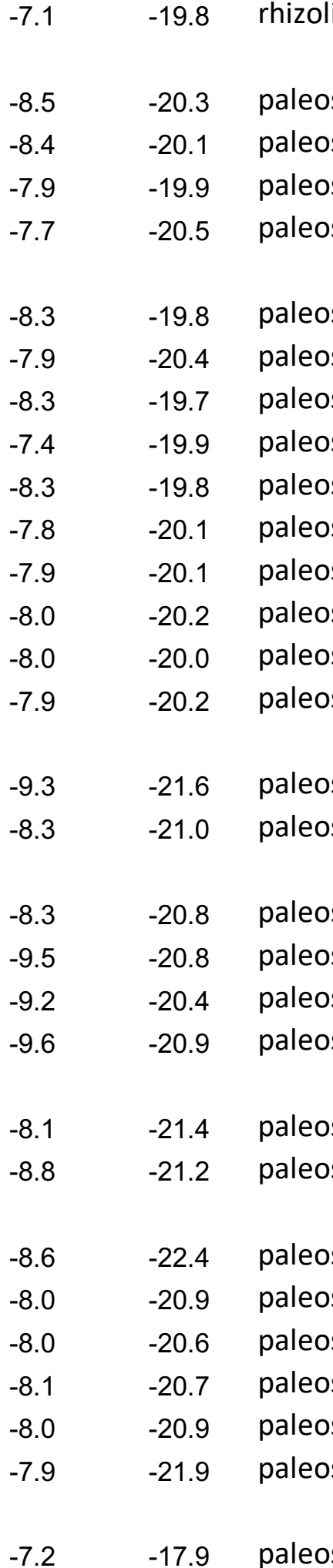

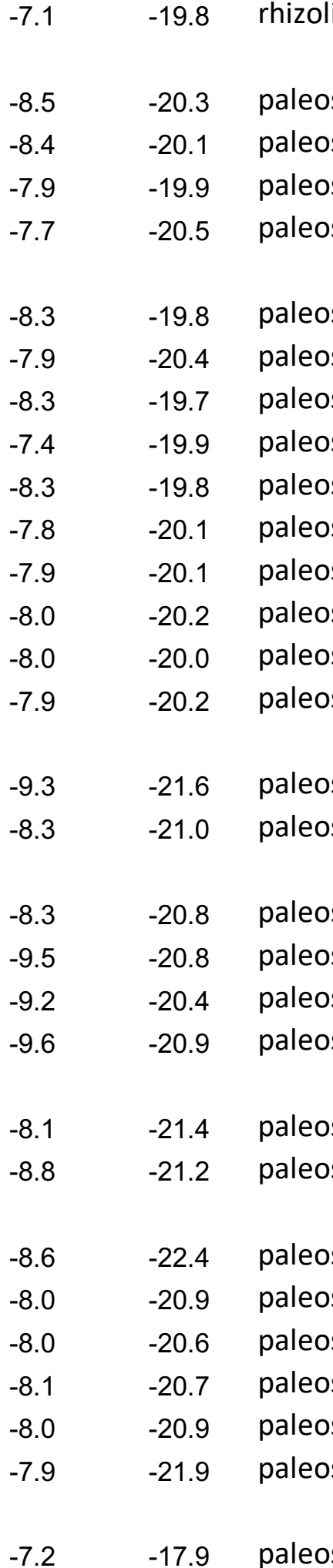

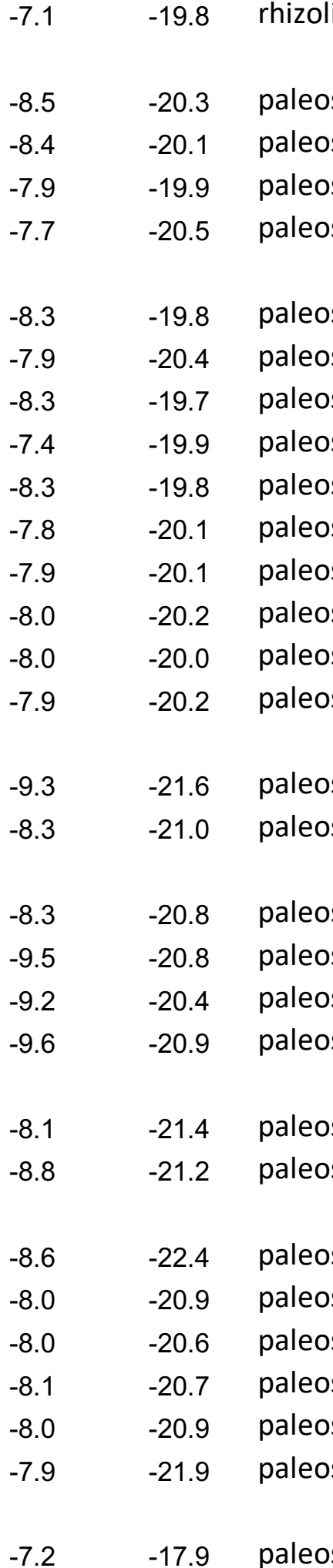

-7.2 -17.9 paleos

$-8.3$

$-8.8$

-19.3 paleo

-20.0 paleo 
6GY-21.5-A1
$6 G Y-21.5-A 2$
$6 G Y-21.5-A 3$
$6 G Y-21.5-C 1$

Dahzuka

1DK-18-A1

1DK-18-B1

1DK-18-A2

1DK-18-C1

1DK-18-D1

1DK-426-A1

1DK-426-A2

1DK-426-A3

1DK-437-A1

1DK-437-C1

1DK437-B1

1DK-437-D1

1DK-489-A1

1DK-489-A2

1DK-489-C1

1DK-489-B1

1DK-489-C1

1DK-640-A1

1DK-640-A2

1DK-640-A2

1DK-640-B1

1DK-640-C1

Xigaze

1XK-3-A1

1XK-3-A2

1XK-3-B1

1XK-3-C1

$\begin{array}{ll}29.528 & 86.542 \\ 29.528 & 86.542 \\ 29.528 & 86.542 \\ 29.528 & 86.542\end{array}$

29.308

29.305

29.305

29.305

29.305

29.305

29.305

29.305

29.304

29.304

29.304

29.304

29.304

29.303

29.303

29.303

29.303

29.303

29.326

29.326

29.326

29.326
88.673

88.673

88.673

88.673
4222
4738

4738

4738

4738

3896

$-8.5$

$-8.5$

$-8.6$

$-9.1$

89.823

89.823

89.823

89.823

89.823

89.823

89.823

89.823

89.823

89.823

89.823

89.823

89.824

89.824

89.824

89.824

89.824
3896

3896

3896

3896

3.3

1.1

2.9

3.2

$-1.0$

4155

4155

4155

4155

4155

4155

4155

4137

4137

4137

4137

4137

4222

4222

4222

4222
4.

4.4

2.8

$-3.0$

$-2.5$

$-2.3$

$-2.6$

$-3.6$

$-4.2$

$-3.1$

$-2.8$

$-2.8$

$-2.4$

$-2.4$

$-2.1$

$-2.0$

$-3.0$

-20.8 limest

-20.3 limest

-20.7 limest

-16.1 limest

-20.5 limest

-20.9 limest

-20.5 limest

-17.1 limest

-21.2 sands

-20.9 sands

-22.0 sands

-21.2 sands

-21.2 sands

-20.9 sands

-20.1 sands

-21.0 sands

-20.2 sands

-19.4 sands

-19.2 sands

-19.0 sands

-19.1 sands

-19.2 sands 


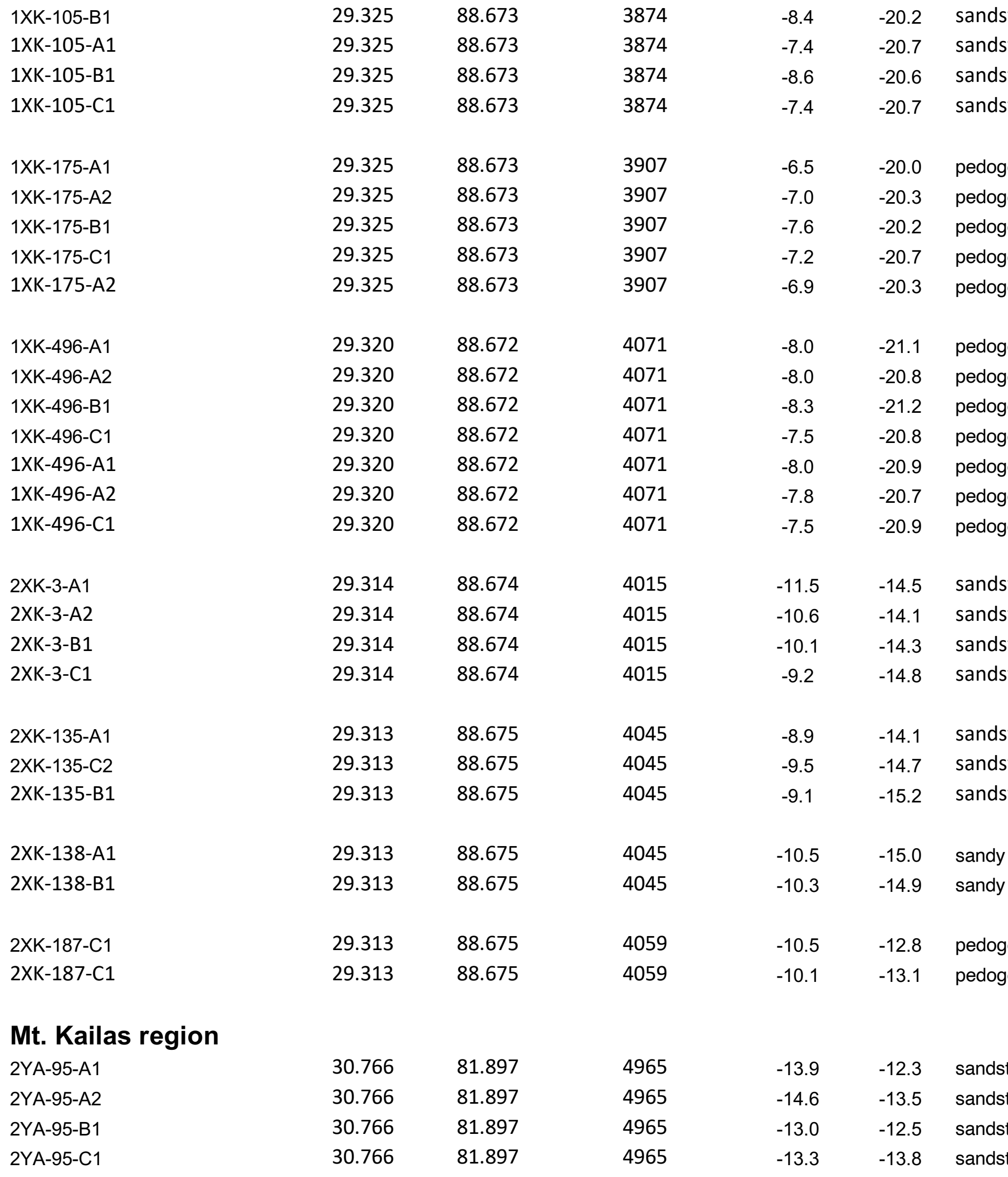




\begin{tabular}{|c|c|c|c|c|c|}
\hline 2YA-96-A1 & 30.766 & 81.897 & 4965 & -13.4 & -13.6 \\
\hline 2YA-96-A2 & 30.766 & 81.897 & 4965 & -12.2 & -13.6 \\
\hline 2YA-96-B1 & 30.766 & 81.897 & 4965 & -12.1 & -13.7 \\
\hline 2YA-96-A1 & 30.766 & 81.897 & 4965 & -13.5 & -13.6 \\
\hline 2YA-97-A1 & 30.766 & 81.897 & 4965 & -13.0 & -13.8 \\
\hline 2YA-97-A2 & 30.766 & 81.897 & 4965 & -13.0 & -13.8 \\
\hline 2YA-97-B1 & 30.766 & 81.897 & 4965 & -12.2 & -12.9 \\
\hline 2YA-97-C1 & 30.766 & 81.897 & 4965 & -12.8 & -13.9 \\
\hline 2YA-97-A1 & 30.766 & 81.897 & 4965 & -12.9 & -13.8 \\
\hline 2YA-97-B1 & 30.766 & 81.897 & 4965 & -12.6 & -13.8 \\
\hline 2YA-97-C1 & 30.766 & 81.897 & 4965 & -12.8 & -13.9 \\
\hline 2YA-108-A1 & 30.766 & 81.897 & 4969 & -14.2 & -13.6 \\
\hline 2YA-108-A2 & 30.766 & 81.897 & 4969 & -14.0 & -13.1 \\
\hline 2YA-108-C1 & 30.766 & 81.897 & 4969 & -14.5 & -13.2 \\
\hline 2YA-108-B1 & 30.766 & 81.897 & 4969 & -13.7 & -12.6 \\
\hline 2YA-123-A2 & 30.766 & 81.897 & 4966 & -13.9 & -13.8 \\
\hline 2YA-123-C1 & 30.766 & 81.897 & 4966 & -15.9 & -13.5 \\
\hline 2YA-123-A1 & 30.766 & 81.897 & 4966 & -15.6 & -13.0 \\
\hline 2YA-123-B1 & 30.766 & 81.897 & 4966 & -15.3 & -13.5 \\
\hline 2YA-123-C1 & 30.766 & 81.897 & 4966 & -15.5 & -13.3 \\
\hline 2YA-125-A2 & 30.766 & 81.897 & 4966 & -15.5 & -13.6 \\
\hline 2YA-125-B1 & 30.766 & 81.897 & 4966 & -15.4 & -13.6 \\
\hline 2YA-125-C1 & 30.766 & 81.897 & 4966 & -15.5 & -13.7 \\
\hline 2YA-125-A1 & 30.766 & 81.897 & 4966 & -15.0 & -13.7 \\
\hline 6.17.12.1-B1 & 30.861 & 81.660 & & 4.3 & -15.5 \\
\hline 6.17.12.1-C1 & 30.861 & 81.660 & & 0.3 & -12.2 \\
\hline 6.17.12.1-D1 & 30.861 & 81.660 & & 0.3 & -16.0 \\
\hline 6.17.12.1-A1 & 30.861 & 81.660 & & 0.9 & -11.0 \\
\hline 3JV-374-A1 & 30.861 & 81.660 & 4773 & -9.3 & -17.4 \\
\hline 3JV-374-A2 & 30.861 & 81.660 & 4773 & -12.0 & -21.3 \\
\hline 3JV-374-B1 & 30.861 & 81.660 & 4773 & -9.4 & -17.6 \\
\hline 3JV-374-C1 & 30.861 & 81.660 & 4773 & -9.6 & -17.6 \\
\hline 3JV-379-A1 & 30.861 & 81.660 & 4773 & -9.4 & -17.2 \\
\hline
\end{tabular}




\begin{tabular}{|c|c|c|c|c|c|}
\hline 3JV-379-A2 & 30.861 & 81.660 & 4773 & -9.5 & -17.3 \\
\hline 3JV-379-B1 & 30.861 & 81.660 & 4773 & -9.3 & -17.2 \\
\hline 3JV-379-C1 & 30.861 & 81.660 & 4773 & -10.2 & -17.5 \\
\hline 3JV-380-A1 & 30.861 & 81.660 & 4773 & -9.7 & -17.4 \\
\hline 3JV-380-A2 & 30.861 & 81.660 & 4773 & -9.5 & -17.1 \\
\hline 3JV-380-B1 & 30.861 & 81.660 & 4773 & -9.4 & -17.1 \\
\hline 3JV-380-C1 & 30.861 & 81.660 & 4773 & -9.5 & -17.3 \\
\hline 3JV-381-A1 & 30.861 & 81.660 & 4773 & -9.7 & -17.2 \\
\hline $3 J V-381-A 2$ & 30.861 & 81.660 & 4773 & -9.6 & -17.0 \\
\hline 4YA-219-A1 & 30.789 & 81.908 & 5091 & 2.2 & -18.4 \\
\hline 4YA-219-B1 & 30.789 & 81.908 & 5091 & 1.8 & -14.7 \\
\hline 4YA-219-C1 & 30.789 & 81.908 & 5091 & 2.0 & -17.9 \\
\hline 4YA357-A1 & 30.787 & 81.907 & 5197 & -2.0 & -16.1 \\
\hline 4YA-357-B1 & 30.787 & 81.907 & 5197 & -2.8 & -16.2 \\
\hline 4YA-357-C1 & 30.787 & 81.907 & 5197 & -2.2 & -16.1 \\
\hline 4YA-389-A1 & 30.787 & 81.907 & 5152 & 1.6 & -16.0 \\
\hline 4YA-389-B1 & 30.787 & 81.907 & 5152 & 2.1 & -16.0 \\
\hline 4YA-389-B2 & 30.787 & 81.907 & 5152 & 4.0 & -10.9 \\
\hline 4YA-389-C1 & 30.787 & 81.907 & 5152 & 1.3 & -16.0 \\
\hline 4YA-418-A2 & 30.786 & 81.907 & 5157 & -4.0 & -15.7 \\
\hline 4YA-471A-A1 & 30.786 & 81.907 & 5265 & -1.9 & -17.0 \\
\hline 4YA-471A-B1 & 30.786 & 81.907 & 5265 & -1.6 & -16.7 \\
\hline 4YA-471B-A1 & 30.786 & 81.907 & 5265 & 1.6 & -17.2 \\
\hline 4YA-471B-B1 & 30.786 & 81.907 & 5265 & 0.9 & -17.7 \\
\hline 4YA-471B-C1 & 30.786 & 81.907 & 5265 & 1.4 & -17.1 \\
\hline 4YA-13-A1 & 30.793 & 81.909 & 4915 & -2.6 & -23.6 \\
\hline 4YA-13-B1 & 30.793 & 81.909 & 4915 & -2.2 & -21.1 \\
\hline 4YA-13-C1 & 30.793 & 81.909 & 4915 & 0.6 & -21.6 \\
\hline TP12-5-A1 & 31.198 & 80.918 & 4960 & 0.1 & -16.1 \\
\hline TP12-5-B1 & 31.198 & 80.918 & 4960 & -0.1 & -14.2 \\
\hline
\end{tabular}


TP12-5-C1

TP12-5-E1

TP12-5-G1

TP12-5-I1

TP12-5-J1

D1 TP12-5

F1 TP12-5
31.198

31.198

31.198

31.198

31.198

31.198

31.198
4960

4960

4960

4960

4960

4960

4960
0.9

1.

1.9

1.

0.3

1.9

1.6
-16.3 limest

-15.3 limest

-16.1 limest

-14.5 limest

-16.5 limest

-15.7 limest

80.918

$-15.5$

limestc 
Table S6 Clumped isotope results

\begin{tabular}{|c|c|c|c|c|c|c|}
\hline sample \# & $\mathbf{N}^{\circ}$ & $\mathbf{E}^{\circ}$ & $\begin{array}{c}\delta^{13} \mathrm{C} \\
\text { VPDB }\end{array}$ & $\begin{array}{c}\delta^{18} 0 \\
\text { VPDB }\end{array}$ & $\Delta_{47} \mathrm{ARF}$ & $\begin{array}{c}\mathrm{T}(47){ }^{\wedge} \\
{ }^{\circ} \mathrm{C}\end{array}$ \\
\hline
\end{tabular}

\section{Nianbo Fm.}

Shar 12.5(1)

Shar 12.5(3)

Shar 12.5(2)

Shar 4.7 (3)

Shar 4.7 (1)

Shar 2 (3)

Shar 2 (1)

PENBO-19b(3)

PENBO-19b(2)

Penbo-23(3)

Penbo-23(1)

Penbo-23

$\begin{array}{rrrrrr}29.972 & 91.194 & -3.6 & -12.9 & 0.55895 & 78 \\ 29.972 & 91.194 & -3.2 & -13.0 & 0.56749 & 73 \\ 29.972 & 91.194 & -3.1 & -13.4 & 0.56893 & 78 \\ 29.972 & 91.194 & -1.3 & -11.9 & 0.56411 & 75 \\ 29.972 & 91.194 & -1.2 & -12.4 & 0.60557 & 59 \\ 29.972 & 91.194 & -0.1 & -13.4 & 0.57607 & 68 \\ 29.972 & 91.194 & 0.1 & -12.5 & 0.55582 & 80 \\ 29.971 & 91.213 & -0.5 & -15.0 & 0.52692 & 99 \\ 29.971 & 91.213 & -0.5 & -15.4 & 0.51914 & 105 \\ 29.982 & 91.203 & -2.5 & -13.7 & 0.52041 & 104 \\ 29.982 & 92.203 & -3.0 & -12.2 & 0.55564 & 80 \\ 29.982 & 93.203 & -2.6 & -13.9 & 0.57261 & 69\end{array}$

\section{Luiqu Conglomerate}

1LQ821(1)

1LQ821(2)

$1 \mathrm{LQ} 474(1)$

1LQ474(2)

1LQ730(2)

1LQ730(1)

6LQ130(1)

6LQ130(2)

4LQ47(1)

4LQ47(2)

\begin{tabular}{rrrrrr}
29.127 & 88.561 & -9.3 & -17.9 & 0.68001 & 28 \\
29.127 & 88.561 & -9.2 & -17.9 & 0.69613 & 20 \\
29.127 & 88.561 & -10.8 & -16.6 & 0.68604 & 24 \\
29.127 & 88.561 & -10.8 & -16.6 & 0.67915 & 25 \\
29.127 & 88.561 & -10.2 & -17.0 & 0.66130 & 29 \\
29.127 & 88.561 & -10.1 & -17.0 & 0.65959 & 33 \\
29.162 & 88.15 & -9.4 & -18.5 & 0.59744 & 59 \\
29.162 & 88.15 & -9.5 & -18.5 & 0.54865 & 91 \\
29.201 & 87.659 & -11.4 & -12.1 & 0.41150 & 257 \\
29.201 & 87.659 & -11.3 & -12.1 & 0.42952 & 221 \\
\hline
\end{tabular}

$1 L Q, 4 L Q$, and $6 L Q$ in sample numbers under the Luiqu Conglomerate denote three separate stratigraphic sections desc Leary et al. (2016). Numbers denote stratigraphic height in section, and numbers in parentheses are individual paleosol nodules.

$\wedge$ paleotemperatures estimated using Kato et al. (2019) 
Table S7 Stable oxygen and hydrogen isotopic composition of small stream waters from the suture zone

\begin{tabular}{|c|c|c|c|c|c|c|}
\hline sample \# & ${ }^{\circ} \mathbf{N}$ & ${ }^{\circ} \mathrm{E}$ & $\begin{array}{l}\text { elevation } \\
(\mathrm{m})\end{array}$ & $\begin{array}{l}\delta^{18} 0 \% \\
\text { VSMOW } \\
\end{array}$ & $\begin{array}{c}\text { SD \%o } \\
\text { VSMOW } \\
\end{array}$ & description \\
\hline AM1 & 29.5431 & 86.3174 & 5024 & -19.6 & -147 & Amchok valley \\
\hline AM2 & 29.5431 & 86.3174 & 5024 & -19.5 & -146 & Amchok valley \\
\hline Li1 & 29.5360 & 86.5940 & 4671 & -19.9 & -147 & Linzizong valley \\
\hline Li2 & 29.5360 & 86.5940 & 4671 & -19.8 & -147 & Linzizong valley \\
\hline Mo1 & 29.5451 & 86.4756 & 4778 & -19.9 & -148 & monastery \\
\hline Mo2 & 29.5451 & 86.4756 & 4778 & -20.0 & -148 & monastery \\
\hline ShE1 & 29.5062 & 86.4620 & 4666 & -18.7 & -146 & East Shigatse \\
\hline ShE2 & 29.5062 & 86.4620 & 4666 & -18.4 & -145 & East Shigatse \\
\hline ShW1 & 29.5006 & 86.3644 & 4729 & -17.7 & -141 & West Shigatse \\
\hline ShW2 & 29.5006 & 86.3644 & 4729 & -19.2 & -146 & West Shigatse \\
\hline TP12-1 & 29.8794 & 84.3815 & 4952 & -18.5 & -143 & $\begin{array}{l}\text { Lopu Kangri } \\
\text { Just below high } p\end{array}$ \\
\hline TP12-2 & 30.8359 & 82.0494 & 5443 & -13.0 & -92 & Gurla \\
\hline TP12-3 & 30.7289 & 81.8436 & 4784 & -16.6 & -127 & Mid-large stream \\
\hline TP12-4 & 30.8484 & 81.6392 & 4734 & -15.2 & -106 & Hor Valley \\
\hline TP12-6 & 31.3893 & 80.5058 & 4744 & -14.2 & -109 & Liuqu, west of Kai \\
\hline TP12-8 & 31.3484 & 80.5042 & 4712 & -13.6 & -106 & Next to TP12-7 \\
\hline TP12-9 & 31.2537 & 80.9218 & 5059 & -16.5 & -118 & Coal Mine Canyor \\
\hline TP12-10 & 29.2000 & 87.6598 & 3981 & -20.0 & -154 & Liuqu section $\mathrm{N}$ \\
\hline TP12-11 & 29.1573 & 88.1574 & 4072 & -14.8 & -116 & Tiny stream in Liu \\
\hline TP12-12 & 29.2733 & 88.8892 & 3833 & -18.3 & -141 & Manasovar Hotel \\
\hline 6.6.12.1MD & 29.1856 & 87.6542 & 4157 & -20.3 & -157 & small stream in $\mathrm{m}$ \\
\hline 6.17.12.1MD & 29.7503 & 84.8670 & 5101 & -17.9 & -142 & small stream in $\mathrm{m}$ \\
\hline
\end{tabular}


